\title{
Uso do padrão AMQP para transporte de mensagens entre atores remotos
}

\author{
Thadeu de Russo e Carmo
}

\author{
DISSERTAÇÃO APRESENTADA \\ $\mathrm{AO}$ \\ Instituto De MatemáticA E EstatísticA \\ DA \\ UNIVERSIDADE DE SÃo PAUlO \\ PARA \\ OBTENÇÃO DO TÍTULO \\ DE \\ Mestre em CiÊnCIAS
}

Programa: Ciência da Computação

Orientador: Prof. Dr. Francisco Carlos da Rocha Reverbel 


\title{
Uso do padrão AMQP para transporte de mensagens entre atores remotos
}

\author{
Esta dissertação contém as correções e alterações \\ sugeridas pela Comissão Julgadora durante a defesa \\ realizada por Thadeu de Russo e Carmo em 08/05/2012. \\ O original encontra-se disponível no Instituto de \\ Matemática e Estatística da Universidade de São Paulo.
}

Comissão Julgadora:

- Prof. Dr. Francisco Carlos da Rocha Reverbel (orientador) - IME-USP

- Profa. Dra. Ana Cristina Vieira de Melo - IME-USP

- Prof. Dr. Arlindo Flávio da Conceição - UNIFESP 


\section{Agradecimentos}

Gostaria de expressar minha enorme gratidão ao Instituto de Matemática e Estatística da Universidade de São Paulo por ter me dado a oportunidade de desenvolver este trabalho. Agradeço a todos os professores no qual tive o prazer de assistir aulas durante o curso. Em especial, agradeço muito ao meu orientador, o professor Dr. Francisco Carlos da Rocha Reverbel, pela oportunidade, tranquilidade e confiança que ele depositou em mim, além de toda sua experiência. Agradeço também aos professores que participaram das bancas de qualificação e defesa, Dr. Marcos Dimas Gubitoso, Dra. Ana Cristina Vieira de Melo e Dr. Arlindo Flávio da Conceição por sua presença e pelas sugestões que nos foram dadas para o desenvolvimento deste trabalho.

Dedico esta dissertação aos meus pais, que apesar de não estarem mais entre nós, tenho certeza que estão muito felizes e orgulhosos. Dedico também esta dissertação a minha amada e querida noiva Juliana pela paciência e apoio nos últimos anos. Agradeço também a IBM, empresa que trabalhei durante o desenvolvimento deste trabalho, e a meus gerentes (Diego, Jamerson, Gerson e Alcântaro), que não pouparam esforços para flexibilizar minha rotina nos momentos mais difíceis.

É impossível não mencionar grandes pessoas que estiveram ao meu lado e me ajudaram, de alguma maneira, a realizar este sonho. Wanderley Guimarães e Alexandre Freire, amigos de longa data que sempre me ajudaram a ficar firme e acreditar no meu objetivo. Ricardo Herrmann, Cristiano Breuel e Domingos Soares por me ajudarem em questões técnicas. Não poderia esquecer de mencionar minha família, em especial meus avós, Janete e Horácio, pelo apoio e suporte nos momentos mais difíceis. 


\section{Resumo}

Uso do padrão AMQP para transporte de mensagens entre atores remotos

O modelo de atores tem sido visto como uma abordagem alternativa à programação concorrente convencional, baseada em travas e variáveis de condição. Atores são agentes computacionais que se comunicam por troca de mensagens e que possuem uma caixa de correio e um comportamento. As mensagens destinadas a um ator são armazenadas na caixa de correio do ator e processadas de maneira assíncrona.

Sistemas de middleware orientados a mensagens trabalham com troca assíncrona de mensagens e formam uma base que simplifica o desenvolvimento de aplicações distribuídas. Tais sistemas permitem interoperabilidade com baixo acoplamento e provêm suporte para tratamento robusto de erros em caso de falhas. Message brokers são frequentemente apresentados como uma tecnologia que pode mudar a maneira com que sistemas distribuídos são construídos. A especificação AMQP é uma proposta recente de padronização de um protocolo para message brokers.

Neste trabalho exploramos a potencial sinergia entre um message broker e uma implementação do modelo de atores. Criamos uma versão modificada da implementação do modelo de atores do projeto Akka que utiliza um message broker AMQP como mecanismo de transporte de mensagens para atores remotos.

Palavras-chave: Modelo de Atores, Padrão AMQP, Projeto Akka, Scala, Message Broker, Atores Remotos. 


\section{Abstract}

Usage of the AMQP standard to transport messages among remote actors

The actor model has been seen as an alternative for conventional concurrent programming based on locks and condition variables. Actors are computational agents that communicate by sending messages and have a mailbox and a behavior. The messages sent to an actor are stored in its mailbox and are asynchronously processed.

Message oriented middleware systems work with asynchronous message exchange and create a base that simplifies the development of distributed applications. These systems have interoperability with low coupling and provide support for robust error handling in case of failures. Message brokers are often presented as a technology that can change the way distributed systems are built. The AMQP specification is a recent proposal of a standard protocol for message brokers.

In this document we explore the potential synergy between a message broker and an implementation of the actor model. We created a modified version of the actor model implementation provided by the Akka project. Our modified implementation uses an AMQP message broker as the transport engine for messages to remote actors.

Keywords: Actor Model, AMQP specification, Akka Project, Scala, Message Broker, Remote Actors. 


\section{Sumário}

Lista de Abreviaturas $\quad$ xi

Lista de Figuras $\quad$ xiii

$\begin{array}{lll}\text { Lista de Tabelas } & \text { xv }\end{array}$

1 Introdução 1

1.1 Troca de mensagens em ambientes corporativos . . . . . . . . . . . . . 1

1.2 Modelos não convencionais de programação concorrente . . . . . . . . . . . . . . . 2

1.3 A linguagem Scala . . . . . . . . . . . . . . . . . . . . . . . 3

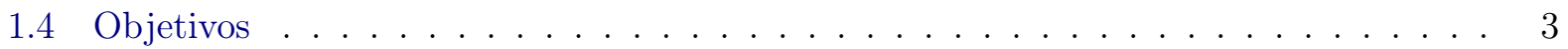

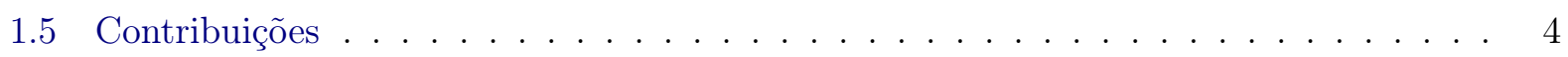

1.6 Organização do Trabalho . . . . . . . . . . . . . . . . . . . . . . 4

2 Atores 5

2.1 Modelo. . . . . . . . . . . . . . . . . . . . . . . . . . . 5

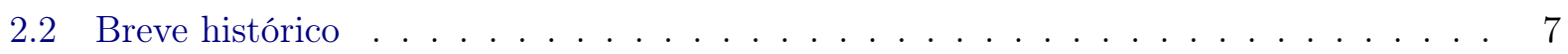

2.3 Implementações . . . . . . . . . . . . . . . . . . . . . . . . . . . . 8

2.3 .1 Linguagens . . . . . . . . . . . . . . . . . 8

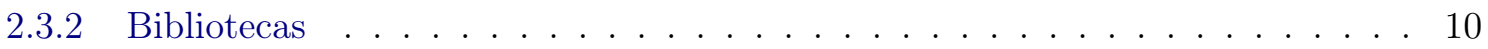

3 Atores no projeto Akka $\quad 13$

3.1 Atores locais . . . . . . . . . . . . . . . . . . . . . 13

3.1 .1 Despachadores . . . . . . . . . . . . . . . . . . 14

3.1 .2 Envios de respostas . . . . . . . . . . . . . . . . . . . . 15

3.2 Hierarquias de supervisão . . . . . . . . . . . . . . . . . . . . 17

3.3 Atores remotos . . . . . . . . . . . . . . . . . . . . . . 19

3.3.1 Fluxo de envio das mensagens . . . . . . . . . . . . . . . . . . . . . . 20 
3.3.2 Formato das mensagens trocadas entre atores remotos . . . . . . . . . . 23

3.3 .3 Seriação de mensagens . . . . . . . . . . . . . . . . . . . . . 25

4 O Padrão AMQP $\quad 27$

4.1 A camada de modelo . . . . . . . . . . . . . . . . . . . . . . 27

4.1 .1 Envios de mensagens . . . . . . . . . . . . . . . . . . . . . . . . 29

4.2 A camada de sessão . . . . . . . . . . . . . . . . . . . . . . . 30

4.3 A camada de transporte . . . . . . . . . . . . . . . . . . . . . . . 30

4.4 Implementações . . . . . . . . . . . . . . . . . . . . . . . . . . 31

4.4.1 RabbitMQ - Biblioteca para clientes Java . . . . . . . . . . . . . . . . 31

5 Troca de mensagens via pontes AMQP $\quad 35$

5.1 Entidades conectadas ponto-a-ponto via sockets . . . . . . . . . . . . . 35

5.1 .1 Atores remotos conectados ponto-a-ponto . . . . . . . . . . . . . 35

5.2 Entidades conectadas via message broker AMQP . . . . . . . . . . . . . . . . 36

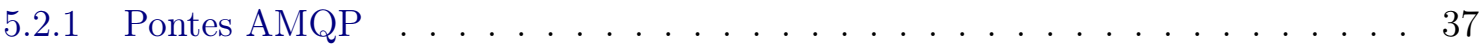

5.2 .2 Gerenciamento de conexões e canais . . . . . . . . . . . . . . . . . 39

5.2 .3 O processo de criação dos objetos no message broker . . . . . . . . . . . . . . 40

5.2.4 Envio e recebimento de mensagens via pontes AMQP . . . . . . . . . . . . . 44

6 Atores Remotos com o Padrão AMQP $\quad 47$

6.1 Novos componentes . . . . . . . . . . . . . . . . . . . . . . . 47

6.2 Integração com o Akka . . . . . . . . . . . . . . . . . . . . . 48

6.2 .1 Alterações no arquivo akka.conf . . . . . . . . . . . . . . . . . . . . . . . 49

6.2 .2 Segurança . . . . . . . . . . . . . . . . . . . . . 50

6.2.3 Alteração no formato do envelope das mensagens remotas . . . . . . . . . . . 51

6.3 Fluxo de envio das mensagens . . . . . . . . . . . . . . . . . . . . . 51

7 Resultados Experimentais $\quad 53$

7.1 Trading System . . . . . . . . . . . . . . . . . . . . . 53

7.2 Trading System com atores remotos f . . . . . . . . . . . . . . . . . 54

7.3 Comparação de desempenho . . . . . . . . . . . . . . . . . 55

$\begin{array}{lll}8 & \text { Trabalhos relacionados } & 61\end{array}$ 
8.1 Replicação de transações no Drizzle com RabbitMQ . . . . . . . . . . . . . . . . 61

8.2 Camada de comunicação entre agentes remotos com RabbitMQ . . . . . . . . . . . . 62

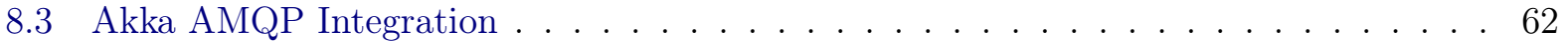

9 Considerações finais $\quad 65$

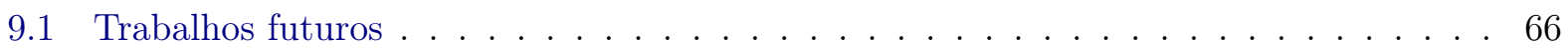

9.1.1 Melhoria no tratamento de erros nas pontes AMQP . . . . . . . . . . . 66

9.1.2 Experimentos em um ambiente de computação em nuvem . . . . . . . . . . 66

$\begin{array}{ll}\text { Referências Bibliográficas } & 69\end{array}$

$\begin{array}{ll}\text { Índice Remissivo } & 74\end{array}$ 


\title{
Lista de Abreviaturas
}

\author{
AMQP Protocolo Avançado para Enfileiramento de Mensagens (Advanced Message Queuing Protocol) \\ API Interface para Programação de Aplicativos (Application Programming Interface) \\ CLR Linguagem Comum de Tempo de Execução (Common Language Runtime) \\ IANA Autoridade de Atribuição de Números da Internet (Internet Assigned Number Authority) \\ JMS Serviço de troca de Mensagens Java (Java Messaging Service) \\ JVM Máquina Virtual Java (Java Virtual Machine) \\ LGPL Licença Pública Geral Menor (Lesser General Public License) \\ MOM Middleware Orientado a Mensagens (Message Oriented Middleware) \\ MPL Licença Pública Mozilla (Mozilla Public License) \\ MTA Agente de Transferência de Correio (Mail Transfer Agent) \\ RPC Chamada Remota de Procedimento (Remote Procedure Call) \\ STM Memória Transacional de Software (Software Transactional Memory) \\ TCP Protocolo para Controle de Transmissão (Transmission Control Protocol) \\ UDP Protocolo de Datagrama de Usuário (User Datagram Protocol) \\ XML Linguagem Extendida de Marcação (Extented Markup Language)
}




\section{Lista de Figuras}

2.1 Máquina de estados de um ator. . . . . . . . . . . . . . . . . 6

3.1 Envio e despacho de mensagens para atores locais. . . . . . . . . . . . . . . . . 14

3.2 Hierarquia de supervisão de atores. . . . . . . . . . . . . . . . . . . . 19

3.3 Relacionamento entre os componentes remotos. . . . . . . . . . . . . . . . 21

3.4 Fluxo de envio de mensagens para atores remotos. . . . . . . . . . . . . . . . 22

4.1 Camadas do padrão AMQP. . . . . . . . . . . . . . . . . . . . . . . . . 27

4.2 Componentes da camada de modelo do padrão AMQP. . . . . . . . . . . . . . . . . 29

4.3 Fluxo de uma mensagem no padrão AMQP. . . . . . . . . . . . . . . . . . . . . . . . 29

4.4 RabbitMQ Java API - Relação entre classes de transporte e sessão. . . . . . . . . . . 33

5.1 Estrutura para troca de mensagens via message broker AMQP . . . . . . . . . . . . 36

5.2 Módulos de acesso ao broker AMQP. . . . . . . . . . . . . . . . . . . 41

5.3 Passos para a criação do ator de conexão. . . . . . . . . . . . . . . . . . . 41

5.4 Passos para a criação do ator do canal de leitura. . . . . . . . . . . . . . . . . . . . 42

5.5 Passos de configuração da classe ServerAMQPBridge. . . . . . . . . . . . . . . . . . 43

5.6 Passos de configuração da classe ClientAMQPBridge. . . . . . . . . . . . . . . . . . 44

5.7 Passos do envio de mensagens de um cliente via pontes AMQP. . . . . . . . . . . . 45

5.8 Passos para recebimento de mensagens via pontes AMQP. . . . . . . . . . . . . . 46

6.1 Relacionamento entre os componentes para atores remotos com AMQP. . . . . . . . 48

6.2 Fluxo de um envio assíncrono de mensagem entre atores com AMQP. . . . . . . . . . 52

7.1 Trading System - Sistema de compra e vendas de ações. . . . . . . . . . . . . . . . 54

7.2 Comparação da quantidade de envios e respostas. . . . . . . . . . . . . . . 57

7.3 Comparação da quantidade de envios e respostas na rede wireless. . . . . . . . . . . 58

7.4 Fluxos nas redes de alta e de baixa latência. . . . . . . . . . . . . . . . . . . . 59 


\section{Lista de Tabelas}

7.1 Medidas de tempo do Trading System com atores remotos. . . . . . . . . . . 56

7.2 Medidas de tempo do Trading System com atores remotos (wireless) . . . . . . . . . 58 


\section{Capítulo 1}

\section{Introdução}

A proposta deste trabalho é explorar a potencial sinergia entre duas classes de sistemas de software baseados em troca de mensagens. A primeira classe, usada em ambientes corporativos, compreende os sistemas de middleware orientados a mensagens (MOMs) e os message brokers. A segunda, voltada para a criação de programas concorrentes, é composta pelas implementações do modelo de atores.

\subsection{Troca de mensagens em ambientes corporativos}

Sistemas de middleware orientados a mensagens trabalham com troca assíncrona de mensagens. As mensagens enviadas são armazenadas e mantidas em filas até que o destinatário esteja pronto para fazer o recebimento e processamento. Em todo envio de mensagem há uma entidade que desempenha o papel de produtor (remetente) e outra que desempenha o papel de consumidor (destinatário) da mensagem. Não existe vínculo entre esses papéis e os papéis de cliente (usuário de um serviço) e servidor (provedor de um serviço), tradicionalmente usados em sistemas baseados em remote procedure call (RPC), já que ambos enviam e recebem mensagens. No contexto de MOMs, os papéis de servidor ou cliente são definidos pela semântica da troca de mensagens. Uma entidade pode estar atuando ora como provedora de um serviço, ora como cliente de um serviço. Portanto, os termos "cliente" e "servidor", não são aplicáveis nesta classe de sistemas do mesmo modo como são aplicáveis em sistemas baseados em RPC.

MOMs formam uma base que simplifica o desenvolvimento de aplicações distribuídas, permite interoperabilidade com baixo acoplamento e provê suporte para o tratamento robusto de erros em caso de falhas. Eles são frequentemente apresentados como uma tecnologia que pode mudar a maneira com que sistemas distribuídos são construídos [ACKM04].

A garantia da entrega de mensagens é uma das características mais importantes dos MOMs. Filas transacionais são utilizadas para garantir que mensagens recebidas pelo MOM sejam salvas de modo persistente. A remoção de uma mensagem de uma fila transacional ocorre somente após a confirmação do seu recebimento pelo destinatário. No caso de avarias no sistema, mensagens previamente salvas pelo MOM e que não tiveram seu recebimento confirmado não são perdidas. Uma vez que o sistema tenha sido restabelecido, essas mensagens podem ser entregues aos seus destinatários. A retirada de uma mensagem de uma fila transacional ocorre como parte de uma transação atômica que pode incluir também outras operações, como envios de mensagens e atualizações em bancos de dados, bem como outras retiradas de mensagens.

MOMs tradicionalmente estabelecem ligações ponto-a-ponto entre sistemas, sendo um tanto inflexíveis no que diz respeito ao roteamento e filtragem de mensagens. Message brokers são descendentes diretos de MOMs que eliminam essas limitações. Eles agem como intermediários e provêem maior flexibilidade para roteamento e filtragem, além de permitirem que se adicione lógica de negócios ao processamento de mensagens no nível do próprio middleware.

Sistemas baseados em message brokers dão suporte ao papel do administrador e incluem ferramentas administrativas. Nesse tipo de sistema, o administrador é responsável por gerenciar as regras 
para roteamento e filtragem de mensagens. Ainda que o papel do administrador exista também em sistemas baseados em MOMs, tal papel possui maior relevância em sistemas baseados em message brokers [ACKM04].

Os protocolos usados por message brokers variam de produto para produto. A especificação de Java Messaging Service (JMS) define uma API padrão para que programas Java possam interagir com message brokers. Boa parte dos message brokers têm implementações do padrão JMS. Dentre os mais conhecidos, podemos destacar JBoss Messaging [JBM], IBM Websphere MQ [IBM] (mais conhecido como MQ Series) e Apache Active MQ [Act].

O padrão AMQP [Gro] (Advanced Message Queuing Protocol) é uma proposta recente de padronização de um protocolo para message brokers. Foi criada por um conjunto de empresas (Red Hat, JPMorgan Chase, Cisco Systems, entre outras), com o objetivo de viabilizar tanto o desenvolvimento quanto a disseminação de um protocolo padrão para esse tipo de sistema.

\subsection{Modelos não convencionais de programação concorrente}

Nos últimos anos, o aumento da velocidade de clock passou a não acompanhar mais o aumento de transistores em processadores por questões físicas, como aquecimento e dissipação, alto consumo de energia e vazamento de corrente elétrica. Por conta dessas e de outras limitações, a busca por ganhos de capacidade de processamento levou à construção de processadores com múltiplos núcleos (multicore).

Um dos principais impactos que processadores multicore causam no desenvolvimento de programas está relacionado com o modo com que programas são escritos. Para usufruírem de ganhos de desempenho com esses processadores, programas precisam ser escritos de forma concorrente [Sut05], uma tarefa que não é simples. A maioria das linguagens de programação e dos ambientes de desenvolvimento não são adequados para a criação de programas concorrentes [SL05].

A abordagem convencional ao desenvolvimento de programas concorrentes é baseada em travas e variáveis condicionais. Em linguagens orientadas a objetos, como Java e C\#, cada instância implicitamente possui sua própria trava, e travamentos podem acontecer em blocos de código marcados como sincronizados. Essa abordagem não permite que travas sejam compostas de maneira segura, criando situações propensas a bloqueios e impasses (deadlocks). A composição de travas é necessária quando há mais de uma instância envolvida na ação a ser executada de modo exclusivo. Existem ainda outras dificuldades no uso de travas, como esquecimento de se obter a trava de alguma instância, obtenção excessiva de travas, obtenção de travas de instâncias erradas, obtenção de travas em ordem errada, manutenção da consistência do sistema na presença de erros, esquecimento de sinalização em variáveis de condição ou de se testar novamente uma condição após o despertar de um estado de espera [JOW07]. Essas dificuldades mostram que a abordagem convencional, baseada em travas, é inviável para uma programação concorrente modular, e ajudaram a impulsionar a pesquisa de abordagens alternativas à programação concorrente convencional.

Dois modelos de programação concorrente não convencionais vem ganhando espaço recentemente. O primeiro deles é a memória transacional implementada por software (software transactional memory, ou STM) [ST95], um mecanismo de controle de concorrência análogo às transações de bancos de dados. O controle de acesso à memória compartilhada é responsabilidade da STM. Cada transação é um trecho de código que executa uma série atômica de operações de leitura e escrita na memória compartilhada.

O segundo modelo não convencional de programação concorrente é o modelo de atores. Atores [Agh86] são definidos como agentes computacionais que possuem uma caixa de correio e um comportamento. Uma vez que o endereço da caixa de correio de um ator é conhecido, mensagens podem ser adicionadas à caixa para processamento assíncrono. No modelo de atores, o envio de uma mensagem é desacoplado do processamento da mensagem pelo ator. 


\subsection{A linguagem Scala}

Scala $\left[\mathrm{OAC}^{+} 06\right]$ é uma linguagem moderna, que possui tipagem estática e inferência de tipos e que unifica os paradigmas de programação funcional e orientado a objetos. Vem sendo desenvolvida desde 2001 no laboratório de métodos de programação da EPFL (École Polytechnique Fédérale de Lausanne). O código escrito em Scala pode ser compilado para execução tanto na JVM (Java Virtual Machine) quanto na CLR (Common Language Runtime). A criação da linguagem Scala foi impulsionada pela necessidade de um bom suporte para o desenvolvimento de sistemas por componentes e escaláveis.

A linguagem foi desenvolvida para interoperar bem tanto com Java quanto com C\#, e adota parte da sintaxe dessas linguagens, além de compartilhar a maioria dos operadores básicos, tipos de dados e estruturas de controle. Contudo, para atingir seus objetivos, Scala abre mão de algumas convenções enquanto adiciona novos conceitos. Algumas de suas características são:

- Scala possui certa semelhança com Java e C\#, de modo que tanto programas escritos em Scala podem utilizar bibliotecas escritas em Java ou C\#, quanto o inverso.

- Scala possui um modelo uniforme para objetos, em que todo valor é um objeto e toda operação é um método.

- Scala é uma linguagem funcional e todas as funções são valores de primeira classe. No contexto de linguagens de programação, valores de primeira classe são entidades que podem ser criadas em tempo de execução, utilizadas como parâmetros, devolvidas por uma função, ou ainda atribuídas a variáveis.

- Scala permite construções via extensão de classes e combinações de feições (traits). Feições ${ }^{1}$ possuem definições de métodos e campos assim como uma classe abstrata, porém não definem construtores. São importantes unidades para reuso de código em Scala, já que classes ou objetos podem ser combinados (mixin) com diversas feições.

- Scala permite a decomposição de objetos via casamento de padrões.

- Scala possui suporte ao tratamento de XML (extended markup language) na própria sintaxe da linguagem.

- Scala não possui o conceito de membros de classes estáticos. A linguagem possui o conceito de singleton object, que representa uma instância única de uma classe. Singleton objects definidos com a construção object ao invés de class. Um singleton object que tenha o mesmo nome que uma classe é denominado objeto acompanhante (companion object) dessa classe.

- Scala possui suporte a currying, que em conjunto com as funções de ordem superior, permite a criação de novas estruturas de controle.

Optamos por desenvolver este trabalho em Scala tanto pela linguagem ser executável na JVM e interoperar naturalmente com Java, como por suas características proverem facilidades para a implementação de atores.

\subsection{Objetivos}

Message brokers provêem diversos benefícios, tais como interoperabilidade com baixo acoplamento, tratamento robusto de erros, filas transacionais para armazenamento de mensagens e ferramentas que auxiliam em tarefas administrativas. Contudo, o emprego de um message broker pode

\footnotetext{
${ }^{1} \mathrm{O}$ termo técnico trait ainda não tem uma tradução consagrada em Português. Neste texto optamos por traduzir trait como feição.
} 
ter impacto negativo sobre o desempenho de um sistema. Dependendo do tipo de sistema, tal impacto será aceitável ou não.

Este trabalho teve como primeiro objetivo criar uma implementação em Scala do modelo de atores que use o padrão AMQP para o transporte de mensagens entre atores remotos. Geramos um protótipo baseado na implementação do modelo de atores do projeto Akka. Substituímos o mecanismo de transporte do Akka por um que utiliza um message broker AMQP.

O segundo objetivo deste trabalho foi avaliar o desempenho do nosso protótipo. Como na implementação original do projeto Akka os atores remotos se comunicam via conexões ponto-a-ponto, que são bastante eficientes, era de se esperar que o uso de um message broker AMQP acarretasse uma perda de desempenho em relação àquela implementação. Assim sendo, nosso propósito foi medir essa perda de desempenho e avaliar se ela é aceitável tendo em vista os benefícios oferecidos pelo message broker.

\subsection{Contribuições}

As principais contribuições deste trabalho são as seguintes:

- uma implementação do modelo de atores que é escrita em Scala e utiliza um message broker AMQP como mecanismo de transporte de mensagens entre atores remotos;

- uma camada de abstração para acesso à biblioteca de conexão do message broker AMQP. Criada para dar suporte ao nosso protótipo, essa camada foi implementada com atores e sua principal motivação é prover acesso concorrente seguro aos serviços oferecidos pela biblioteca de conexão do message broker.

\subsection{Organização do Trabalho}

No Capítulo 2, apresentamos o modelo de atores, sua semântica e algumas das implementações do modelo. No Capítulo 3, analisamos em maiores detalhes a implementação do modelo de atores feita no projeto Akka. No Capítulo 4, apresentamos as camadas do padrão AMQP, mencionamos algumas das implementações desse protocolo e examinamos algumas das principais classes da biblioteca para clientes Java da implementação utilizada neste trabalho. No Capítulo 5, apresentamos a camada de abstração criada para prover acesso concorrente seguro às classes de comunicação da biblioteca para clientes Java da implementação de AMQP que utilizamos. No Capítulo 6, apresentamos nossa implementação de atores remotos, que utiliza a camada de abstração descrita no Capítulo 5. No Capítulo 7, apresentamos uma comparação de desempenho entre a implementação original de atores remotos do projeto Akka e o protótipo desenvolvido neste trabalho. No Capítulo 8 apresentamos sucintamente trabalhos que possuem relação com o nosso. Finalmente, no Capítulo 9 , apresentamos sugestões para pesquisas futuras e discutimos as conclusões obtidas neste trabalho. 


\section{Capítulo 2}

\section{Atores}

Apresentamos neste capítulo o modelo de atores. Na Seção 2.1 apresentamos a semântica do modelo de atores. Na Seção 2.2 apresentamos um breve histórico com alguns estudos relacionados ao modelo. Por fim, na Seção 2.3 apresentamos algumas das implementações do modelo.

\section{$2.1 \quad$ Modelo}

O modelo de atores é um modelo para programação concorrente em sistemas distribuídos, que foi apresentado como uma das possíveis alternativas ao uso de memória compartilhada e travas. Atores são agentes computacionais autônomos e concorrentes que possuem uma fila de mensagens e um comportamento [Agh86].

O modelo define que toda interação entre atores deve acontecer via trocas assíncronas de mensagens. Uma vez que o endereço da fila de mensagens de um ator é conhecido, mensagens podem ser enviadas ao ator. As mensagens enviadas são armazenadas para processamento assíncrono, desacoplando o envio de uma mensagem do seu processamento.

Toda computação em um sistema de atores é resultado do processamento de uma mensagem. Cada mensagem recebida por um ator é mapeada em uma 3-tupla que consiste de:

1. um conjunto finito de envios de mensagens para atores cujas filas tenham seus endereços conhecidos (um desses atores pode ser o próprio ator destinatário da mensagem que está sendo processada);

2. um novo comportamento (mapeamento de mensagens em 3-tuplas), que será usado para processar a próxima mensagem recebida;

3. um conjunto finito de criações de novos atores.

Um ator que recebe mensagens faz o processamento individual de cada mensagem em uma execução atômica. Cada execução atômica consiste no conjunto de todas as ações tomadas para processar a mensagem em questão, não permitindo intercalações no processamento de duas mensagens.

Em um sistema de atores, envios de mensagens (também chamados de comunicações) são encapsulados em tarefas. Uma tarefa é uma 3-tupla que consiste em um identificador único, o endereço da fila do ator destinatário e a mensagem. A configuração de um sistema de atores é definida pelos atores que o sistema contém e pelo conjunto de tarefas não processadas. É importante ressaltar que o endereço da fila de mensagens na tarefa deve ser válido, ou seja, ele deve ter sido previamente comunicado ao ator remetente da mensagem. Há três maneiras de um ator, ao receber uma mensagem $m$, passar a conhecer um destinatário ao qual o ator pode enviar mensagens:

1. o ator já conhecia o endereço da fila do destinatário antes do recebimento da mensagem $m$;

2. o endereço da fila estava presente na mensagem $m$; 
3. um novo ator foi criado como resultado do processamento da mensagem $m$.

Um aspecto importante do modelo de atores é a existência de imparcialidade (fairness) no processamento das mensagens: tanto a entrega das mensagens é garantida como o progresso no seu processamento [AMST98]. A garantia de entrega de mensagens é uma forma de imparcialidade e, no contexto de atores, significa que uma mensagem que foi depositada na fila de mensagens de um ator não deve ficar armazenada indefinidamente sem ser, mais cedo ou mais tarde, processada pelo ator. A ordem de chegada de mensagens obedece uma ordem linear e fica a cargo da implementação do modelo arbitrar no caso de conflitos. A garantia de entrega de mensagens não pressupõe que as mensagens entregues tenham um processamento semanticamente significativo. O processamento de uma mensagem depende do comportamento definido no ator. Por exemplo, um tipo de atores poderia optar por descartar todas as mensagens recebidas.

Gul Agha, em sua definição da semântica do modelo de atores [Agh86], afirma que "em qualquer rede real de agentes computacionais, não é possível prever quando uma mensagem enviada por um agente será recebida por outro". A afirmação é enfatizada para redes dinâmicas, em que agentes podem ser criados ou destruídos, e reconfigurações como migrações de agentes para diferentes nós podem acontecer. Em sua conclusão, Agha afirma que um modelo realista deve pressupor que a ordem de recebimento das mensagens não é determinística, mas sim arbitrária e desconhecida. O não determinismo na ordem de recebimento das mensagens pelo ator não interfere na garantia de entrega das mensagens.

O comportamento de um ator define como o ator irá processar a próxima mensagem recebida. Ao processar uma mensagem, o ator deve definir o comportamento substituto que será utilizado para processar a próxima mensagem que lhe for entregue. Mostramos na Figura 2.1 a máquina de estados de um ator processando uma mensagem recebida e definindo seu novo comportamento. Nessa figura, o ator $A$ com comportamento inicial $B_{1}$ retira a mensagem $m_{1}$ de sua fila e a processa. Para esse exemplo, o processamento da mensagem $m_{1}$ resultou na criação de um novo ator $A^{\prime}$, com comportamento inicial $B_{1^{\prime}}$, e no envio da mensagem $m_{1^{\prime}}$ do ator $A$ para o ator $A^{\prime}$. O ator $A$ passa a ter o comportamento $B_{2}$, que será usado no processamento da mensagem $m_{2}$. Vale ressaltar que o comportamento substituto não precisa ser necessariamente diferente do comportamento anterior. Assim, os comportamentos $B_{1}$ e $B_{2}$ podem ser comportamentos idênticos.

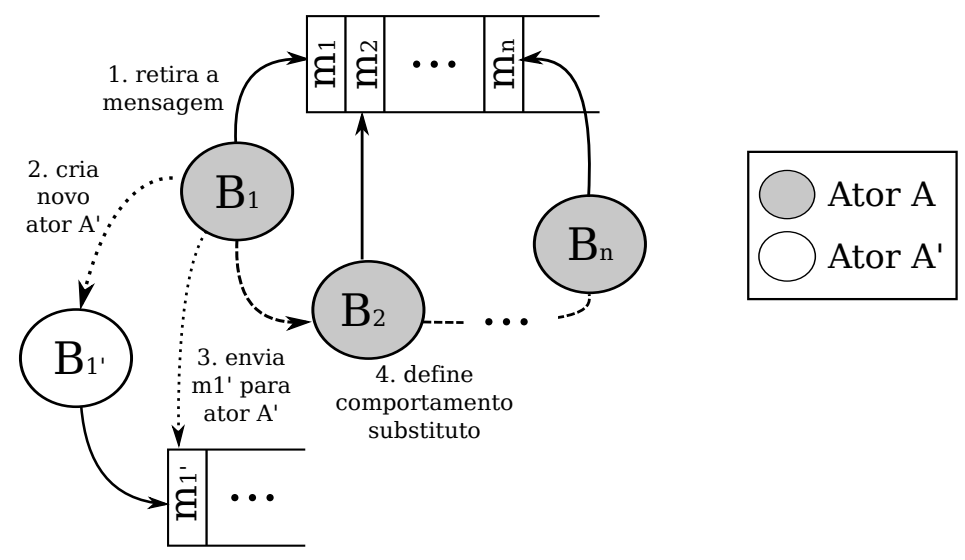

Figura 2.1: Máquina de estados de um ator.

No modelo de atores, a real localização de um ator não afeta a interação com outros atores. Os atores que um ator conhece podem estar distribuídos em diferentes núcleos de um processador, ou mesmo em diferentes nós de uma rede de computadores. A transparência da localidade abstrai a infraestrutura e permite que programas sejam desenvolvidos de modo distribuído, sem que a real localização de seus atores seja conhecida. Uma consequência direta da transparência da localidade é a capacidade de se mover atores entre os diferentes nós de uma rede de computadores. 
Apesar do modelo ser bem explícito e claro em relação à interação ser via troca de mensagens e dizer que o estado de um ator não deve ser compartilhado, implementações poderiam permitir que um ator fizesse acesso ao estado interno de outro ator. Por exemplo, um ator poderia invocar algum método de outro ator. Mesmo que a interface de um ator não permita o compartilhamento do seu estado, mensagens enviadas poderiam expor um compartilhamento indesejado de estado com atores residentes no mesmo processo ("atores co-locados"). O uso de mensagens imutáveis ou passadas via "cópia funda" é uma abordagem mais apropriada para evitar um compartilhamento indesejado de memória entre atores co-locados.

Mobilidade é definida como a habilidade de se poder mover um programa de um nó para outro, e pode ser classificada como mobilidade fraca ou mobilidade forte. Mobilidade fraca é a habilidade de se transferir código entre nós, enquanto que mobilidade forte é definida como a habilidade de se transferir tanto o código quanto o estado da execução [FPV98]. Em um sistema baseado em atores, mobilidade fraca permite que atores que não possuam mensagens em suas filas e não estejam fazendo processamento algum sejam transferidos para outros nós.

Pelo fato do modelo de atores prover transparência de localidade e encapsulamento, a mobilidade se torna natural. Mover atores entre diferentes nós em um sistema de atores é uma necessidade importante para se obter um melhor desempenho, tolerância a falhas e reconfigurabilidade [PA94].

A semântica do modelo de atores apresentada nesta seção objetiva proporcionar uma arquitetura modular e componível [AMST98], e um melhor desempenho para sistemas concorrentes e distribuídos, em particular para situações em que as aplicações precisem de escalabilidade [KA95].

\subsection{Breve histórico}

O modelo de atores foi originalmente proposto por Carl Hewitt em 1971 [Hew71]. O termo ator foi originalmente utilizado para descrever entidades ativas que analisavam padrões para iniciar atividades. O conceito de atores passou então a ser explorado pela comunidade científica e, em 1973, a noção de atores se aproximou do conceito de agentes existente na área de inteligência artificial distribuída, pois tanto atores quanto agentes possuem intenções, recursos, monitores de mensagens e um agendador [HBS73].

Em 1975, Irene Greif desenvolveu um modelo abstrato de atores orientado a eventos em que cada ator guardava um histórico dos seus eventos [Gri75]. O objetivo do estudo era analisar a relação causal entre os eventos. Em 1977, Baker e Hewitt formalizaram um conjunto de axiomas para computação concorrente [HB77]. No mesmo ano, Hewitt apresentou um estudo sobre como o entendimento dos padrões de troca de mensagens entre atores pode ajudar na definição de estruturas de controle. Esse estudo demonstrou o uso do estilo de passagem de continuações no modelo de atores.

O conceito de guardião foi definido em 1979 por Attardi e Hewitt [HAL79]. Um guardião é uma entidade que regula o uso de recursos compartilhados. Guardiões incorporam explicitamente a noção de estado e são responsáveis por agendar o acesso e fazer a proteção dos recursos. No mesmo ano, Hewitt e Atkinson definiram um conceito relacionado ao de guardião denominado seriador (serializer) [HA79]. Um seriador age como um monitor, porém, ao invés de aguardar sinais explícitos vindos dos processos, seriadores procuram ativamente por condições que permitam que processos em espera possam voltar a ser executados. Em 1987, Henry Lieberman implementou em Lisp a linguagem Act1 [Lie87], uma linguagem de atores com guardiões, seriadores e atores chamados de "trapaceiros" (rock-bottom). Atores trapaceiros são atores que podem burlar as regras do modelo de atores para, por exemplo, fazer uso de dados primitivos e funções da linguagem usada em sua implementação.

Gul Agha definiu em 1986 um sistema simples de transição para atores [Agh86]. Em seu trabalho foram desenvolvidos os conceitos de configurações, recepcionistas e atores externos. Atores recepcionistas são atores que ocultam a existência de outros atores em um sistema de atores, agindo como 
intermediários no recebimento das mensagens. $\mathrm{O}$ uso de atores recepcionistas permite uma forma de encapsulamento, já que eles acabam agindo como interface para atores externos. Em 1987, esse modelo foi implementado na linguagem Acore, por Carl Manning [Man87], e em 1988, na linguagem Rosette, por Tomlinson e outros [TKS $\left.{ }^{+} 88\right]$.

\subsection{Implementações}

O suporte ao modelo de atores pode estar disponível em uma linguagem de programação, seja fazendo parte da estrutura da linguagem, ou ainda como uma biblioteca. Apresentamos na Subseção 2.3.1 algumas linguagens de programação baseadas no modelo de atores. Essas linguagens possuem primitivas que facilitam a criação de sistemas baseados em atores. Apresentamos na Subseção 2.3.2 algumas bibliotecas que adicionam o suporte ao modelo de atores a linguagens mais gerais.

\subsubsection{Linguagens}

Linguagens como Axum [Cor09], SALSA [VA01] e Erlang [Arm07] são exemplos de linguagens baseadas no modelo de atores. Nessas linguagens, o suporte é dado via primitivas na estrutura da linguagem.

\section{Axum}

Axum (anteriormente conhecida como Maestro) é uma linguagem experimental orientada a objetos $^{1}$ criada pela Microsoft Corporation para o desenvolvimento de sistemas concorrentes na plataforma .Net [Cor09]. A criação da linguagem teve como motivação permitir que sistemas modelados como componentes que interajam entre si pudessem ser traduzidos naturalmente para código. Pelo fato de ser uma linguagem da plataforma .Net, Axum pode interagir com outras linguagens da plataforma, como VB.Net, C\# e F\#.

Em Axum, o termo "ator" é substituído pelo termo "agente" (agent). Agentes são executados como threads dentro da CLR (Common Language Runtime) e são definidos com o uso da palavrachave agent. A troca de mensagens é feita via canais. Os canais são responsáveis por definir os tipos de dados que trafegam neles com o uso das palavras-chaves input e output. Canais possuem duas extremidades, a extremidade implementadora (implementing end) e a extremidade de uso (using end). Agentes que implementam o comportamento da extremidade implementadora de um canal passam a agir como servidores que processam as mensagens recebidas por seus respectivos canais. A extremidade de uso do canal é visível e deve ser utilizada por outros agentes para fazer o envio de mensagens.

A linguagem possui ainda o conceito de domínio. Domínios são definidos com a palavra-chave domain e permitem que agentes definidos dentro de um domínio compartilhem informações de estado. Uma instância de domínio pode ter atributos que são usados para compartilhamento seguro e controlado de informações.

Apesar de Axum ter seu desenvolvimento interrompido na versão 0.3, no início de 2011, segundo os seus autores os conceitos implementados na linguagem poderão ser portados para as linguagens C\# e Visual Basic [Corb].

\section{SALSA}

SALSA (Simple Actor Language System and Architecture) é uma linguagem que foi criada em meados de 2001 no Rensselaer Polytechnic Institute para facilitar o desenvolvimento de sistemas abertos dinamicamente reconfiguráveis. SALSA é uma linguagem concorrente e orientada a objetos que implementa a semântica do modelo de atores. A linguagem possui um pré-processador que converte o código fonte escrito em SALSA para código fonte Java, que por sua vez pode ser compilado

\footnotetext{
${ }^{1} \mathrm{O}$ projeto está em uma encubadora de projetos.
} 
para bytecode e ser executado sobre a JVM.

A linguagem possui primitivas para a criação, uso e organização dos atores. A construção behavior é semelhante à construção class de Java, e é utilizada para definir os métodos que definem o comportamento do ator. Há uma relação de herança em behaviors, similar à herança de classes Java. A hierarquia de behaviors segue regras análogas às da hierarquia de classes Java: não existe herança múltipla e um behavior podem implementar zero ou múltiplas interfaces. O behavior salsa.language. UniversalActor é análogo a classe java.lang.object, e todos os behaviors o estendem direta ou indiretamente. A primitiva <- é utilizada para enviar uma mensagem a um ator.

A implementação de atores da linguagem utiliza o objeto salsa. language. Actor como ator base que estende java. lang. Thread, de modo que cada ator é executado em uma thread. Cada ator possui uma fila de mensagens onde as mensagens recebidas ficam armazenadas até que o método run as retire para que o método correspondente seja executado via reflexão.

Além de prover a implementação da semântica do modelo de atores, a linguagem introduz ainda três abstrações para facilitar a coordenação das interações assíncronas entre os atores:

1. Continuações com passagem de token (token-passing continuations): Envios de mensagens para atores resultam em invocações de métodos. Esses métodos podem devolver valores que precisarão ser repassados a outros atores. Os valores devolvidos são definidos como tokens. Essa abstração permite que uma mensagem enviada a um ator contenha uma referência para o ator que irá consumir o token, como mostrado no exemplo a seguir:

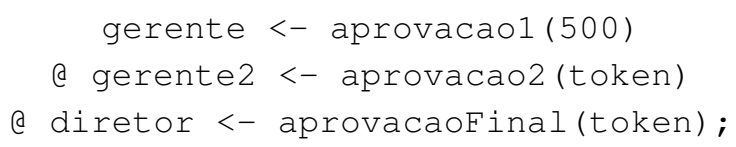

Nesse exemplo, gerente processa a mensagem aprovacao1 (500) e produz um valor que é passado como token no envio da mensagem para o ator gerente2. A palavra token é uma palavra-chave e seu valor é associado no contexto do último token passado. O ator diretor recebe como argumento o resultado da computação do ator gerente2. Ainda nesse exemplo, utilizamos a primitiva @ para indicar que desejamos utilizar a continuação com passagem de token.

2. Continuações de junção (join continuations): Atores podem receber vetores com tokens recebidos de diversos atores. Essa abstração permite que os tokens sejam agrupados para que o ator que os está recebendo só prossiga depois de todos os tokens aguardados terem sido recebidos. Por exemplo:

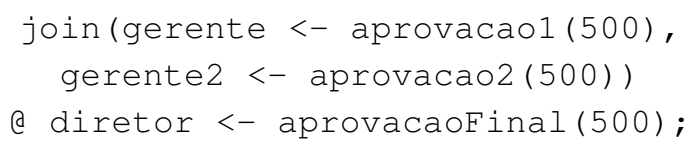

Nesse exemplo, os dois atores gerente e gerente2 fazem suas aprovações em paralelo e, somente quando os dois tiverem dado suas aprovações, o ator diretor irá receber a mensagem de aprovacaofinal.

3. Continuações de primeira classe (first-class continuations): Essa abstração é análoga às funções de ordem superior, na qual funções podem receber outras funções. No caso da linguagem SALSA, a abstração permite que continuações sejam passadas como parâmetro para outras continuações. O processamento da mensagem pode optar por delegar o restante do processamento à continuação recebida, por exemplo em chamadas recursivas. No processamento de uma mensagem, a continuação recebida como parâmetro é acessada pela palavra-chave currentcontinuation. 


\section{Erlang}

Erlang é uma linguagem funcional, com tipagem dinâmica e executada por uma máquina virtual Erlang. Voltada para o desenvolvimento de sistemas distribuídos de larga escala e tempo real, foi desenvolvida nos laboratórios da Ericsson no período de 1985 à 1997 [Arm97].

A linguagem em si, embora bem enxuta, possui características interessantes para simplificar o desenvolvimento de sistemas concorrentes. Exemplos de tais características são: variáveis de atribuição única, casamento de padrões e um conjunto de primitivas que inclui spawn para criação de atores, send e ! para o envio de mensagens, receive para o recebimento de mensagens e link para a definição de adjacências entre atores. Ademais, a linguagem dá suporte a hierarquias de supervisão entre atores e troca quente de código (hotswap).

Em Erlang, atores são processos ultra leves criados dentro de uma máquina virtual. Embora Erlang implemente o modelo de atores, sua literatura e suas bibliotecas não utilizam o termo "ator" (actor), mas sim o termo "processo" (process). A criação, destruição e troca de mensagens entre atores é extremamente rápida. Num teste feito em um computador com $512 M B$ de memória, com um processador de $2.4 \mathrm{GHz}$ Intel Celeron rodando Ubuntu Linux, a criação de 20000 processos levou em média $3.5 \mu \mathrm{s}$ de tempo de CPU por ator e $9.2 \mu \mathrm{s}$ de tempo de relógio por ator [Arm07]. Esses números mostram que a criação dos atores é rápida e que com pouca memória, muitos atores podem ser criados.

Com a possibilidade de se criar uma quantidade considerável de atores, o uso de uma hierarquia de supervisão torna-se extremamente importante. No que diz respeito ao tratamento de erros em atores filhos, as primitivas existentes na linguagem dão suporte a três abordagens:

1. Não se tem interesse em saber se um ator filho foi terminado normalmente ou não.

2. Caso um ator filho não tenha terminado normalmente, o ator criador também é terminado.

3. Caso um ator filho não tenha terminado normalmente, o ator criador é notificado e pode fazer o controle de erros da maneira que julgar mais apropriada.

Em Erlang é possível criar atores em nós remotos (remote spawn). Vale ressaltar que o código do ator deve estar acessível na máquina virtual onde o ator irá ser executado. Erlang possui o módulo erl_prim_loader que auxilia no carregamento de módulos em nós remotos. Uma vez que alguns detalhes de infra-estrutura foram observados (as máquinas virtuais Erlang necessitam se autenticar umas com as outras), a troca de mensagens entre atores remotos acontece de maneira transparente. No processo de envio, as mensagens trafegam com o uso de sockets TCP e UDP.

\subsubsection{Bibliotecas}

Diversas linguagens de programação possuem suporte ao modelo de atores via bibliotecas. Essas bibliotecas disponibilizam arcabouços para desenvolvimento de sistemas concorrentes baseados no modelo de atores. Listamos a seguir algumas linguagens e referências para algumas de suas bibliotecas:

- $\mathrm{C}++$ : Act ++ [KML93], Thal [Kim97] e Theron [Mas];

- Smalltalk: Actalk [Bri89];

- Python: Parley [Lee] e Stackless Python [Tis];

- Ruby: Stage [Sil08] e a biblioteca de atores presente na distribuição Rubinius ${ }^{2}$ [RUB];

\footnotetext{
${ }^{2}$ Rubinius é uma implementação da linguagem Ruby que possui uma máquina virtual escrita em $\mathrm{C}++$.
} 
- .Net: Asynchronous Agent Library [Cora] e Retlang [Retb];

- Java: Akka [AKK], Kilim [SM08], Jetlang [Reta] e Actor Foundry [AFY];

- Scala: Scala Actors [HO09], Akka [AKK] e Scalaz [Sca].

Pelo fato de nossa implementação ter sido desenvolvido sobre a JVM, mais especificamente na linguagem Scala, optamos por não descrever todas as bibliotecas listadas acima, pois isso nos distanciaria do escopo deste trabalho. Em [KSA09], Karmani e Agha apresentam uma análise comparativa de algumas implementações de atores para a JVM. Essa análise traz comparações entre as várias implementações da semântica de execução e das abstrações. Apresentamos a seguir informações sobre duas bibliotecas de atores Scala que foram consideradas como opções e analisadas para o desenvolvimento do nosso trabalho.

\section{A biblioteca de atores de Scala}

A distribuição de Scala inclui uma biblioteca de atores inspirada pelo suporte a atores de Erlang. Nessa biblioteca os atores foram projetados como objetos baseados em threads Java. Elas possuem métodos como send, !, receive, além de outros métodos como act e react. Cada ator possui uma caixa de correio para o recebimento e armazenamento temporário das mensagens. O processamento de uma mensagem é feito por um bloco receive.

No bloco receive são definidos os padrões a serem casados com as mensagens que o ator processa e as ações associadas. A primeira mensagem que casar com qualquer dos padrões é removida da caixa de correio e a ação correspondente é executada. Caso não haja casamento com nenhum dos padrões, o ator é suspenso.

Atores são executados em um thread pool ${ }^{3}$ que cresce conforme a demanda. É importante ressaltar que o uso do método receive fixa o ator à thread que o está executando, limitando superiormente a quantidade de atores pelo número de threads que podem ser criadas. É recomendado o uso do método react ao invés do método receive sempre que possível, pois dessa forma um ator que não estiver em execução cederá sua thread para que ela execute outro ator. Do ponto de vista de funcionalidade, o método receive é bloqueante e pode devolver valores, enquanto que o método react, além de não devolver valores, faz com que o ator passe a reagir aos eventos (recebimentos de mensagens). Da perspectiva do programador, uma implicação prática do uso de react em vez de receive é o uso da estrutura de controle loop ao invés de laços tradicionais, para indicar que o ator deve continuar reagindo após o processamento de uma mensagem (o emprego de laços tradicionais bloquearia a thread) [HO09].

Além de métodos para envio de mensagens equivalentes às primitivas de Erlang, a biblioteca de atores de Scala implementa dois métodos adicionais, que facilitam o tratamento de algumas necessidades específicas. Esses métodos são: !?, que faz envio síncrono e aguarda uma resposta dentro de um tempo limite especificado e ! !, que faz o envio assíncrono da mensagem e recebe um resultado futuro correspondente a uma resposta.

O suporte a atores remotos faz parte da biblioteca, porém com algumas restrições em comparação com os atores de Erlang. Não é possível a criação de um ator em um nó que não seja o local, ou seja, remote spawns não são possíveis. Os atores são acessíveis remotamente via proxies. Para obter uma referência a um ator remoto, um cliente faz uma busca em um determinado nó (uma JVM identificada por um par com o endereço do hospedeiro e a porta), utilizando como chave o nome sob o qual o ator foi registrado. Esta abordagem, apesar de soar restritiva, evita um problema importante que é a necessidade de carga remota da classe do ator (remote class loading) e torna desnecessário o uso de interfaces remotas como em Java RMI. O tráfego das mensagens é feito via seriação padrão Java e sockets TCP.

\footnotetext{
${ }^{3}$ Idealmente o tamanho do thread pool corresponde ao número de núcleos do processador.
} 


\section{O projeto Akka}

O projeto Akka é composto por um conjunto de módulos escritos em Scala ${ }^{4}$, que implementam uma plataforma voltada para o desenvolvimento de aplicações escaláveis e tolerantes a falhas. Na versão 1.0, suas principais características são: uma nova biblioteca de atores locais e remotos, suporte a STM, hierarquias de supervisão e uma combinação entre atores e STM ("transactors") que dá suporte a fluxos de mensagens baseados em eventos transacionais, assíncronos e componíveis. Akka oferece ainda uma série de módulos adicionais para integração com outras tecnologias.

A biblioteca de atores do projeto Akka é totalmente independente da que é parte da distribuição de Scala, embora também siga as ideias de Erlang. O comportamento dos atores Akka no recebimento de mensagens inesperadas (que não casam com nenhum dos padrões especificados em um receive) é diferente do comportamento dos atores de Erlang e Scala, em que o ator é suspenso. No caso de atores Akka, tais mensagens provocam o lançamento de exceções.

O suporte a atores remotos do projeto Akka é bem mais completo do que o oferecido pela biblioteca de atores de Scala e será discutido no Capítulo 3. Assim como a biblioteca de atores de Scala, a de Akka oferece métodos para diferentes tipos de envio de mensagens: ! !, semelhante ao método ! ? da biblioteca de atores de Scala, no qual o remetente fica bloqueado aguardando uma resposta durante um tempo limite, e !!!, que é semelhante ao método !! da biblioteca de atores de Scala, o qual devolve um resultado futuro ao remetente.

No que diz respeito à seriação das mensagens para um ator remoto, o Akka oferece as seguintes opções: JSON [Cro06], Protobuf [Goo], SBinary [Har] e seriação Java padrão. O transporte das mensagens é feito via sockets TCP, com o auxílio do JBoss Netty [JNY], um arcabouço para comunicação assíncrona dirigido a eventos e baseado em sockets. Esse arcabouço oferece facilidades para compressão de mensagens, e tais facilidades são utilizadas pelo Akka.

Optamos por utilizar a implementação de atores do projeto Akka para o desenvolvimento deste trabalho. Tomamos como base a versão 1.0 do Akka por ser a última versão estável disponível quando iniciamos o desenvolvimento. Nossa escolha pela implementação de atores do projeto Akka foi motivada pelos fatores a seguir:

- O projeto Akka tem código aberto.

- A implementação de atores é escrita em Scala.

- O Akka possui uma implementação mais completa de atores remotos em comparação com outras bibliotecas que examinamos.

- O grau de acoplamento entre a implementação de atores remotos e o mecanismo de transporte é relativamente baixo.

- O projeto tem grande volume de atividade em sua comunidade de usuários e de desenvolvedores.

Os principais detalhes da implementação da biblioteca de atores feita no projeto são apresentados no Capítulo 3.

\footnotetext{
${ }^{4} \mathrm{O}$ projeto disponibiliza também uma versão de suas APIs voltada para aplicações Java.
} 


\section{Capítulo 3}

\section{Atores no projeto Akka}

O projeto Akka disponibiliza tanto atores locais quanto remotos. O termo "ator local" é usado para denotar um ator que pode receber mensagens apenas de atores residentes na mesma máquina virtual. Por outro lado, um ator remoto pode receber mensagens de quaisquer outros atores, inclusive daqueles residentes em outras máquinas virtuais. Em outras palavras, o termo "ator remoto" é um sinônimo de "ator remotamente acessível".

Na Seção 3.1 examinamos a implementação de atores locais. Nosso objetivo é focar a criação desses atores, o envio e despachamento de mensagens e a hierarquia de supervisão. Na Seção 3.3 examinamos a implementação de atores remotos. Nosso objetivo é focar a estrutura definida para o suporte a atores remotos, a seriação de mensagens e o formato definido para o envio de mensagens.

\subsection{Atores locais}

Para se definir um ator local, cria-se uma classe que é combinada com a feição akka.actor . Actor e que provê uma implementação para o método receive, como mostrado na Listagem 3.1. A classe que define um ator descreve o comportamento inicial que o ator terá. Entretanto, o ator propriamente dito não é uma instância dessa classe, e sim da feição akka.actor.ActorRef, cujas instâncias têm o papel de referências para atores. Essas referências são imutáveis, seriáveis, identificáveis e armazenam o endereço do nó onde foram criadas.

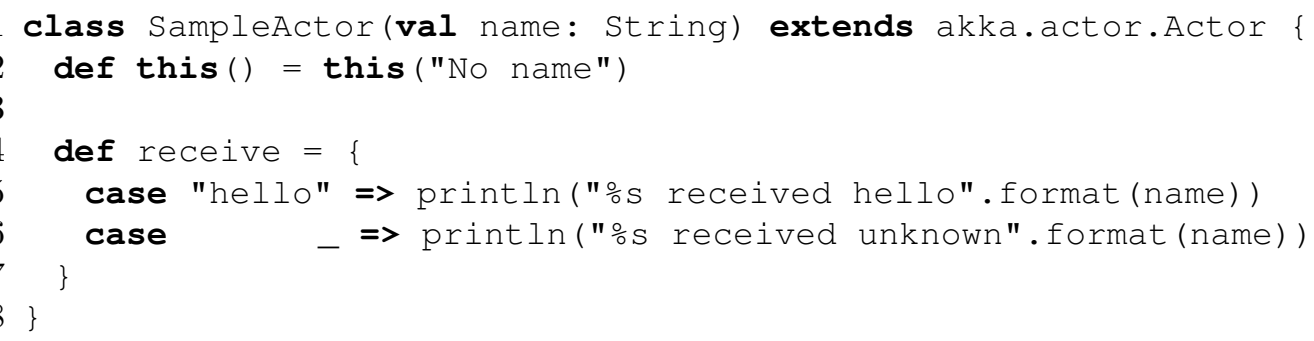

Listagem 3.1: Classe SampleActor.

Atores são criados pelo método actorof do objeto akka.actor.Actor, um objeto singleton que é o objeto acompanhante da feição de mesmo nome. A Listagem 3.2 mostra o uso do método actorof, que devolve uma instância de akka.actor. ActorRef.

1 val theActor = Actor.actorof [SampleActor]. start

2 theActor! "hello"

Listagem 3.2: Criação e inicialização de SampleActor via construtor padrão.

A instância do ator criado possui uma referência para uma instância da classe que define o comportamento do ator. Na Listagem 3.2, esta instância é criada por reflexão com base no tipo SampleActor. O construtor utilizado durante a reflexão é o construtor padrão. A Listagem 3.2 
ilustra também o uso do método ! para fazer o envio assíncrono da mensagem "hello" ao ator referenciado por theActor. O processamento dessa mensagem resultará na impressão do texto "No name received hello".

O método actorof é sobrecarregado para permitir que uma função de inicialização (uma função sem argumentos e com tipo de retorno Actor) possa ser utilizada como alternativa ao construtor padrão na criação do ator. A Listagem 3.3 ilustra a criação do ator via função de inicialização.

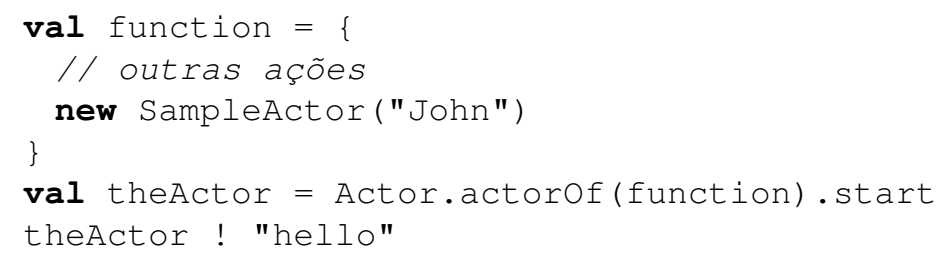

Listagem 3.3: Criação e inicialização de SampleActor via função de inicialização.

Nas Listagens 3.2 e 3.3, tivemos que chamar explicitamente o método start para iniciar o ator. Os atores do projeto Akka possuem um conjunto de estados simples e linear. Um ator, logo após sua criação, está no estado "novo" e ainda não pode receber mensagens. Após a invocação do método start, o ator passa ao estado "iniciado" e está apto a receber mensagens. Uma vez que o método stop é invocado, o ator passa ao estado "desligado" e não executa mais ação alguma.

A feição Actor possui em sua declaração uma referência para o seu ActorRef, acessível via atributo self. Com essa referência, a classe que define o comportamento do ator pode alterar as definições padrão providas pelo Akka e utilizar o métodos do ActorRef para, por exemplo, enviar uma resposta ao remetente de uma mensagem ou encaminhar a outro ator uma mensagem recebida. Vale mencionar que, no caso de atores locais, self referencia uma instância da classe akka.actor. LocalActorRef.

As mensagens que são enviadas para um ator são colocadas sincronamente na fila de mensagens do ator, levando tempo $O(1)$. As mensagens enfileiradas são então despachadas assincronamente para a função parcial definida no bloco receive da classe que define o comportamento do ator, como mostrado na Figura 3.1.

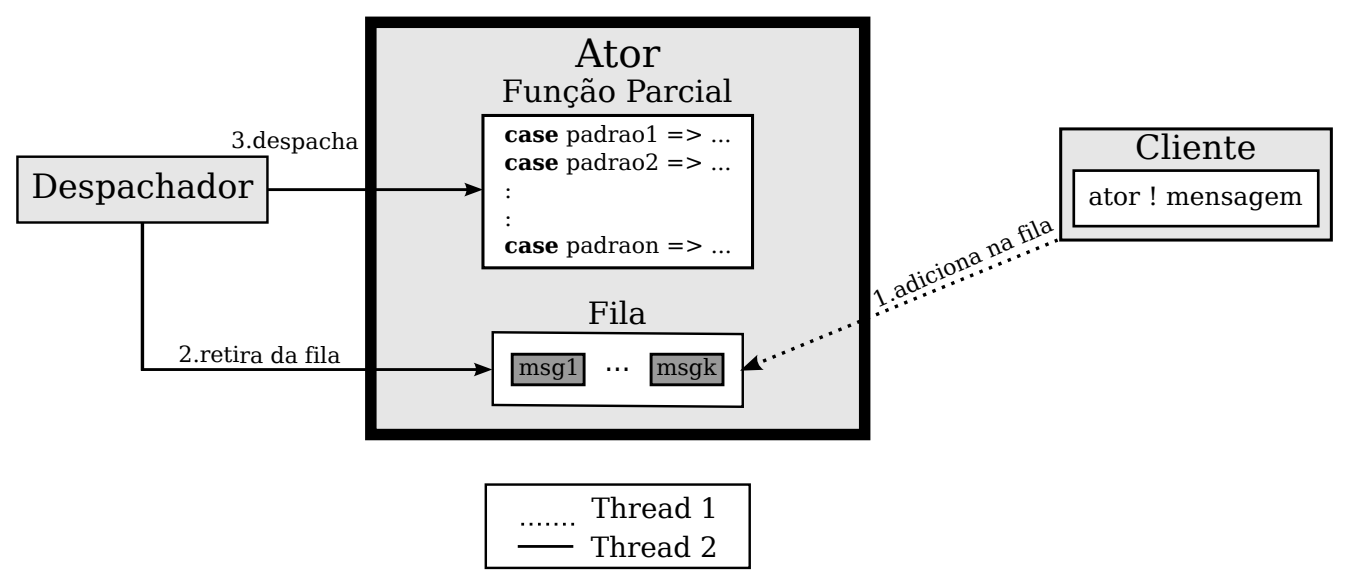

Figura 3.1: Envio e despacho de mensagens para atores locais.

\subsubsection{Despachadores}

O despachador de um ator é uma entidade que possui um papel importante. O despachador permite a configuração do tipo da fila do ator e a semântica do despachamento das mensagens. A fila de um ator pode ser durável ou transiente e ter seu tamanho limitado superiormente ou não. O 
Akka possui em sua distribuição os quatro despachadores listados a seguir:

- Despachador baseado em threads: É o despachador mais simples de todos os despachadores, que associa uma thread a cada ator. Essa thread processa sequencialmente as mensagens na fila do ator. O uso deste despachador implica no uso de uma fila transiente. Internamente, é utilizada uma fila que faz o bloqueio da thread que está tentando adicionar uma mensagem, caso o limite superior da fila tenha sido atingido. Este despachador é definido na classe ThreadBasedDispatcher.

- Despachador impulsionado por eventos: É um despachador normalmente compartilhado por diversos atores de diferentes tipos, já que ele utiliza um thread pool para agendar as ações de despachamento. Este é o despachador mais flexível em termos de configurações, pois permite que parâmetros do thread pool e da fila de mensagens sejam configurados. É definido na classe ExecutorBasedEventDrivenDispatcher.

- Despachador impulsionado por eventos com balanceamento de carga: É um despachador semelhante ao despachador anterior, já que também é impulsionado por eventos. Este despachador deve ser compartilhado por atores do mesmo tipo, pois permite que atores que não estejam processando mensagens possam "roubar" mensagens das filas dos atores que estejam sobrecarregados. Dessa forma, o despachador dá suporte a uma forma de balanceamento do processamento das mensagens entre os atores. É definido na classe ExecutorBasedEventDrivenWorkstealingDispatcher.

- Despachador quente: É um despachador inspirado no Grand Central Dispacher do Mac OS X [App09]. Este despachador define um thread pool cujo tamanho é ajustado automaticamente para minimizar a quantidade de threads concorrentes e inativas ${ }^{1}$. Sua vantagem é a capacidade de agrupar múltiplos eventos gerados pela aplicação, por exemplo diversas mensagens recebidas, gerando uma única tarefa assíncrona. Este despachador é definido na classe HawtDispatcher.

Por padrão, atores são associados a um despachador global impulsionado por eventos. A configuração padrão desse despachador define uma fila transiente sem limite máximo de mensagens. Caso seja necessário outro despachador a um ator, a atribuição deve acontecer antes do ator ser iniciado via método self.dispatcher. O Akka permite ainda que novos despachadores sejam criados.

\subsubsection{Envios de respostas}

Além do método !, que faz o envio assíncrono de uma mensagem sem devolver resposta alguma ao remetente, o Akka oferece dois métodos para envio de mensagem com resposta ao remetente. $\mathrm{O}$ primeiro deles é o método !!, que faz envio síncrono da mensagem e deixa o remetente bloqueado aguardando uma resposta durante um tempo limite. O segundo é o método !!!, que devolve um resultado futuro ao remetente.

Todos os métodos para envio de mensagem capturam implicitamente uma referência para o ator remetente (sender). Uma cópia da referência ao sender é enviada junto com a mensagem para que o ator destinatário possa, eventualmente, enviar uma mensagem de resposta. O ator destinatário pode enviar uma mensagem de resposta via método self.reply. No caso dos envios de mensagem com resposta ao remetente, a chamada self.reply é obrigatória.

A Listagem 3.4 mostra a assinatura de um dos métodos de envio, o método ! !. Note a presença do parâmetro implícito sender, que normalmente não é fornecido pelo chamador do método.

\footnotetext{
${ }^{1}$ Idealmente a quantidade de threads corresponde ao número de núcleos disponíveis.
} 


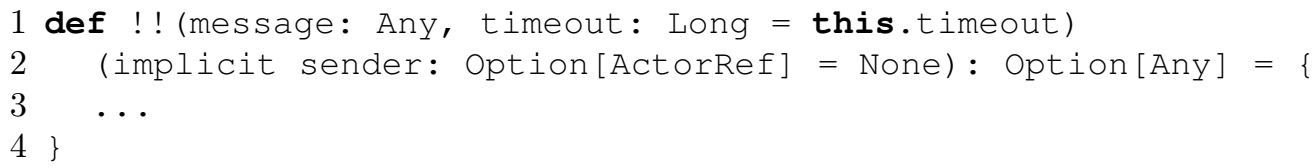

Listagem 3.4: Assinatura do método !!.

A implementação dos métodos !! e !!! é baseada em resultados futuros. Resultados futuros são representações de resultados de computações assíncronas. Na biblioteca de Java, a classe java - util.concurrent. FutureTask provê funcionalidades básicas para resultados futuros. O projeto Akka tem sua própria implementação de resultados futuros de computações assíncronas. Essa implementação provê algumas facilidades que não são oferecidas pela implementação de Java e que são necessárias ao Akka. A feição CompletableFuture define métodos para que resultados futuros possam ser completados por outras entidades, como mostra a Listagem 3.5. A implementação do Akka é inspirada no projeto Actorom [Bos] e é construída sobre classes do pacote java.util. concurrent.

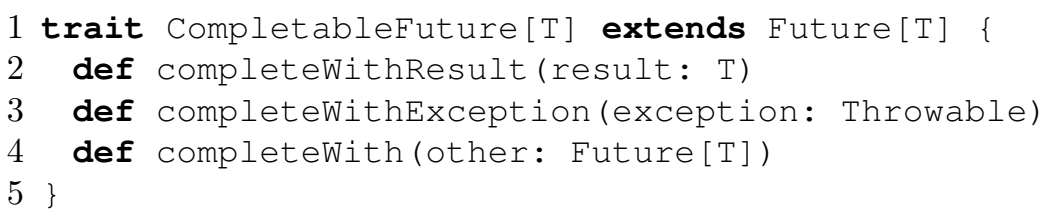

Listagem 3.5: Feição CompletableFuture.

Envios de mensagens via métodos !! e !!! são considerados como feitos por "remetentes futuros". Uma vez que o ator destinatário enviou a mensagem de resposta, essa mensagem não é colocada em uma fila de mensagens como no caso de um envio via !, mas é utilizada para indicar no resultado futuro que a computação foi completada. Na ActorRef, um envio de uma mensagem feito via método ! ! ! é processado da seguinte maneira:

1. Uma instância de CompletableFuture é criada dentro do método.

2. Assim como para um envio assíncrono via !, a mensagem é colocada na fila do ator destinatário. Além disso, uma referência para a instância de completableFuture criada no passo anterior é colocada juntamente com a mensagem.

3. Uma outra cópia da referência para o CompletableFuture criado no passo 1 é devolvida para quem invocou o método !!! .

4. Ao final do processamento da mensagem, o completableFuture é completado com o resultado. Como a instância completada (seja com um resultado válido ou com uma exceção) é a mesma referenciada por quem fez a invocação do método !!!, o resultado pode então ser utilizado.

Um envio feito via método !! possui quase os mesmos passos de processamento. A diferença está na devolução da referência. Como o envio é síncrono, a espera do resultado acontece de modo bloqueante dentro do próprio método !!. Quando o CompletableFuture estiver preenchido, o resultado será devolvido ao chamador do método !!.

Envios de mensagens não são limitados somente a atores. Qualquer objeto ou classe pode enviar uma mensagem a um ator. Podemos notar que o código da Listagem 3.2 não está definido em um ator. Num envio de mensagem com resposta ao remetente (!! ou !!!), o ator destinatário pode verificar se há um remetente definido a mensagem recebida, porém existe um modo alternativo e mais simples: o método self.reply_? faz o envio ao remetente somente no caso em que há 
remetente definido, devolvendo o valor booleano true para indicar se houve envio ou false caso contrário.

\subsection{Hierarquias de supervisão}

A biblioteca de atores do Akka permite que o tratamento de erros possa ser feito por atores definidos como supervisores. Sua implementação é totalmente baseada na abordagem feita na linguagem Erlang [Arm07], conhecida como "deixe que falhe" (let it crash).

Uma hierarquia de supervisão é criada com o uso de ligações entre atores. A ligação de dois atores pode acontecer via métodos link e startLink, definidos em ActorRef. A chamada al. link (a2) faz a ligação dos atores a1 e a2. A chamada a1.startLink (a2) também faz a ligação dos atores a1 e a2, porém coloca o ator a2 no estado "iniciado". As ligações são unidirecionais, ou seja, o ator alvo da chamada que criou uma ligação (a1) receberá uma notificação em caso de falha em algum um ator ligado a ele (a2).

Quando se define uma hierarquia de supervisão, é necessário definir, em cada ator supervisionado, o ciclo de vida que esse ator deverá ter. O ciclo de vida de um ator indica ao ator supervisor como proceder no caso de erros no ator supervisionado. Existem dois tipos de ciclo de vida:

1. Permanente: Indica que o ator possui um ciclo de vida permanente e sempre deve ser reiniciado no caso de falhas. Este ciclo é definido pela classe Supervision.Permanent.

2. Temporário: Indica que o ator possui um ciclo de vida temporário e não deve ser reiniciado no caso de falhas. Ademais, esse ciclo de vida indica que o ator deve ser colocado no estado "desligado", como se ele tivesse encerrado sua execução normalmente (ou seja, como se ele tivesse sido alvo de uma chamada ao método stop). Este ciclo é definido na classe Supervision. Temporary.

A definição de um ator com ciclo de vida permanente é mostrada na Listagem 3.6. A definição do ciclo de vida do ator acontece na linha 2.

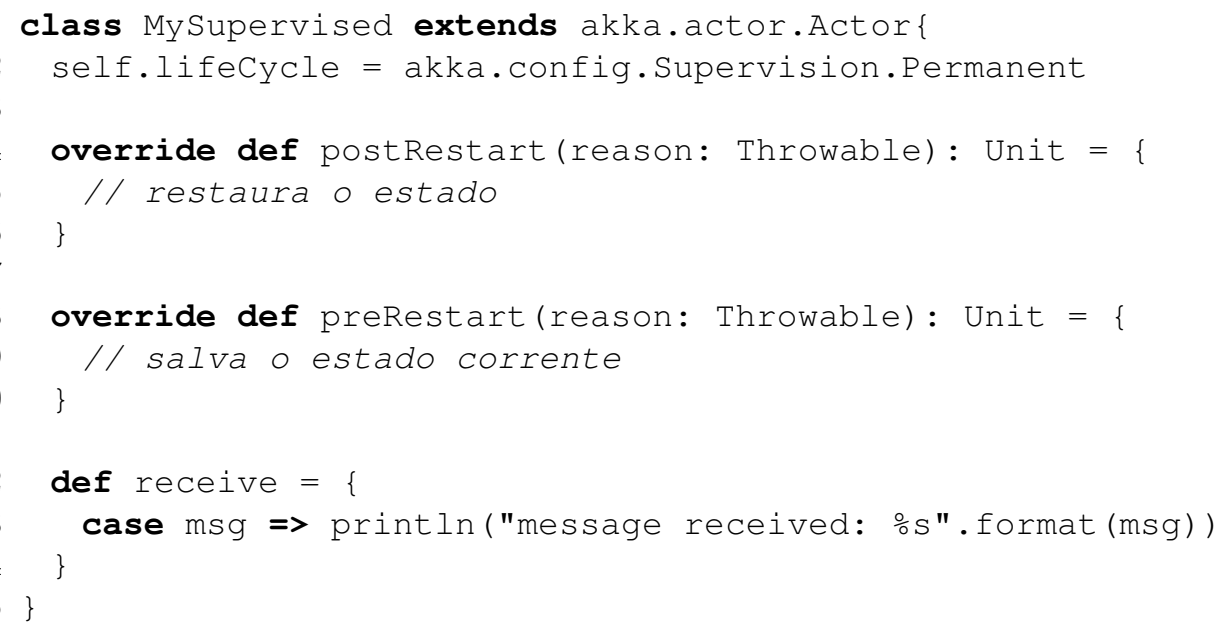

Listagem 3.6: Ator com ciclo de vida permanente.

O processo de reinicialização de um ator consiste na criação de uma nova instância da classe que define o ator. Os métodos de callback preRestart e postRestart são invocados, respectivamente, antes do ator passar ao estado "desligado" e logo após ele ter sido reiniciado. Alguns detalhes importantes a observarmos sobre a reinicialização de atores:

- O método preRestart é invocado na instância em que ocorreu o erro. 
- O método postRestart é invocado na nova instância.

- A nova instância criada utiliza a mesma ActorRef da instância em que ocorreu o erro, ou seja, tanto a instância nova quanto a anterior possuem o mesmo valor de self.

- A criação da nova instância é feita da mesma maneira que a do ator original, o qual pode ter sido criado via construtor padrão (é o caso do ator da Listagem 3.2) ou com o uso de uma função de inicialização (é o caso do ator da Listagem 3.3).

No ator supervisor, por sua vez, deverá ser definida a estratégia de reinicialização para os atores que ficarão ligados a ele. Existem duas estratégias possíveis:

1. Um por um: Com esta estratégia, uma exceção lançada por um ator supervisionado que possua ciclo de vida permanente faz com que somente esse ator seja reiniciado. Esta estratégia é definida na classe Supervision. OneForOneStrategy.

2. Todos por um: Com esta estratégia, uma exceção lançadas por um ator supervisionado que possua ciclo de vida permanente faz com que todos os atores sob o mesmo supervisor sejam reiniciados. Esta estratégia é definida na classe Supervision.AllForonestrategy.

Junto com a estratégia de reinicialização, é necessário definir quais são as exceções que o ator supervisor tem interesse em tratar, além de configurações relacionadas à quantidade de tentativas de reinicialização de um ator supervisionado que podem ser feitas dentro de um período de tempo. Mostramos na Listagem 3.7 a definição de um ator supervisor. Na linha 2 dessa listagem definimos a estratégia um por um, tratando exceções do tipo java.lang.Exception, com duas tentativas de reinicialização em um período de cinco segundos. Caso o limite de tentativas de reinicialização tenha sido atingido, sem que se tenha obtido sucesso na reinicialização do ator supervisionado, uma mensagem específica é enviada para o ator supervisor.

1 class MySupervisor extends akka.actor. Actor \{

2 self.faulthandler = akka.config.Supervision. OneForonestrategy(List ( classof [Exception]), 2, 5000)

3

4 def receive $=\{$

5 case _ => // ignora todas as mensagens

$6\}$

$7\}$

Listagem 3.7: Ator supervisor.

Apresentamos na Listagem 3.8 a criação de uma hierarquia de supervisão entre os atores apresentados nas Listagens 3.6 e 3.7.

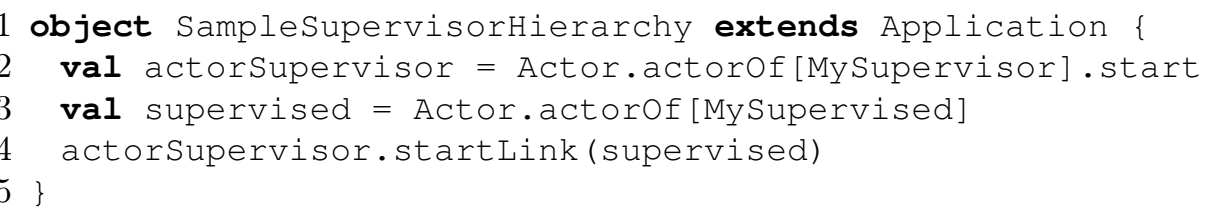

Listagem 3.8: Criação da hierarquia de supervisão.

Quando criamos uma ligação de supervisão entre dois atores, como na linha 4 da Listagem 3.8, a referência para o ator supervisor fica armazenada no ator supervisionado. Essa referência é acessível via método self. supervisor. Um ator supervisor também pode ser supervisionado por outro ator, como mostrado na Figura 3.2. O encadeamento de atores supervisores abre a possibilidade da criação de sub-hierarquias, cada uma com seu supervisor. 


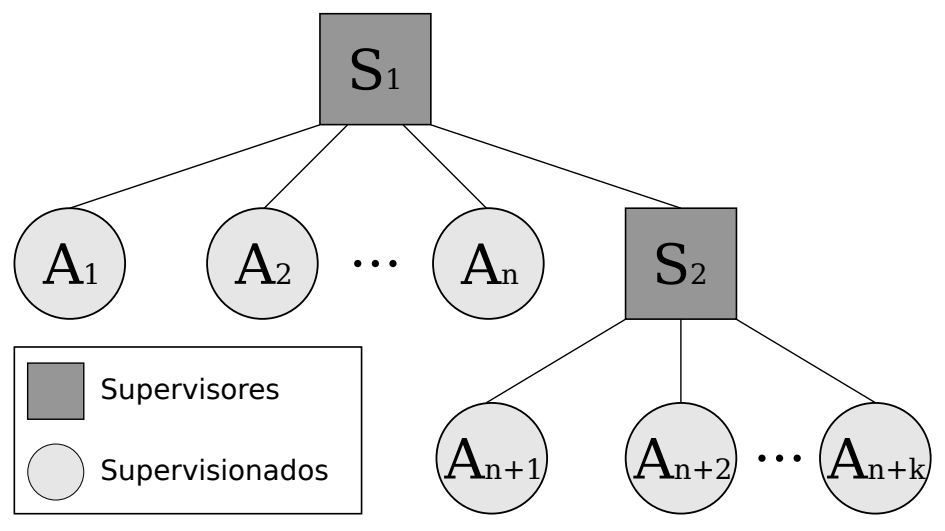

Figura 3.2: Hierarquia de supervisão de atores.

\subsection{Atores remotos}

No contexto de envios de mensagens para atores remotos, o termo cliente se refere ao processo (máquina virtual) onde residem as referências para os atores remotos e as demais entidades que, normalmente, iniciam o envio de mensagens. O termo servidor denota o processo (máquina virtual) no qual reside o ator remoto. A infraestrutura de atores remotos utiliza os seguintes elementos:

- RemoteServerModule: É uma feição que define as responsabilidades do componente utilizado no lado do servidor. Suas implementações têm como responsabilidade manter registrados os atores, bem como encaminhar a eles as mensagens recebidas de clientes remotos. Cada RemoteserverModule é associado a um endereço de hospedeiro (host) e a uma porta TCP. Um mesma máquina virtual pode conter múltiplos RemoteServerModules. A documentação do Akka utiliza para este componente a terminologia "servidor remoto" (remote server).

- RemoteClientModule: É uma feição que define as responsabilidades do componente usado no lado do cliente. Suas implementações têm como responsabilidade visível oferecer uma interface para obtenção de referências a atores remotos. Ademais, oferece também suporte em tempo de execução para a infraestrutura de atores do lado do cliente, provendo uma série de serviços não visíveis para o usuário. Tais serviços incluem os seguintes: seriação de mensagens, envio de mensagens para atores remotos, conversão de ator local em ator remoto e intermediação de mensagens de resposta vindas do RemoteServerModule, no caso de envios via ! ! ou ! ! !. A documentação do Akka utiliza para este componente a terminologia "cliente remoto" (remote client).

- RemoteSupport: Esta classe abstrata é responsável por concentrar as responsabilidades definidas para os módulos remotos do cliente e do servidor e ser um ponto único de suporte remoto. É acessível via Actor.remote.

- RemoteActorRef: É uma classe equivalente a LocalActorRef, porém utiliza o suporte remoto para fazer envio das mensagens.

Atores remotamente acessíveis possuem as mesmas características de atores locais no que diz respeito ao envio, recebimento e despachamento de mensagens. A criação de um ator remoto pode ocorrer tanto por iniciativa do nó onde reside a aplicação servidora, como por iniciativa de uma aplicação cliente remota. A Listagem 3.9 mostra a criação de um ator remoto gerenciado pelo servidor (server managed actor). Nessa listagem, um servidor remoto é inicializado na linha 2 para que os atores possam ser registrados. Na linha 3 registramos o ator sob o nome hello-service. O ator passou a estar remotamente acessível a aplicações que residam em outras máquinas virtuais. Um detalhe importante a ser destacado é a inicialização implícita do ator feita pelo método register, 
tornando opcional a chamada ao método start no ator. Note que o fato de um ator ser remoto não altera a declaração da classe do ator. A classe do ator remoto da Listagem 3.9, é a mesma do ator local da Listagem 3.2.

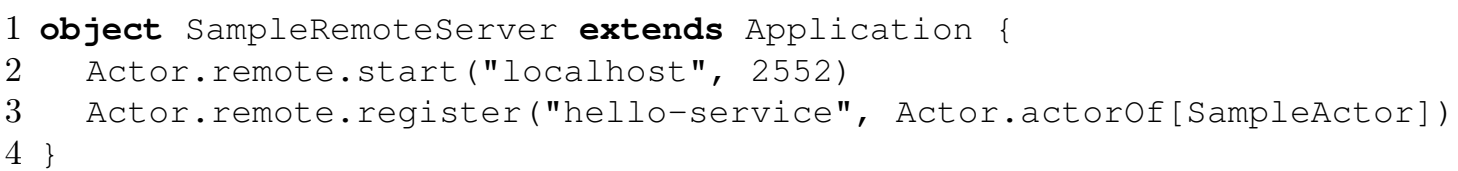

Listagem 3.9: Aplicação SampleRemoteServer.

Referências para atores remotos são obtidas via método actorFor. Esse método possui diversas sobrecargas, sendo que a mais simples recebe como argumentos o nome do ator, o endereço do hospedeiro e a porta do remote server onde o ator foi registrado. A linha 2 da Listagem 3.10 mostra como uma aplicação cliente obtém uma referência para um ator remoto. Podemos notar que, no uso do ator na linha 3, não há nenhuma indicação que caracterize um envio remoto. O método actorFor devolve, na maioria das vezes, uma instância de RemoteActorRef que representam proxies locais para o ator remoto. A implementação desse método possui otimizações para que referências locais sejam utilizadas sempre que possível. Por exemplo, caso a entidade que está enviando a mensagem resida no mesmo nó que o ator remoto, uma instância de LocalActorRef é devolvida.

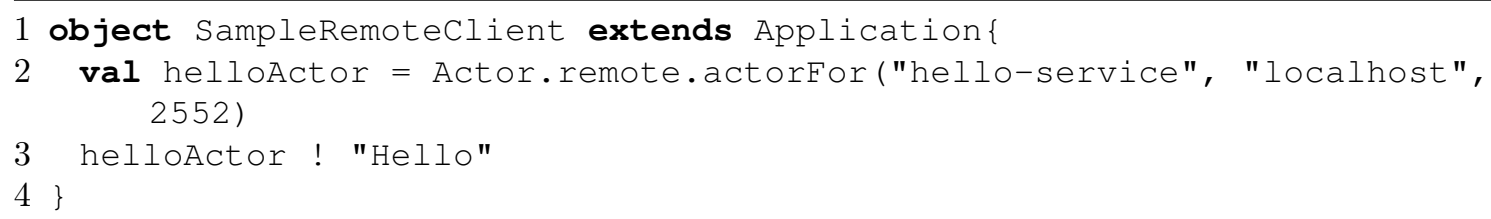

Listagem 3.10: Aplicação SampleRemoteClient.

Aplicações cliente podem optar por criar e iniciar atores em nós diferentes do nó corrente. Esses atores são denominados atores gerenciados pelo cliente (client managed actors). A biblioteca de atores fornece uma versão alternativa do método actorFor que recebe parâmetros adicionais para indicar o nó onde o ator criado será executado. Como o Akka não oferece suporte a carga remota de classes, é necessário que o conjunto de classes com a definição de um ator esteja acessível para a máquina virtual onde o ator será instanciado e executado. Outra observação importante diz respeito ao servidor remoto que irá executar um ator criado via actorFor: é necessário que esse servidor esteja em execução antes do método actorfor ser invocado. Detalhes como esses motivam discussões entre a comunidade de desenvolvedores do Akka para que o suporte a atores gerenciados pelo cliente seja tornado obsoleto e removido em versões futuras, já que os mesmos resultados podem ser obtidos com o uso de atores gerenciados pelo servidor.

A biblioteca de atores remotos do Akka implementa os componentes de suporte remoto com o auxílio do JBoss Netty [JNY]. A Figura 3.3 mostra como esses componentes se relacionam. Dividimos a figura em duas camadas, sendo a primeira a camada de interface remota, e a segunda a camada de implementação. A camada de implementação é associada ao suporte remoto em tempo de execução, permitindo que outras implementações possam ser utilizadas. Na implementação padrão feita com o Netty, a inicialização de um servidor remoto (linha 2 da Listagem 3.9) tem como consequência a instanciação de um componente do Netty para monitorar o socket associado ao par hospedeiro e porta.

\subsubsection{Fluxo de envio das mensagens}

O envio assíncrono de uma mensagem a um ator remoto tem alguns passos adicionais em relação a um envio local de mensagens. O processo de um envio assíncrono de uma mensagem para um ator remoto é ilustrado na Figura 3.4 e acontece em sete passos: 


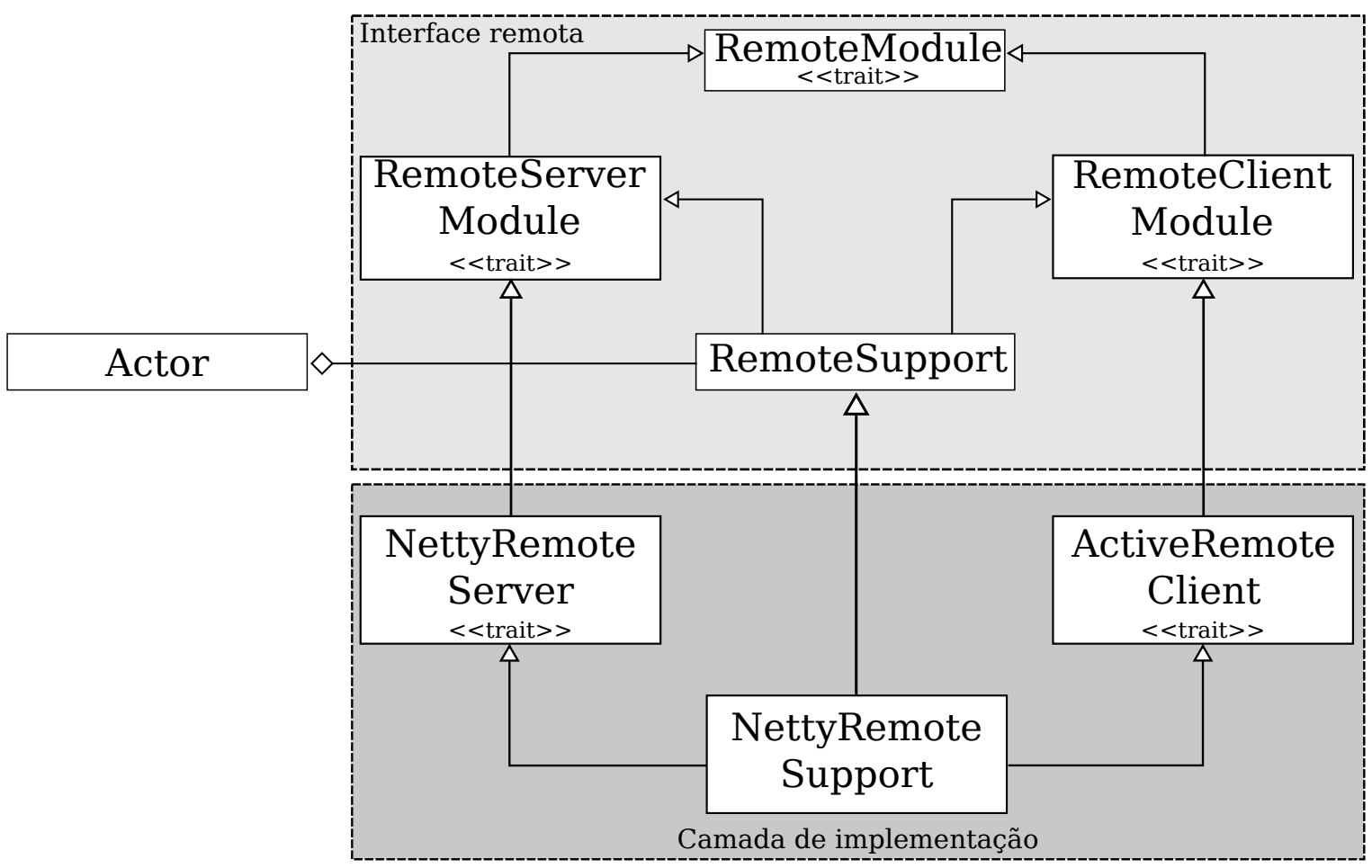

Figura 3.3: Relacionamento entre os componentes remotos.

1. O processo de envio começa com o proxy local embrulhando a mensagem e adicionando a ela informações de cabeçalho necessárias para o envio e processamento posterior. A mensagem embrulhada e com as informações de cabeçalho é então repassada ao seriador.

2. O seriador é responsável por converter a informação recebida em um vetor de bytes para que o transporte possa ocorrer. Uma vez que a informação esteja no formato a ser transportado, o proxy utiliza uma implementação de Remotesupport (que na Figura 3.4 é uma instância de NettyRemoteSupport) para enviar a mensagem ao Remotesupport que está no lado do servidor.

3. A classe ClientBootstrap repassa a mensagem para o ServerBootstrap ao qual se está conectada. O processo de envio, do ponto de vista do cliente, leva tempo $O(1)$, já que o transporte da mensagem pelo JBoss Netty entre o ClientBootstrap e o ServerBootstrap é feito de modo assíncrono.

4. A classe ServerBootstrap repassa a mensagem ao handler que lhe foi associado.

5. A implementação do handler feita no Akka repassa a mensagem para o seriador para que a desseriação seja feita.

6. O seriador desseria a mensagem, deixando-a no formato original e, em seguida, repassa novamente a mensagem ao handler.

7. Por fim, a implementação do handler utiliza as informações de cabeçalho da mensagem para identificar qual o ator destinatário e buscá-lo no registro local de atores, bem como para verificar se o envio é assíncrono ou não. No caso de envio assíncrono, o ator destinatário tem seu método ! invocado. Além de receber como parâmetro a mensagem, essa chamada ao método ! recebe um segundo parâmetro (que normalmente não é fornecido por ser implicitamente capturado) com uma referência para o ator remetente (sender) ou com o valor None, caso o remetente não seja um ator. O despachador associado ao ator destinatário tem o mesmo comportamento já mostrado na Figura 3.1. 


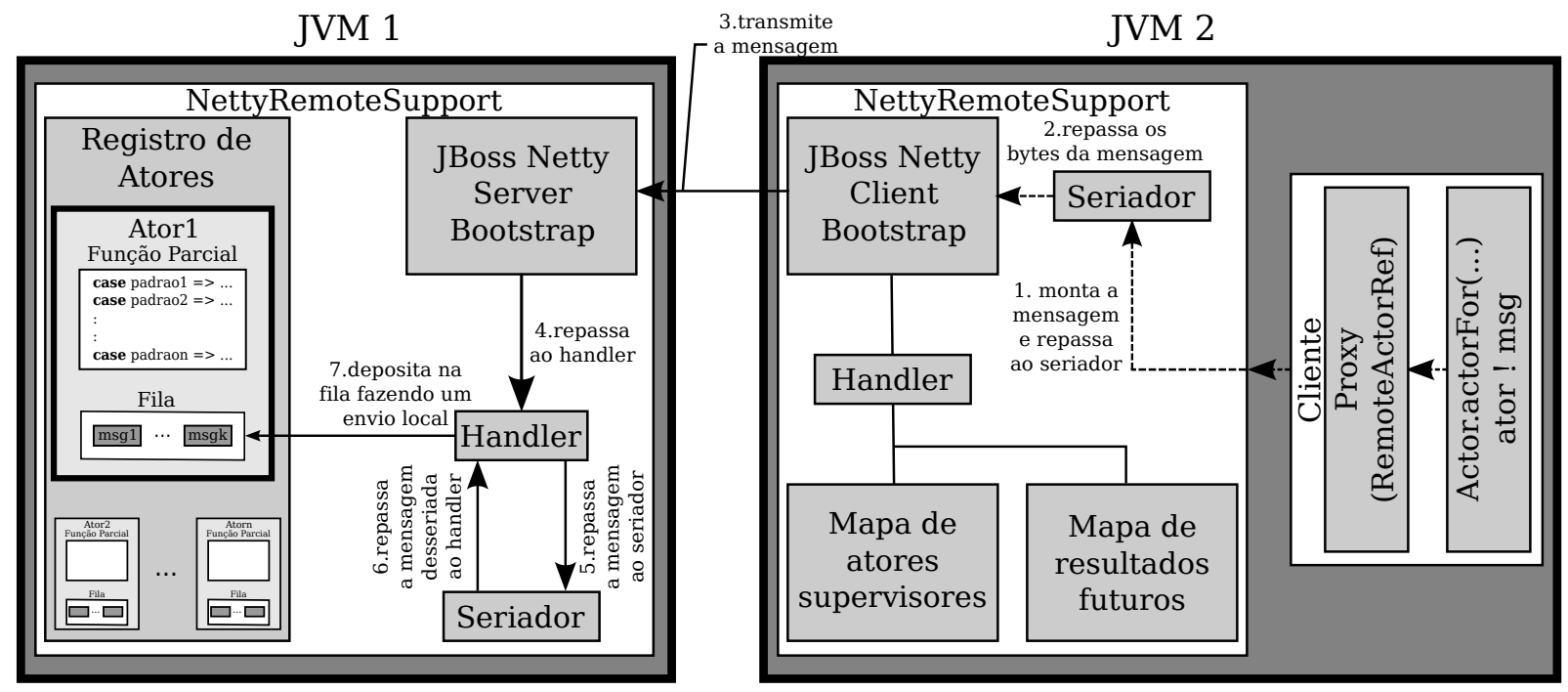

Figura 3.4: Fluxo de envio de mensagens para atores remotos.

Os envios feitos via métodos !! e !!! para atores remotos são análogos, mas possuem um passo adicional em relação aos mostrados na Figura 3.4. O passo adicional acontece entre os passos 2 e 3. Antes da mensagem ser enviada, é colocada no mapa de resultados futuros uma referência para a instância de CompletableFuture criada pela chamada ao método ! ! ou ! ! !. A chave para essa instância é o identificador da mensagem.

Um envio feito mediante chamada ao método !! ou !!! gera uma mensagem de resposta no caminho contrário ao mostrado na Figura 3.4. O conteúdo dessa mensagem de resposta (seja um resultado de sucesso ou uma exceção) é utilizado para completar o resultado futuro. Caso a mensagem de resposta contenha uma exceção e caso o ator que gerou a resposta possua um ator supervisor residente na JVM do lado cliente, esse ator supervisor é localizado no mapa de supervisores e recebe uma mensagem assíncrona de notificação enviada localmente.

O Akka possui uma configuração opcional de segurança em que cada JVM pode definir um cookie. O cookie nada mais é do que uma chave que o usuário pode definir e que deve ter o mesmo valor para todas as JVMs cujos atores vão interagir. Em outras palavras, o cookie é um segredo comum compartilhado por todos os nós de um "aglomerado lógico". O valor do cookie é uma das informações presentes no cabeçalho das mensagens. Quando a verificação de segurança está habilitada, a cada envio de mensagem, a infraestrutura do Akka no destinatário verifica se a valor do cookie presente na mensagem confere com a valor esperado. Essa verificação ocorre entre os passos 6 e 7 da Figura 3.4. Caso os valores sejam iguais, o passo 7 é executado. Caso contrário, uma exceção de segurança é lançada na JVM onde a mensagem foi recebida e o passo 7 não será executado.

O Netty oferece algumas opções específicas para o transporte de mensagens baseado em sockets TCP. Exemplos dessas opções são a definição do tamanho máximo da janela utilizada para o envio das mensagens a atores remotos, o tempo limite de espera para leitura na socket, o intervalo de espera para tentativa de reconexão e o intervalo máximo em que o cliente deve tentar se conectar. Além dessas opções, o Netty fornece ainda a possibilidade de compactação das mensagens durante o envio. O Akka faz uso de todas as opções mencionadas, permitindo que os usuários da biblioteca definam os valores desejados. As configurações de todos os módulos do Akka são feitas no arquivo akka.conf.

O arquivo akka.conf é o ponto de entrada para todas as configurações parametrizáveis de todos os módulos do projeto Akka. Nesse arquivo existe uma seção específica para as configurações correspondentes aos atores remotos. Na distribuição padrão, boa parte das propriedades configuráveis de atores remotos são relacionadas ao Netty. Exemplos de tais propriedades são: o algoritmo e o nível de compressão, o tamanho da janela da mensagem e o tempo limite de espera por conexão 
no cliente. Contudo, existem algumas propriedades que são mais gerais, como a habilitação ou não da autenticação via cookies pré-definidos, o valor do cookie de segurança e ainda a classe que implementa a camada de suporte para atores remotos. A Listagem 3.11 mostra a seção referente às configurações do módulo de atores remotos.

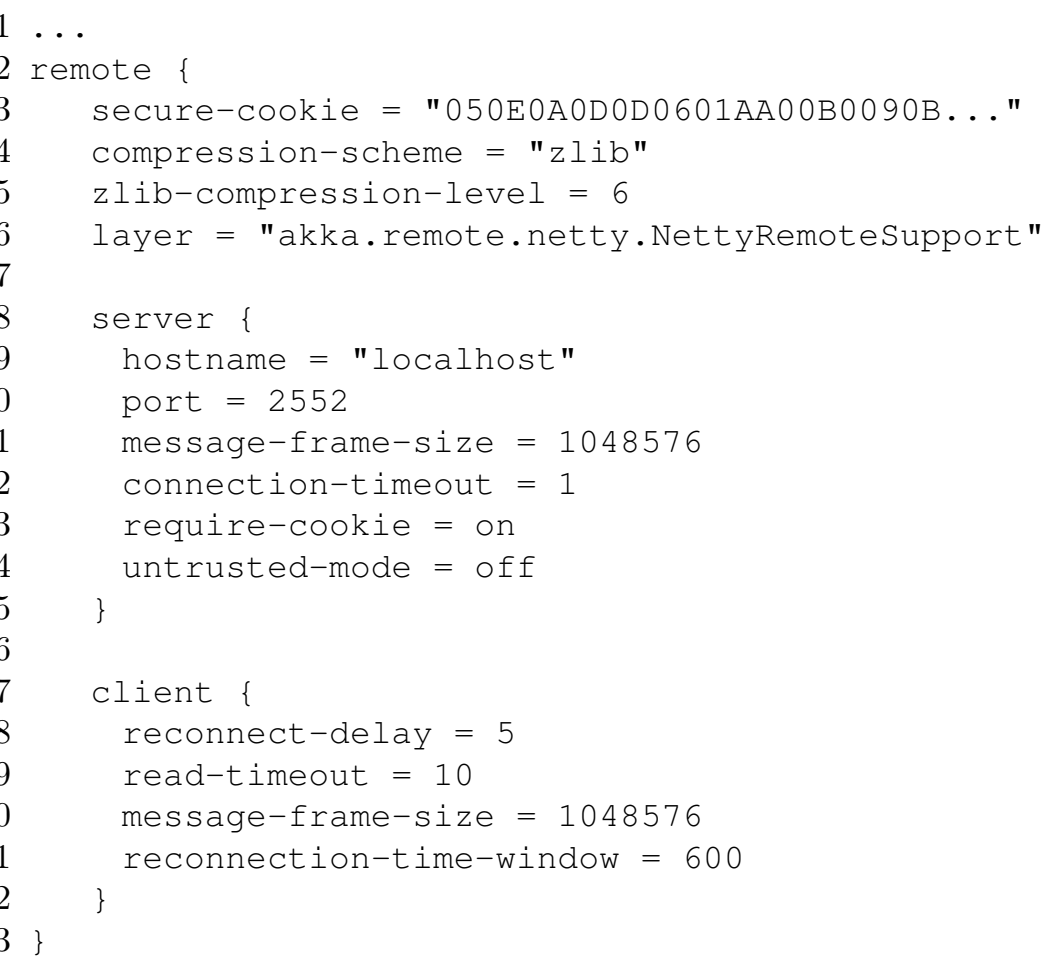

Listagem 3.11: Seção remote do arquivo akka.conf.

\subsubsection{Formato das mensagens trocadas entre atores remotos}

O formato das mensagens utilizado para envios de mensagens entre atores remotos é definido no Akka com o uso do Protobuf [Goo], uma caixa de ferramentas que permite que dados estruturados sejam representados em um formato eficiente e extensível. Essa caixa de ferramentas possui um compilador que aceita definições de formatos de mensagens numa linguagem declarativa específica do Protobuf e que converte tais definições em classes Java, Python e $\mathrm{C}++$.

A linguagem declarativa utiliza a palavra-chave message para definir o formato de uma mensagem. No contexto do Protobuf, o termo "mensagem" significa "tipo de dados estruturado". Mensagens podem conter tipos primitivos de dados como números, cadeias de caracteres e valores booleanos, podem conter outras mensagens, e podem conter vetores de tipos primitivos ou de outras mensagens. Ademais, a linguagem permite que se defina a obrigatoriedade ou não de valores para os atributos, com as palavras-chaves required e optional.

O formato de uma mensagem é mostrado na Listagem 3.12. A mensagem é definida pelo tipo de seriação (linha 2) utilizado para transformar o conteúdo da mensagem numa sequência de bytes (Listagem 3.13), pelos bytes com o conteúdo da mensagem seriado (linha 3) e por um atributo de manifesto, que é utilizado para informar o nome da classe da mensagem. Em toda mensagem enviada a um ator remoto, o tipo de seriação é o especificado na JVM que enviou a mensagem. Para que a JVM destinatária possa fazer o processamento correto, a informação do tipo de seriação deve estar presente na mensagem. O atributo de manifesto da mensagem (linha 4) é opcional, porém é utilizado para forçar o carregamento da classe por um class loader da JVM destinatária. 


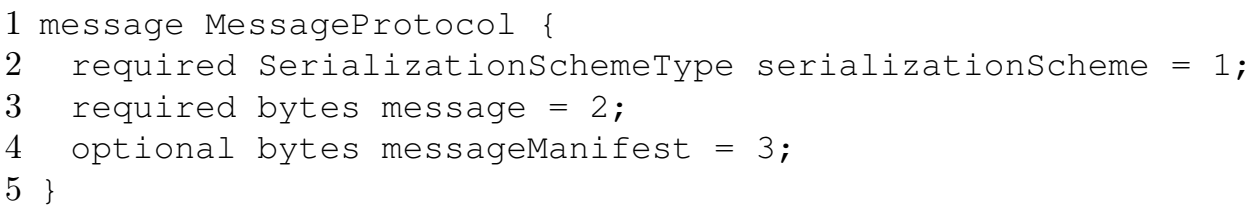

Listagem 3.12: Formato de uma mensagem.

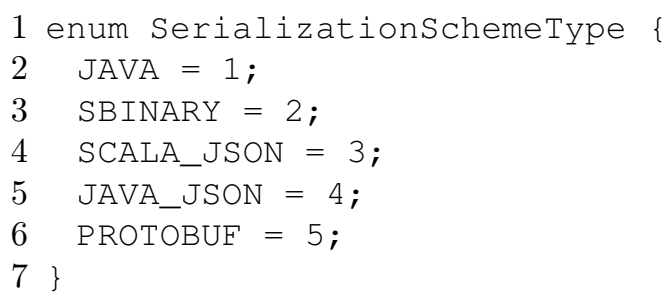

Listagem 3.13: Enumeração com os tipos de seriação suportados.

Pelo fato da referência remota de um ator que faz um envio de mensagem ser enviada junto à mensagem, foi definido um formato para as RemoteActorRefs. Esse formato, mostrado na Listagem 3.14, contém um nome único utilizado para identificar o ator (linha 2), a classe que foi utilizada para a criação do ator (linha 3), o endereço do nó onde o ator remoto foi criado (linha 4) e, por fim, um valor opcional que indica o valor padrão do tempo máximo de bloqueio de um cliente durante um envio síncrono ao ator (linha 5). O formato de mensagem AddressProtocol utilizado na linha 3 , consiste em um par de atributos com o endereço do hospedeiro e a porta.

1 message RemoteActorRefProtocol \{

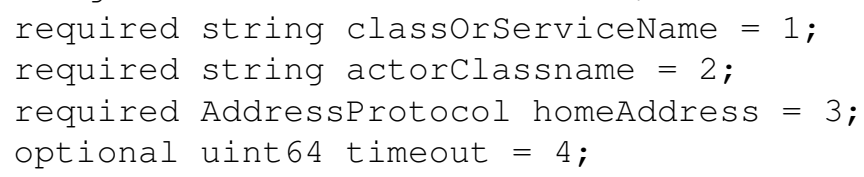

Listagem 3.14: Formato para referências de atores remotos.

Por fim, é apresentado na Listagem 3.15, o formato de mensagem utilizado como envelope para as mensagens remotas. Esse formato contém a mensagem envelopada (linha 5) e uma referências remota para o remetente (linha 8), além de outros atributos. Na linha 2, o atributo uuid é um identificador único da mensagem. O formato UuidProtocol utiliza a biblioteca UUID [Bur], que é uma implementação de identificadores globais únicos.

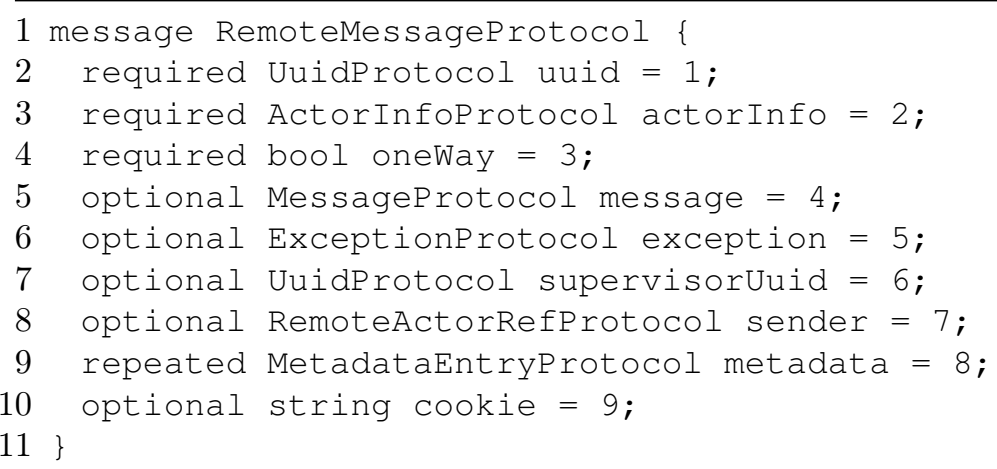

Listagem 3.15: Formato do envelope para envio de mensagem remota. 
Podemos notar na linha 5 um atributo booleano que indica se é esperada uma mensagem de resposta. As mensagens enviadas via método ! possuem valor oneWay = true, enquanto que as enviadas via métodos ! ! e !! ! possuem valor oneWay = false.

Optamos por não detalhar os demais formatos utilizados que estão presentes no envelope de uma mensagem remota. Apesar de serem importantes para o suporte a atores remotos, esses formatos não possuem grande relevância para o desenvolvimento deste trabalho.

\subsubsection{Seriação de mensagens}

A transformação do conteúdo de uma mensagem em uma sequência de bytes (linha 3 da Listagem 3.12) é efetuada por meio de um dos tipos de seriação suportados pelo Akka. As seguintes opções estão disponíveis: seriação Java, SBinary, JSON e Protobuf. Essas opções correspondem aos itens da enumeração na Listagem 3.13. Por padrão, o Akka utiliza seriação Java para seriar o conteúdo das mensagens e as mesmas regras para seriação de objetos Java se aplicam aos objetos enviados como mensagens remotas.

O módulo Serializable define um conjunto de feições que podem ser utilizadas para trocar a seriação Java por algum dos outros formatos. O módulo Serializer define um objeto chamado de MessageSerializer que é o responsável pela seriação e desseriação das mensagens. A seleção do tipo de seriação empregado para uma dada mensagem, é feita com base no tipo da mensagem. Caso a mensagem seja combinada com uma das feições do módulo serializable mencionadas acima, será usado o tipo de seriação correspondente à essa feição. Por exemplo, se a instância utilizada como argumento para um envio de mensagem for combinada com a feição Scala JSON, o conteúdo binário da mensagem estará no formato JSON. Caso a mensagem não seja combinada com nenhuma daquelas feições, será usada seriação Java. 


\section{Capítulo 4}

\section{O Padrão AMQP}

AMQP [Gro] (Advanced Message Queuing Protocol) é um protocolo aberto para sistemas corporativos de troca de mensagens. Especificado pelo AMQP Working Group, o protocolo permite completa interoperabilidade para middleware orientado a mensagens. A especificação [AMQ08] define não somente o protocolo de rede, mas também a semântica dos serviços da aplicação servidora. Também é parte do foco que capacidades providas por sistemas de middleware orientados a mensagem possam estar disponíveis nas redes das empresas, incentivando o desenvolvimento de aplicações interoperáveis baseadas em troca de mensagens.

AMQP é um protocolo binário e assíncrono, com suporte a múltiplos canais. A especificação apresenta o protocolo dividido em três camadas, como mostrado na Figura 4.1.

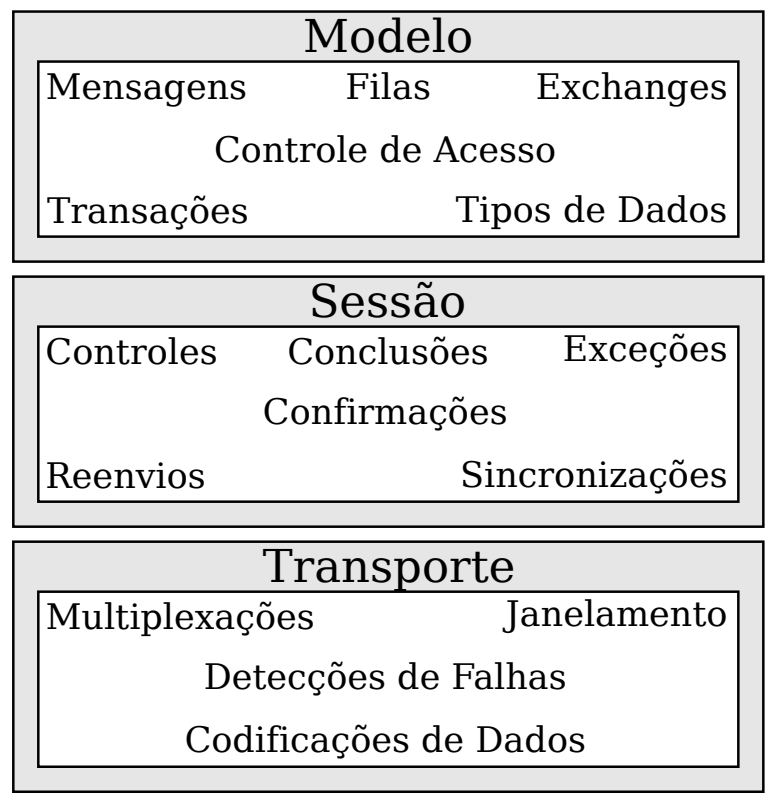

Figura 4.1: Camadas do padrão $A M Q P$.

Na Seção 4.1 descrevemos a camada de modelo, que é a camada em que é definido o conjunto de objetos que utilizamos em nosso trabalho. Na Seção 4.2 descrevemos camada de sessão que age como intermediária entre as camadas de modelo e transporte. Comentamos brevemente na Seção 4.3 sobre a camada de transporte, já que os detalhes dessa camada não se enquadram no escopo deste trabalho. Por fim, apresentamos na Seção 4.4 algumas das implementações disponíveis do padrão e a implementação que escolhemos para o desenvolvimento deste trabalho.

\subsection{A camada de modelo}

A camada de modelo é a camada em que está definido o conjunto de comandos e dos objetos que as aplicações podem utilizar. A especificação dos requisitos dessa camada inclui, entre outros 
itens: garantir a interoperabilidade das implementações, prover controle explícito sobre a qualidade do serviço, oferecer um mapeamento natural entre os comandos do protocolo e as bibliotecas do nível de aplicação e proporcionar clareza em tal mapeamento, de modo que cada comando seja responsável por uma única ação. Os componentes desta camada são:

- Servidor: É o processo, conhecido também como broker, que aceita conexões de clientes e implementa as funções de filas de mensagens e roteamento.

- Filas: São entidades internas do servidor que armazenam as mensagens, tanto em memória quanto em disco, até que elas sejam enviadas em sequência para as aplicações consumidoras. As filas são totalmente independentes umas das outras. Na criação de uma fila, várias propriedades podem ser especificadas: a fila pode ser pública ou privada, armazenar mensagens de modo durável ou transiente, e ter existência permanente ou temporária (e.g.: a existência da fila é vinculada ao ciclo de vida de uma aplicação consumidora). A combinação de propriedades como essas viabiliza a criação de diversos tipos de fila, como por exemplo: fila armazena-e-encaminha (store-and-forward), que armazena as mensagens e as distribui para vários consumidores na forma round-robin, fila temporária para resposta, que armazena as mensagens e as encaminha para um único consumidor; e fila pub-sub, que armazena mensagens provenientes de vários produtores e as envia para um único consumidor.

- Exchanges: São entidades internas do servidor que recebem e roteiam as mensagens das aplicações produtoras para as filas, levando em conta critérios pré-definidos. Essas entidades inspecionam as mensagens, verificando, na maioria dos casos, a chave de roteamento presente no cabeçalho de cada mensagem. Com o auxílio da tabela de bindings, uma exchange decide como encaminhar as mensagens às respectivas filas, jamais armazenando mensagens. Há vários tipos de exchanges, porém neste trabalho utilizamos apenas exchanges diretas (direct). Em tais exchanges, o valor da chave de roteamento, que é parte do cabeçalho da mensagem, deve ser exatamente igual a uma entrada da tabela de bindings para que a mensagem seja roteada para a fila.

- Bindings: São relacionamentos entre exchanges e filas. Esses relacionamentos definem como deverá ser feito o roteamento das mensagens.

- Virtual hosts: São coleções de exchanges, filas e objetos associados. Virtual hosts são domínios independentes no servidor e compartilham um ambiente comum para autenticação e segurança. As aplicações clientes escolhem um virtual host após se autenticarem no servidor.

A Figura 4.2 mostra os componentes acima descritos e como eles se relacionam.

Em modelos pré-AMQP, as tarefas das exchanges e das filas eram feitas por blocos monolíticos que implementavam tipos específicos de roteamento e armazenamento. O padrão AMQP separa essas tarefas e as atribui a entidades distintas (exchanges e filas), que têm os seguintes papéis: (i) receber as mensagens e fazer o roteamento para as filas; (ii) armazenar as mensagens e fazer o encaminhamento para as aplicações consumidoras. Vale frisar que filas, exchanges e bindings podem ser criados tanto de modo programático como por meio de ferramentas administrativas.

Há uma analogia entre o modelo AMQP e sistemas de email:

1. Uma mensagem AMQP é análoga a uma mensagem de email.

2. Uma fila é análoga a uma caixa de mensagens.

3. Um consumidor corresponde a um cliente de email que carrega e apaga as mensagens. 


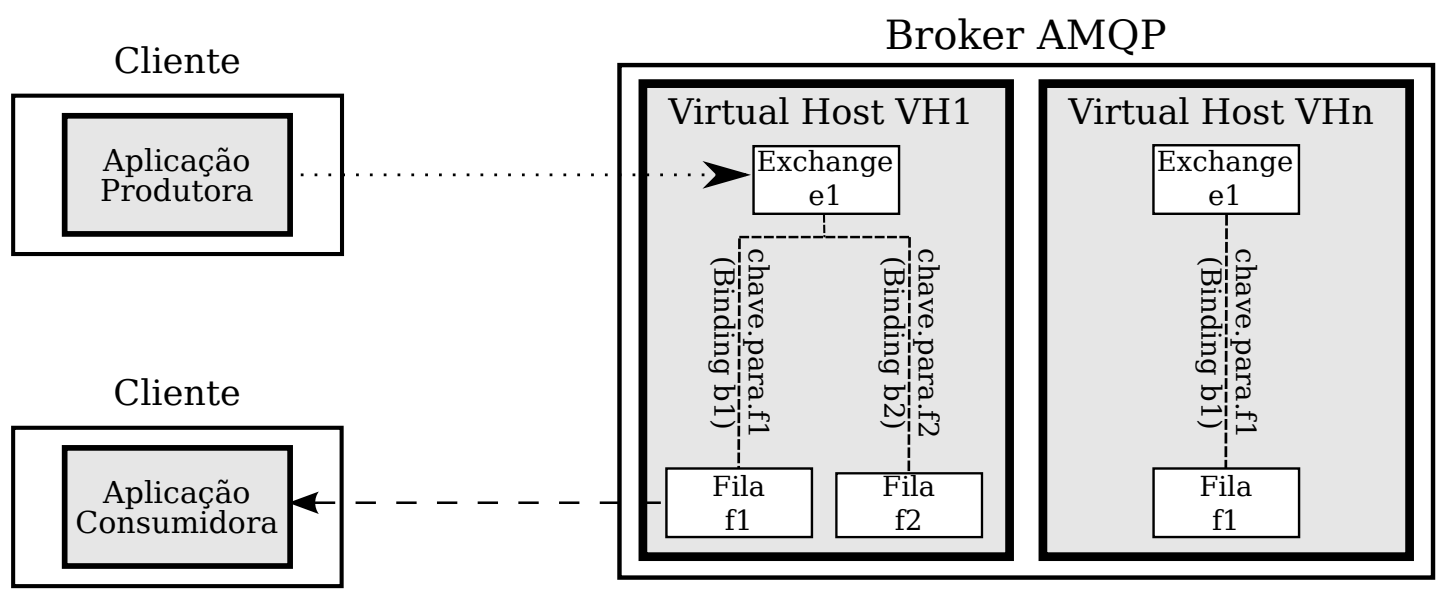

Figura 4.2: Componentes da camada de modelo do padrão AMQP.

4. Uma exchange corresponde a um mail transfer agent (MTA) que inspeciona as mensagens e, com base nas chaves de roteamento, verifica as tabelas de registro e decide como enviar as mensagens para uma ou mais caixas de mensagens. No caso do correio eletrônico as chaves de roteamento são os campos de destinatário e cópias (To, Cc e Bcc).

5. Um binding corresponde a uma entrada nas tabelas de roteamento do MTA.

\subsubsection{Envios de mensagens}

Para enviar uma mensagem, uma aplicação produtora deve especificar a exchange de um determinado virtual host, uma rotulação com informação de roteamento e, eventualmente, algumas propriedades adicionais, bem como os dados do corpo da mensagem. Uma vez que a mensagem tenha sido recebida no servidor AMQP, ocorre o roteamento para uma ou mais filas do conjunto de filas do virtual host especificado. No caso de não ser possível rotear a mensagem, seja qual for o motivo, as opções são: rejeitar a mensagem, descartá-la silenciosamente, ou ainda fazer o roteamento para uma exchange alternativa. A escolha depende do comportamento definido pelo produtor. Quando a mensagem é depositada em alguma fila (ou possivelmente em algumas filas), a fila tenta repassá-la imediatamente para a aplicação consumidora. Caso isso não seja possível, a fila mantém a mensagem armazenada para uma futura tentativa de entrega. Uma vez que a mensagem foi entregue com sucesso a um consumidor, ela é removida da fila. A Figura 4.3 mostra os passos do envio e recebimento de uma mensagem.

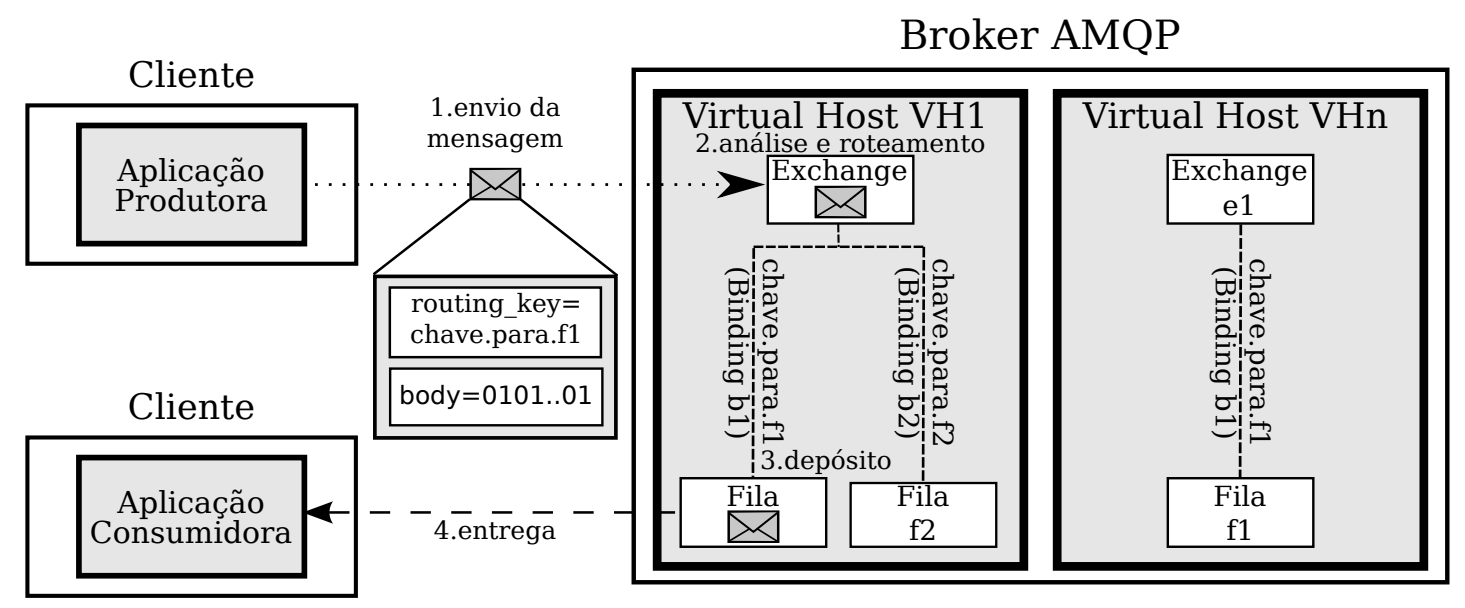

Figura 4.3: Fluxo de uma mensagem no padrão $A M Q P$. 
A aceitação ou confirmação de recebimento de uma mensagem fica a critério da aplicação consumidora, podendo acontecer imediatamente depois da retirada da mensagem da fila ou após a aplicação consumidora ter processado a mensagem.

\subsection{A camada de sessão}

A camada de sessão age como uma intermediária entre as camadas de modelo e transporte, proporcionando confiabilidade para a transmissão de comandos ao broker. É parte das suas responsabilidades dar confiabilidade às interações entre as aplicações cliente e o broker.

Sessões são interações nomeadas entre um cliente e um servidor AMQP, também chamados de pares (peers). Todos os comandos, como envios de mensagens e criações de filas ou exchanges, devem acontecer no contexto de uma sessão. O ciclo de vida de alguns dos objetos da camada de modelo como filas, exchanges e bindings podem ser limitados ao escopo de uma sessão.

Os principais serviços providos pela camada de sessão para a camada de modelo são:

- Identificação sequencial dos comandos: Cada comando emitido pelos pares é identificado, única e individualmente dentro da sessão, para que o sistema seja capaz de garantir a execução do comando exatamente uma vez. Utiliza-se um esquema de numeração sequencial. A noção de identificação permite a correlação de comandos e a devolução de resultados assíncronos. O identificador do comando é disponibilizado para a camada de modelo e, quando um resultado de um comando é devolvido, o identificador desse comando é utilizado para estabelecer a correlação entre o comando e o resultado.

- Confirmação que comandos serão executados: É utilizado para que o par solicitante possa descartar, seguramente, o estado associado a um comando, com a certeza de que ele será executado. A camada de sessão controla o envio e recebimento das confirmações permitindo que o gerenciamento do estado seja mantido na sessão corrente. O estado da sessão é importante para que o sistema possa se recuperar no caso de falhas temporárias em um dos pares. As confirmações podem ser entregues em lotes ou mesmo serem deferidas indefinidamente, no caso do par solicitante não requerer a confirmação de que o comando será executado.

- Notificação de comandos completados: Diferentemente do conceito de confirmação, este serviço notifica o par que solicitou a execução de um comando que o comando foi executado por completo. As notificações de comandos completados tem como motivação a sincronização e a garantia da ordem de execução entre diferentes sessões. Quando o par que solicitou a execução do comando não exige confirmação imediata, as confirmações podem ser acumuladas e enviadas em lotes, reduzindo o tráfego de rede.

- Reenvio e recuperação no caso de falhas na rede: Para que o sistema possa se recuperar no caso de falhas na rede, a sessão deve ser capaz de reenviar um comando cujo recebimento pelo outro par é duvidoso. A camada de sessão provê as ferramentas necessárias para identificar o conjunto com os comandos rotulados como duvidosos e reenviá-los, sem o risco de causar duplicidade.

\subsection{A camada de transporte}

A camada de transporte é responsável por tarefas como multiplexação de canais, detecção de falhas, representação de dados e janelamento (framing). A lista dos requisitos dessa camada inclui, entre outros itens, possuir uma representação de dados binária e compacta que seja rápida de se embrulhar e desembrulhar, trabalhar com mensagens sem um limite significante de tamanho, permitir que sessões não sejam perdidas no caso de falhas de rede ou de aplicação, possuir assincronia e neutralidade em relação à linguagens de programação. 


\subsection{Implementações}

Dentre as implementações de message brokers baseados no padrão AMQP disponíveis, destacamos Apache Qpid [Qpi], ZeroMQ [ZMQ] e RabbitMQ [RMQ].

O projeto Apache Qpid é uma implementação de código aberto com uma distribuição escrita em Java e uma outra escrita em $\mathrm{C}++$. A implementação está disponível sob a licença Apache 2.0 [APL04] e possui bibliotecas para aplicações clientes em diversas linguagens, como Java, $\mathrm{C}++$, Ruby, Python e C\#. A implementação da biblioteca cliente para Java é compatível com a versão 1.1 do padrão Java Message Service [Pro03].

O projeto ZeroMQ é uma implementação de código aberto feita em $\mathrm{C}++$, com bibliotecas disponibilizadas para aplicações clientes em mais de vinte linguagens, incluindo Java, Python, $\mathrm{C}++$ e C. A implementação está disponível sob a licença LGPL [LGP07]. A biblioteca para clientes Java depende de outras bibliotecas nativas específicas para cada sistema operacional.

Assim como os outros dois projetos, o projeto RabbitMQ também é um projeto de código aberto, implementado na linguagem Erlang e disponível sob a licença MPL [MPL]. Ele possui bibliotecas para aplicações clientes em diversas linguagens como Java, Erlang e Python. A implementação da biblioteca para clientes Java é totalmente feita em Java e não possui dependências de código nativo, sendo totalmente independente de plataforma.

Como a especificação do padrão AMQP não define uma API padrão para as aplicações clientes, tivemos de optar por uma implementação para o desenvolvimento deste trabalho. Optamos por utilizar o RabbitMQ. Tomamos como base para nossa decisão os seguintes fatores:

- Grande quantidade de atividade na comunidade de usuários e desenvolvedores.

- Facilidade para se obter informações, seja via tutoriais ou em listas de discussões.

- Possuir código aberto e sua biblioteca para clientes Java ser independente de plataforma.

- Se tratar não só de um projeto, mas sim de um produto ${ }^{1}$.

- Ter sido escrito em Erlang, uma linguagem desenvolvida para o desenvolvimento de sistemas distribuídos e concorrentes [Arm97].

- Possuir ferramentas para administração e monitoramento.

Apresentamos a seguir uma visão geral de alguns dos principais componentes da biblioteca para clientes Java do projeto RabbitMQ e como eles estão relacionados.

\subsubsection{RabbitMQ - Biblioteca para clientes Java}

A biblioteca para clientes Java disponibilizada pelo projeto RabbitMQ [API] define diversas classes para que seja possível a interação com o broker. A conexão acontece com uma instância de com.rabbitmq.client. Connection, que pode ser obtida pela classe com.rabbitmq.client . Connectionfactory, via método newConnection. É na classe Connectionfactory que informamos os valores dos parâmetros necessários para conexão com o broker (Listagem 4.1).

As conexões têm como papel principal estabelecer a comunicação da aplicação cliente com o broker. Conexões podem ser vistas como sendo a implementação de uma parte considerável da camada de transporte do padrão AMQP. Como descrito na Seção 4.3, a camada de transporte deve ser capaz de prover a multiplexação de canais. A classe connection provê, dentre outros métodos, o método createchannel. A invocação desse método resulta em uma instância de com. rabbitmq.client. Channel, na qual podemos executar os comandos definidos na camada de sessão

\footnotetext{
${ }^{1}$ A empresa responsável pelo suporte é a Spring Source, uma divisão da VMware
} 
(Listagem 4.2). Tais comandos incluem os comandos para criação de exchanges (exchangeDeclare), de filas (queueDeclare), de bindings (queueBind) e os comandos para envio (basicPublish) e recebimento de mensagens (basicconsume).

1 val factory = new Connectionfactory()

2 factory.setHost (...)

3 factory.setport (...)

4 factory.setUsername (...)

5 factory.setpassword (...)

6 factory.setVirtualHost (...)

7 val connection = factory $\cdot$ newConnection

Listagem 4.1: Configuração e uso de uma ConnectionFactory.

1 val channel = connection.createchannel

2 channel.exchangeDeclare (...)

3 channel.queueDeclare (...)

4 channel.queueBind (...)

5 channel.basicPublish (...)

Listagem 4.2: Criação e uso de canais.

O recebimento das mensagens é feito com o uso de consumidores que são instâncias de com .rabbitmq.client.Consumer. Os consumidores são registrados nos canais e podem receber as mensagens assincronamente através do método handleDelivery (Listagem 4.3). A Figura 4.4 mostra como uma fábrica de conexões, uma conexão, um canal e um consumidor estão relacionados.

Um detalhe sobre a biblioteca para clientes Java do RabbitMQ é a verificação da existência de um objeto antes da criação efetiva do objeto. Por exemplo, se tivéssemos criado uma fila durável $F_{1}$ e tentássemos criar uma nova fila durável $F_{1}$, a fila não seria recriada e a execução seguiria normalmente. Eventuais mensagens em $F_{1}$ não sofreriam alterações. Contudo, caso estivéssemos tentando recriar $F_{1}$ como não durável, uma exceção seria lançada e o canal utilizado para executar o comando de criação seria fechado. Nesse caso, o procedimento correto é remover $F_{1}$, seja via código ou via alguma aplicação administrativa do RabbitMQ, para depois fazer a criação.

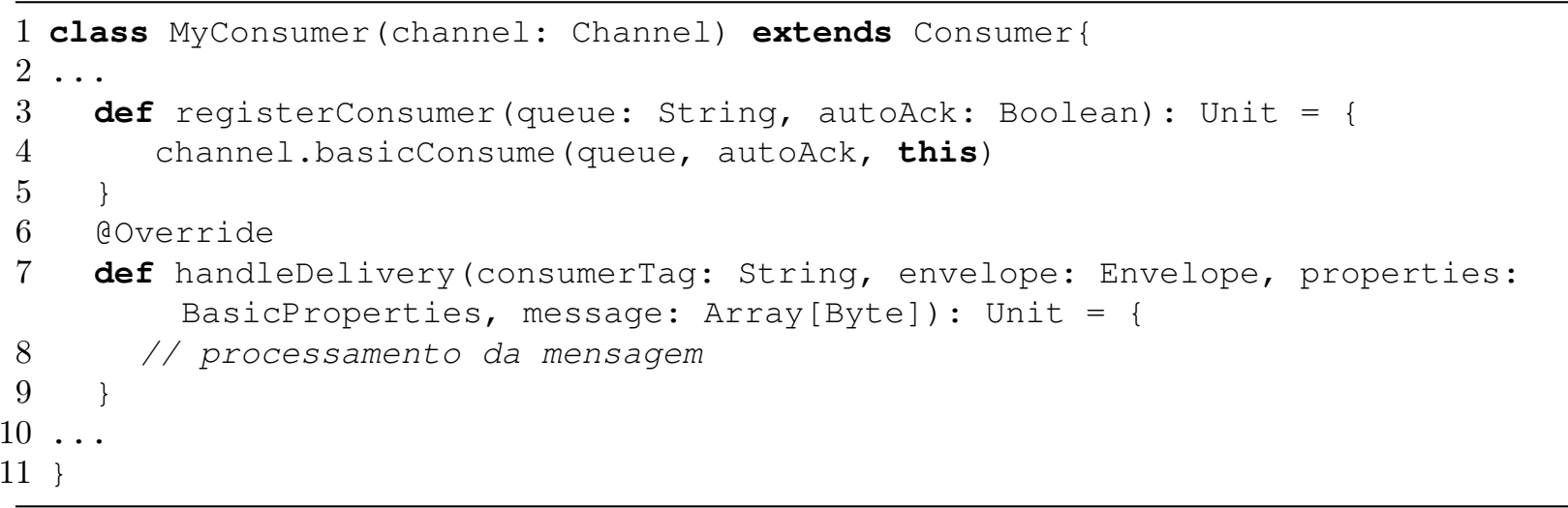

Listagem 4.3: Registro de um consumidor.

Canais permitem ainda que sejam registrados tratadores de erros (setReturnListener), para lidar com casos como o de uma mensagem que não possa ser enviada ou entregue ao seu destinatário. Em situações como essa, o corpo da mensagem e algumas informações do envio, como o nome da exchange, a chave de roteamento e o código de rejeição, são repassados para o tratador de erros que foi registrado no canal. A aplicação produtora passa a ter autonomia para fazer o tratamento apropriado. 


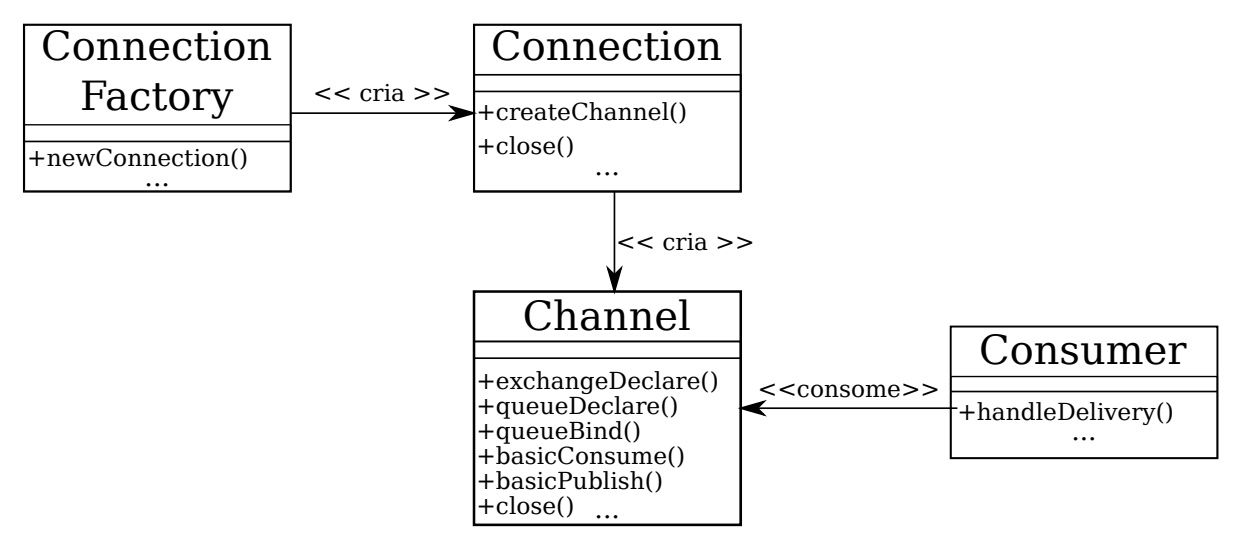

Figura 4.4: RabbitMQ Java API-Relação entre classes de transporte e sessão.

Para finalizar este capítulo, é importante destacar que a implementação de canais [RAG] não é segura para acesso concorrente (thread safe). Assim sendo, a aplicação tem a responsabilidade de evitar que diferentes threads façam uso concorrente de um canal. 


\section{Capítulo 5}

\section{Troca de mensagens via pontes AMQP}

Apresentamos nesse capítulo a estrutura que definimos para a troca de mensagens entre entidades remotas via message broker AMQP. A estrutura apresentada neste capítulo foi utilizada como suporte para o desenvolvimento dos novos componentes da camada de implementação para transporte de mensagens entre atores remotos do projeto Akka (Figura 3.3). Entretanto, antes de apresentar a estrutura que definimos, comentamos brevemente algumas características de entidades conectadas ponto-a-ponto via sockets que são afetadas ou deixam de fazer sentido com a nova abordagem.

\subsection{Entidades conectadas ponto-a-ponto via sockets}

Em uma transferência de mensagens entre duas entidades conectadas ponto-a-ponto por sockets TCP ou UDP, ambas as entidades devem conhecer detalhes sobre a conexão e sobre o formato das mensagens que são enviadas. $\mathrm{O}$ fato de não haver uma entidade intermediando a troca de mensagens permite que uma das entidades identifique uma eventual desconexão da outra, ou ainda que uma entidade conheça o endereço do nó hospedeiro onde está a outra entidade. Nos casos em que as entidades estão em nós que não fazem parte de uma rede interna, a informação de localidade pode não indicar exatamente o nó real da entidade, mas o endereço de alguma porta de ligação (gateway).

A comunicação entre entidades conectadas ponto-a-ponto via sockets tem a seguinte característica: cada socket utiliza exclusivamente uma porta para aceitar as conexões remotas, criando uma relação um para um entre portas e entidades. Para a numeração de portas, os protocolos TCP e UDP utilizam inteiros de 16 bits sem sinal, limitando o número de portas a 65536 (0 - 65535)[Ins81]. Ademais, algumas portas que são utilizadas para serviços comuns, como por exemplo servidores de correio eletrônico, possuem numeração fixa definida pela IANA [IAN] (Internet Assigned Numbers Authority) e não podem ser empregadas por outros serviços.

\subsubsection{Atores remotos conectados ponto-a-ponto}

É indesejável que o número de portas disponíveis em um nó limite a quantidade de atores remotos que podem ser criados no nó. Assim, uma implementação de atores remotos deve, de alguma maneira, permitir que múltiplos atores sejam associados a uma porta.

Na implementação de atores remotos do Akka apresentada na Seção 3.3, vimos que os atores são agrupados por endereço do nó hospedeiro e da porta e ficam registrados no RemoteserverModule. Vimos também, na Seção 3.1, que atores são identificáveis, o que permite que eles sejam localizados no RemoteServerModule para que possam receber as mensagens. Ainda que a implementação de atores remotos do Akka agrupe os atores, evitando que o número de atores fique limitado pelo número de portas disponíveis, um RemoteclientModule possui conhecimento do hospedeiro e da porta ao qual está conectado. Além disso, o RemoteserverModule que recebe uma mensagem pode obter o hospedeiro e a porta do RemoteclientModule remetente.

A implementação de atores remotos de Erlang não usa portas explicitamente. Cada máquina virtual Erlang possui um nome associado. O nome de uma máquina virtual é definido durante a 
ativação da máquina virtual, por meio de um parâmetro na linha de comando. Diversas máquinas virtuais podem estar em execução em um determinado hospedeiro e são unicamente identificadas por name@host. O nome de uma máquina virtual é utilizado, juntamente com a informação do hospedeiro, para especificar onde um ator remoto deve ser criado. Em outras palavras, pode-se criar um ator remoto numa máquina virtual especificada por name@host.

\subsection{Entidades conectadas via message broker AMQP}

A substituição de um mecanismo ponto-a-ponto por um mecanismo baseado em AMQP naturalmente introduz novas características à interação entre as entidades. Elas deixam de estar conectadas diretamente, já que o message broker passa a ser o componente central de conexão entre todas as entidades. Funcionalidades baseadas na comunicação ponto-a-ponto, como por exemplo a deteç̧ão de desconexão, ainda que possíveis, não são triviais. O message broker passa a ser o responsável por abrir uma porta para que as demais entidades possam se conectar e é responsável por fazer o gerenciamento de múltiplas conexões nesta porta.

Rotulações de entidades por hospedeiro e porta ou por nome e hospedeiro deixam de fazer sentido. Tais rotulações tornam-se redundantes, pois as entidades passam a ser identificadas somente por seus nomes. Para poder receber mensagens, cada nova entidade que entrar no sistema deve criar uma fila no message broker e associá-la a uma exchange. Uma entidade que desempenhe o papel de servidora deve antes criar essa exchange. Por outro lado, uma entidade que desempenhe o papel de cliente faz o binding de sua fila na exchange criada por alguma entidade servidora. Podemos fazer uma analogia da exchange com um server socket.

O suporte ao desenvolvimento dos novos componentes da camada de implementação de transporte remoto do projeto Akka é dado com a ajuda de alguns componentes intermediários. Os componentes ServerAMQPBridge e ClientAMQPBridge formam uma ponte entre a nova camada de transporte remoto e a biblioteca Java do message broker RabbitMQ. A Figura 5.1 mostra como ficaria, sob a perspectiva do message broker, a criação de uma ponte servidora de nome nodel com duas pontes clientes associadas a ela. A exchange e a fila que foram criadas pela ponte servidora estão marcadas em preto. Pela Figura 5.1, podemos notar como a exchange definida pela ponte servidora tem o papel de ponto central para envio de mensagens para todas as filas criadas para a ponte servidora de nome node1. A ponte servidora define a fila de entrada de mensagens. As pontes clientes definem as filas de saída de mensagens. As mensagens roteadas para as filas de saída são as mensagens de resposta vindas da ponte servidora. Devemos observar que a ponte servidora precisa do identificador de uma ponte cliente para poder lhe enviar uma mensagem.

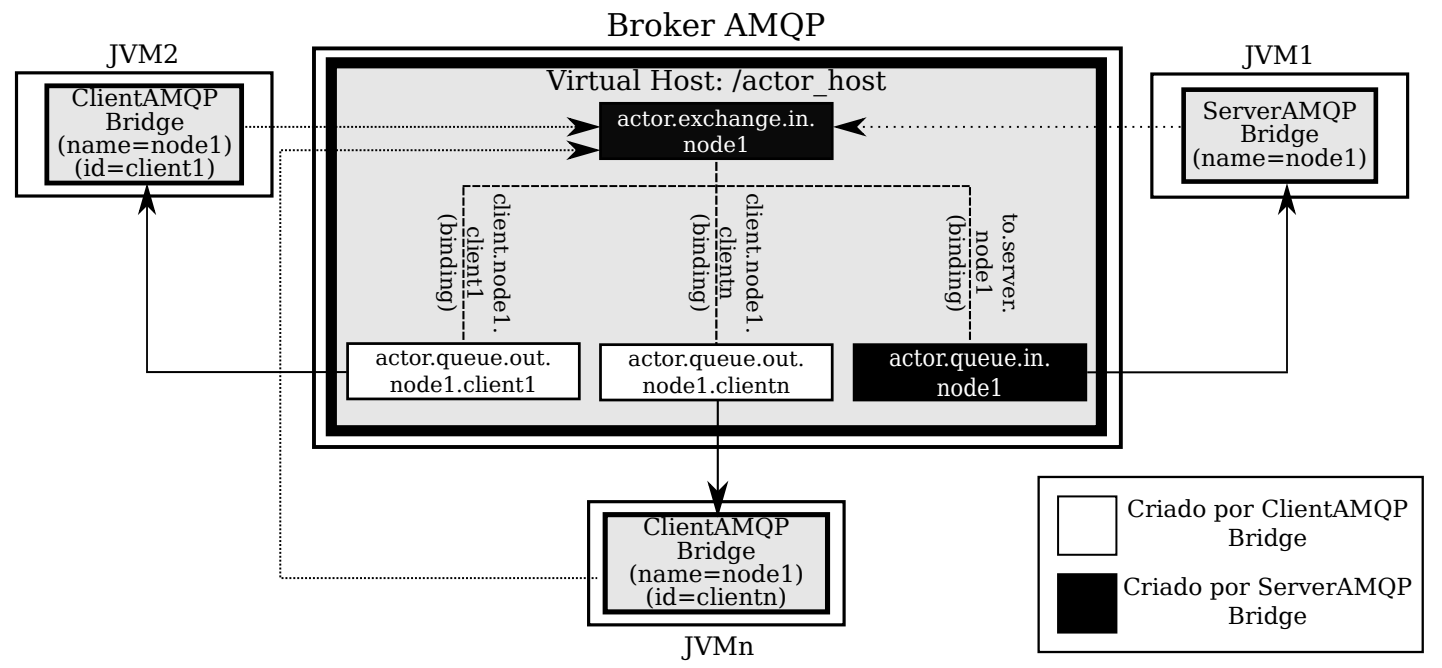

Figura 5.1: Estrutura para troca de mensagens via message broker $A M Q P$. 
Segundo a especificação do padrão AMQP [Gro], as implementações de brokers devem permitir ao menos 256 filas por virtual host. Contudo, a recomendação é que não haja imposição de limites arbitrários, que não sejam motivados por questões de disponibilidade de recursos. A especificação também menciona que o número mínimo de exchanges por virtual host é de 16, e faz a mesma recomendação quanto a não imposição de limites arbitrários. A implementação RabbitMQ utilizada neste trabalho segue essas recomendações.

Cabe ainda ressaltar que tarefas administrativas, como a criação de virtual hosts, a criação de usuários e a definição das permissões dos usuários, não são de responsabilidade das entidades. Essas tarefas devem ter sido executadas previamente.

\subsubsection{Pontes AMQP}

O módulo AMQPBridge é responsável por fornecer as classes que agem como pontes de comunicação para o message broker, bem como classes auxiliares. Juntas, as classes desse módulo definem uma interface com funcionalidades básicas para troca de mensagens, tais como envio de mensagens, recebimento de mensagens e tratamento de mensagens rejeitadas. Além disso, o módulo AMQPBridge provê suporte a conexão de múltiplas entidades clientes a uma mesma entidade servidora. Esse módulo contém as seguintes classes:

- AMQPBridge: É a classe abstrata que define o comportamento básico de uma entidade conectada a um message broker AMQP. O construtor de AMQPBridge recebe como argumentos o nome que identifica a ponte e uma conexão para um message broker AMQP. Essa classe define ainda o padrão de nomeação utilizado na criação dos objetos, como mostra a Listagem 5.1. Note que esse padrão de nomeação é utilizado na Figura 5.1. A classe possui também um objeto acompanhante que define métodos para a criação de instâncias das subclasses de AMQPBridge.

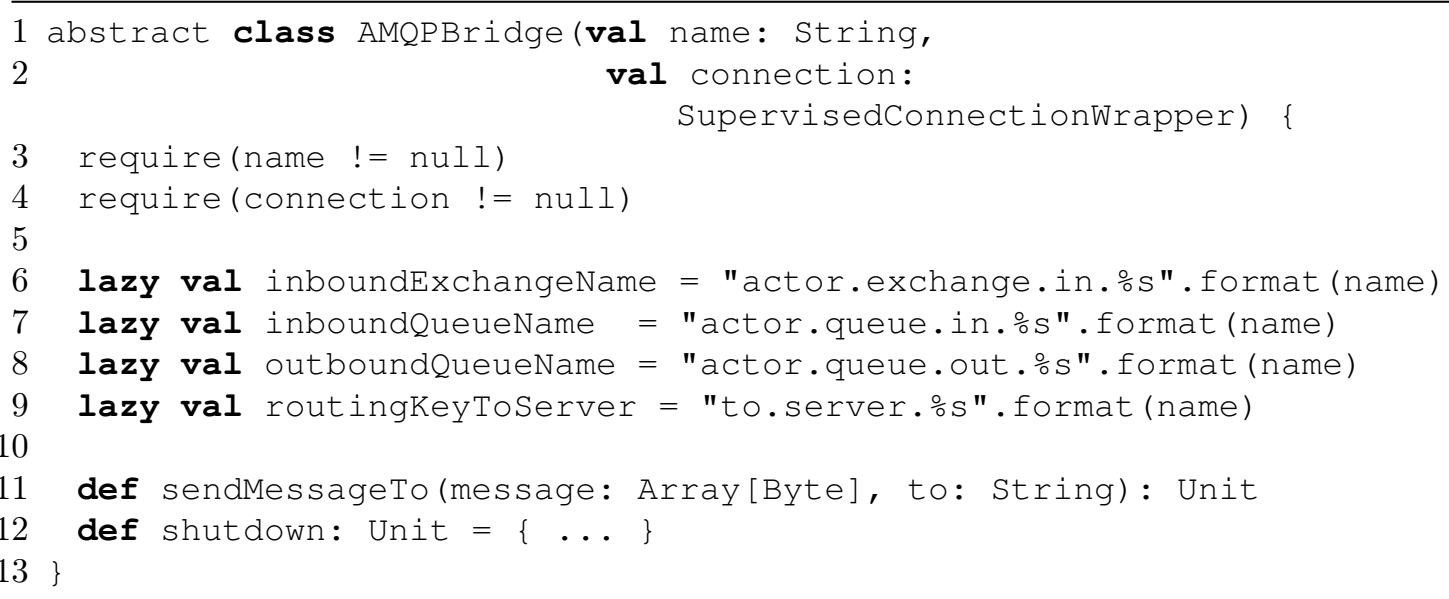

Listagem 5.1: Classe AMQPBridge do módulo AMQPBridge.scala.

- MessageHandler: É a feição que define os métodos a serem invocados quando mensagens forem recebidas ou envios feitos pela entidade forem rejeitados pelo message broker.

- ServerAMQPBridge: É uma das duas subclasses de AMQPBridge e define o comportamento para entidades que atuam como servidoras. Essa classe é mostrada na Listagem 5.2. Além dos métodos herdados, ela ainda define o método setup. Esse método recebe como argumento uma implementação de MessageHandler e os parâmetros com as configurações da fila e da exchange que serão criadas durante a execução do método.

- ClientAMQPBridge: É a outra subclasse de AMQPBridge e define o comportamento para entidades que atuam como clientes. Essa classe é mostrada na Listagem 5.3. Ela tem em seu 
construtor um parâmetro adicional em relação à classe ServerAMQPBridge. O parâmetro id é utilizado para identificar o cliente. Tal identificação é necessária para compor a chave de roteamento que associa a exchange criada pela ponte servidora cujo nome é name à fila de saída de mensagens específica para esta entidade cliente.

1 class ServerAMQPBridge (name: String,

2

3

4

Listagem 5.2: Classe ServerAMQPBridge do módulo AMQPBridge.scala.

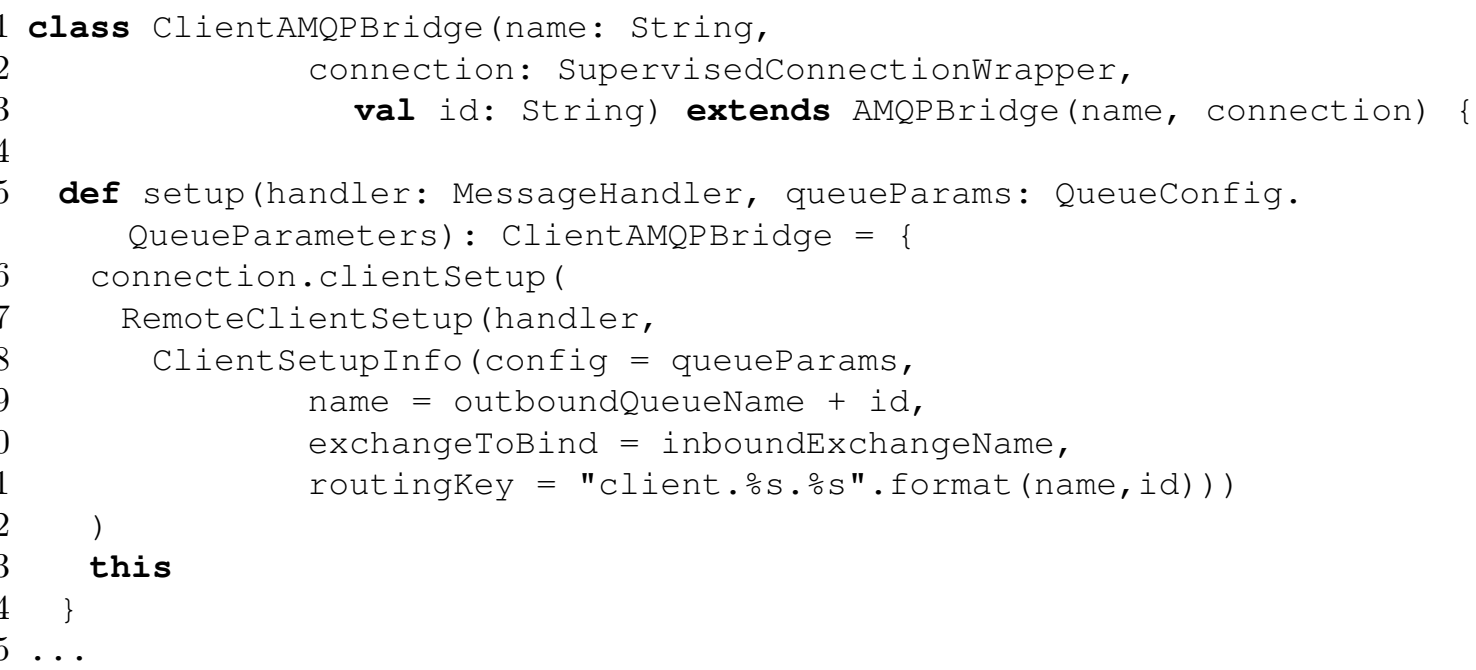

Listagem 5.3: Classe ClientAMQPBridge do módulo AMQPBridge.scala.

Definimos também um módulo auxiliar chamado AMQP. Esse módulo possui algumas classes com configurações pré-definidas para os objetos a serem criados no message broker. A enumeração StorageAndConsumptionPolicy define um conjunto de valores para políticas de armazenamento e de consumo. A enumeração é composta pela combinação das enumerações QueueConfig e ExchangeConfig. Essas duas enumerações definem as configurações específicas e detalhadas para filas e exchanges, respectivamente. A combinação dos seus valores dá semântica às seguintes políticas:

1. DURABLE: Define uma configuração na qual os objetos (filas e exchanges) criados são duráveis, ou seja, continuam a existir caso o message broker seja reiniciado. 
2. TRANSIENT: Define uma configuração na qual os objetos criados são transientes, ou seja, deixam de existir caso o message broker ser reiniciado.

3. EXCLUSIVE_AUTODELETE: Define uma configuração no qual os objetos estão atrelados ao ciclo de vida da aplicação que os criou. Os objetos são removidos pelo message broker quando a conexão em que os objetos foram criados é fechada. Ademais, as filas criadas por essa configuração possuem acesso exclusivo a um único consumidor. O consumidor fica atrelado ao canal em que a criação da fila ocorreu.

\subsubsection{Gerenciamento de conexões e canais}

O módulo ConnectionPoolsupervisor é responsável por encapsular os detalhes da interação com o message broker. Como mostrado na Subseção 4.4.1, o envio de comandos e recebimentos de mensagens com o RabbitMQ acontece por meio de canais que são abertos em uma conexão. Esses canais não oferecem proteção para acesso concorrente, deixando a cargo da aplicação fazer a proteção.

A principal missão desse módulo é prover uma implementação segura para acesso concorrente aos canais e conexões abertos com o RabbitMQ. Além disso, o módulo ainda define uma interface simples e clara para as pontes AMQP, abstraindo toda a responsabilidade em relação à interação com o message broker.

Para que os canais possam ser acessados concorrentemente de modo seguro, optamos por encapsulá-los em atores Akka ${ }^{1}$. A classe SupervisedConnectionWrapper define uma conexão supervisionada, expondo uma interface muito simples com apenas quatro métodos. Os métodos dão suporte a funcionalidades básicas para configuração da conexão (clientSetup e serverSetup), envio de mensagens (publishto) e fechamento da conexão (close), como mostrado na Listagem 5.4. Nessa listagem podemos notar também que o construtor da classe recebe como argumento três atores, sendo o primeiro ator um ator referente a conexão, o segundo um ator referente ao canal utilizado para recebimento de mensagens (canal de leitura), e por último, o ator referente ao canal utilizado para o envio de mensagens (canal de escrita). Esses atores são os responsáveis por executar efetivamente as ações, já que a classe supervisedConnectionWrapper delega aos atores todas as ações via envios síncronos ou assíncronos de mensagens.

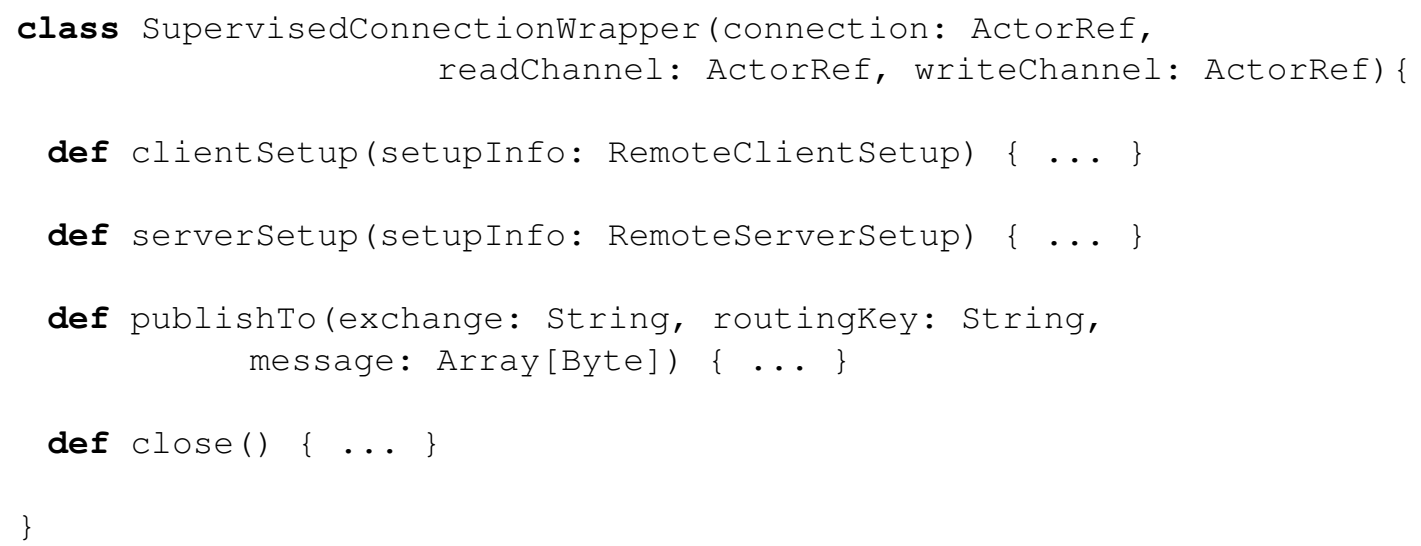

Listagem 5.4: Classe SupervisedConnection Wrapper.

Além da classe SupervisedConnectionWrapper, o módulo ConnectionPoolsupervisor possui outras classes, dentro os quais destacamos as seguintes:

\footnotetext{
${ }^{1} \mathrm{~A}$ ideia de encapsular o acesso aos canais em atores foi inspirada na implementação de um dos módulos adicionais do projeto Akka.
} 
- BridgeConsumer: É uma implementação de um consumidor padrão de mensagens para o RabbitMQ.

- ChannelActor: É a feição que define o comportamento inicial de um ator responsável por um canal genérico.

- ReadChannelActor: É a classe que define o comportamento inicial de um ator responsável por um canal de leitura, utilizado para o recebimento de mensagens.

- WriteChannelActor: É a classe que define o comportamento inicial de um ator responsável por um canal de escrita, utilizado para o envio de mensagens.

- ConnectionActor: É a classe que define o comportamento inicial de um ator responsável pela conexão e abertura de canais com o message broker. Uma outra responsabilidade desse ator é supervisionar os atores que lhe solicitaram a abertura de canais.

- AMQP Supervisor: É a feição que define o comportamento padrão a ser utilizado por um ator que será responsável por supervisionar os atores de conexão. Essa feição define ainda métodos que interagem com a fábrica de conexões do RabbitMQ para a criação de novas conexões.

- AMQPConnectionFactory: É a classe raiz da hierarquia de supervisão. Essa classe herda de AMQPSupervisor e define o despachador para todos os atores que estarão direta ou indiretamente sob supervisão. A classe possui ainda um objeto acompanhante que define métodos para a criação dos atores de canais e conexões.

- ConnectionSharePolicy: É a enumeração que define a política de compartilhamento de uma conexão. A enumeração possui apenas dois valores que indicam se os canais de escrita e de leitura devem ser abertos na mesma conexão, ou se em conexões diferentes. O uso de uma conexão por canal permite que a alta atividade em um canal não impacte o outro.

O módulo possui ainda diversas classes menores (case classes) que são utilizadas para definir as mensagens que cada ator aceita em sua função receive. São exemplos dessas classes as mensagens RemoteServerSetup e ServerSetupInfo utilizadas na Listagem 5.2. Um outro exemplo são as mensagens RemoteClientSetup e ClientSetupInfo utilizadas na Listagem 5.3. A Figura 5.2 mostra como os módulos AMQP, AMQPBrigde e ConnectionPoolsupervisor estão relacionados.

\subsubsection{O processo de criação dos objetos no message broker}

A criação de objetos (filas e exchanges) no message broker é iniciada nas pontes AMQP. O método setup das classes ServerAMQPBridge e ClientAMQPBridge serve como ponto de entrada para a criação e configuração dos objetos. A criação de uma ponte AMQP é feita via métodos definidos no objeto AMQPBridge e depende da criação de uma conexão supervisionada.

A conexão supervisionada é criada pelo objeto AMQP ConnectionFactory. Para que essa conexão seja criada, é necessário que os atores que encapsulam a conexão e os canais também sejam criados. A primeira instância a ser criada é a do ator responsável pela conexão. A criação do ator de conexão é ilustrada na Figura 5.3 e acontece em quatro passos:

1. Uma instância de ConnectionActor é criada e inicializada.

2. O ator é ligado (link) ao ator supervisor ${ }^{2}$.

3. A mensagem Connect é enviada sincronamente para o ator.

\footnotetext{
${ }^{2}$ A classe AMQPConnectionfactory é o ator supervisor de todos os atores de conexão.
} 


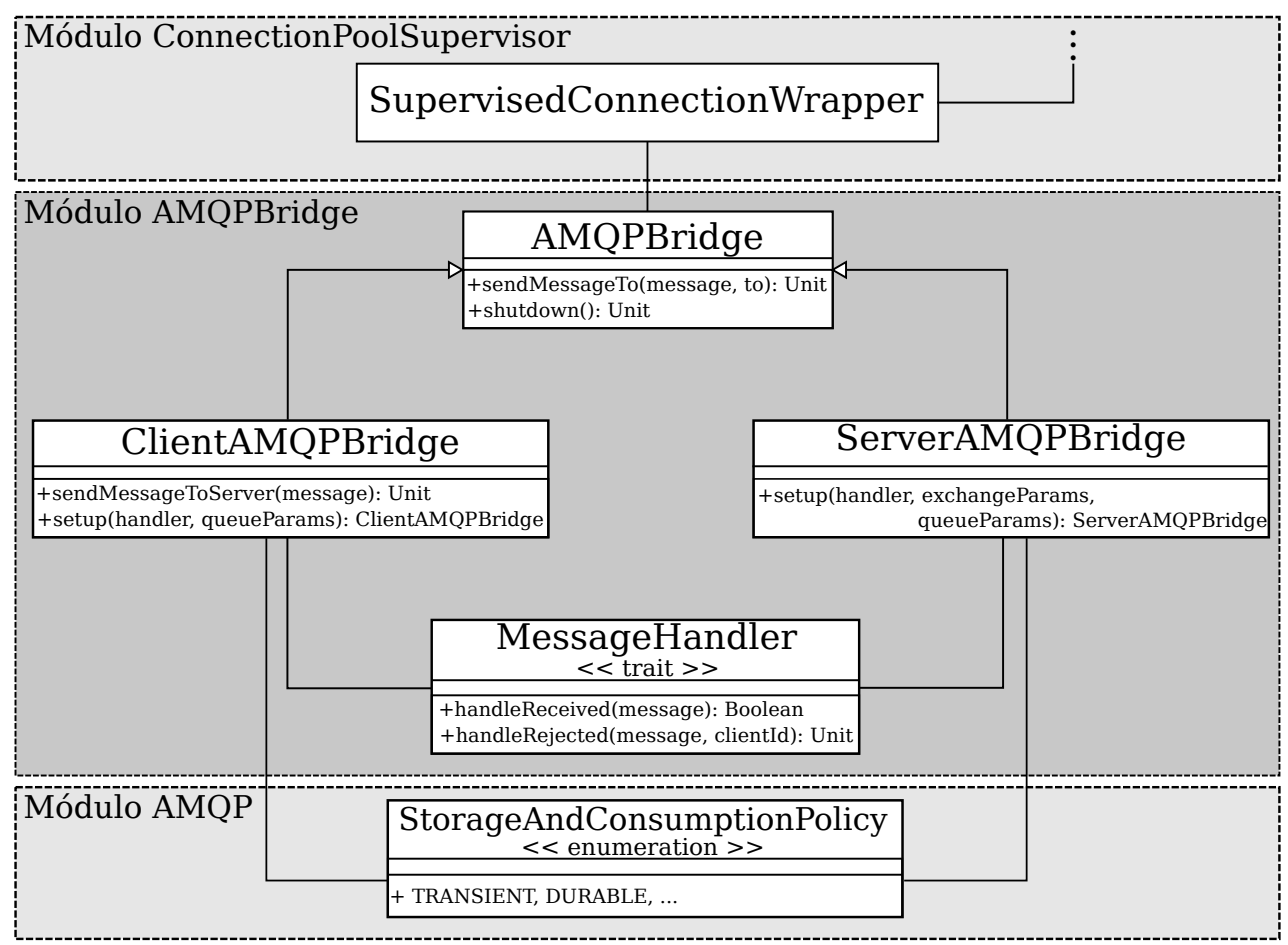

Figura 5.2: Módulos de acesso ao broker $A M Q P$.

4. A mensagem Connect é processada pelo ator. Seu processamento leva à solicitação de uma nova conexão para a fábrica de conexões do RabbitMQ. Dependendo do tipo de política definida para o compartilhamento da conexão entre os canais de leitura e escrita, o passo 4 é executado duas vezes.

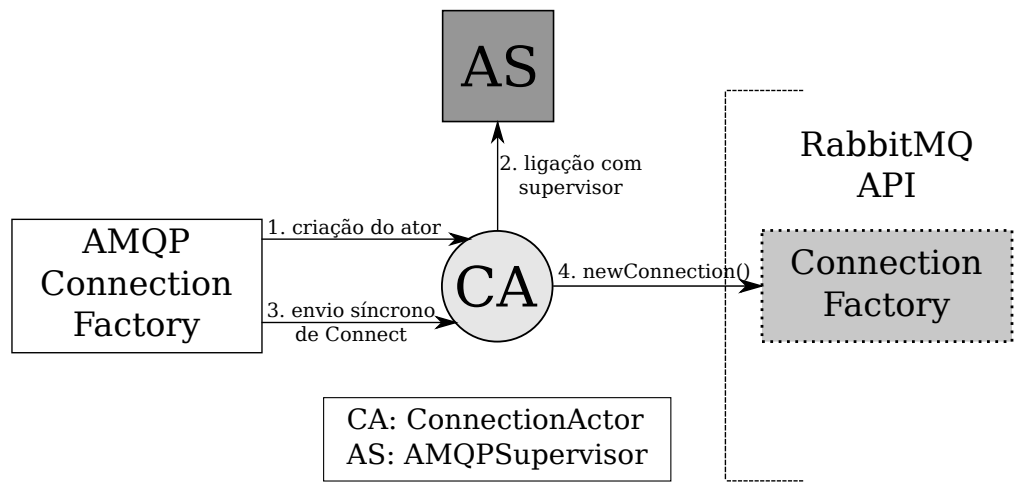

Figura 5.3: Passos para a criação do ator de conexão.

Uma vez que o ator de conexão foi criado, são criados os atores responsáveis pelo canal de leitura e pelo canal de escrita. A criação do ator responsável pelo canal de leitura é ilustrada na Figura 5.4 e acontece em seis passos:

1. Uma instância de ReadChannelActor é criada e inicializada.

2. O ator é ligado (link) ao ator supervisor, que neste caso é o ator de conexão recém criado.

3. A mensagem StartReadChannel é enviada sincronamente para o ator. 
4. A mensagem StartReadChannel é processada pelo ator. Seu processamento faz um envio síncrono da mensagem ReadChannelRequest para o ator de conexão que foi definido como supervisor.

5. O ator de conexão solicita um novo canal à sua conexão de leitura.

6. O novo canal é enviado como resposta para ReadChannelRequest.

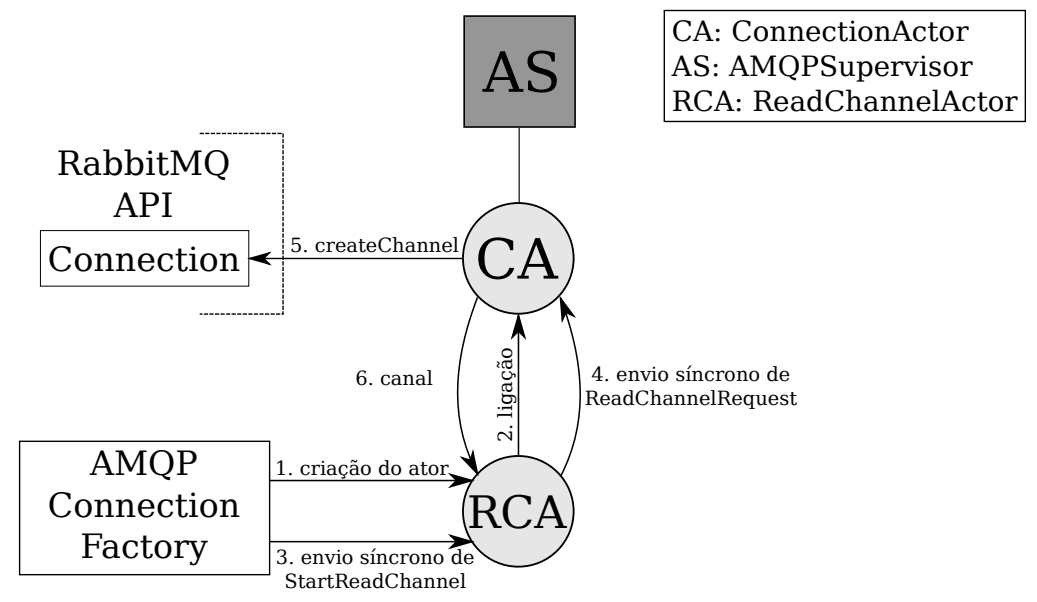

Figura 5.4: Passos para a criação do ator do canal de leitura.

O processo para criação do ator responsável pelo canal de escrita é bem semelhante, com diferenças nas mensagens enviadas nos passos 3 e 4. São utilizadas as mensagens StartWriteChannel e WriteChannelRequest, respectivamente. No passo 5, o novo canal é solicitado para a conexão de escrita. As conexões de escrita e de leitura, se referem à mesma instância no caso de uma política de compartilhamento de conexões.

É importante destacar que todos os parâmetros de configurações utilizados para a criação de uma conexão, como por exemplo a política de compartilhamento de conexões e o endereço do message broker, são lidos de um arquivo de propriedades. Informações sobre esse arquivo serão apresentadas no Capítulo 6.

Uma vez que os atores de conexão e de canais foram criados, a ponte que está sendo criada tem seu método setup executado. A execução do método setup tem diferentes passos para cada tipo de ponte. A execução do método setup da classe ServerAMQPBridge é ilustrada na Figura 5.5 e acontece em oito passos:

1. O método setup da classe SupervisedConnection é invocado.

2. A mensagem RemoteServerSetup é enviada para o canal de escrita com as configurações dos objetos a serem criados.

3. O processamento da mensagem RemoteserverSetup leva à criação de uma exchange direta com a configuração de durabilidade solicitada.

4. A implementação de MessageHandler informada é utilizada na associação do tratador de mensagens rejeitadas (return listener).

5. A mensagem Remoteserversetup é enviada para o canal de leitura com as configurações dos objetos a serem criados.

6. O processamento da mensagem Remoteserversetup leva à criação de uma fila com a configuração de durabilidade solicitada. 
7. O binding entre a fila recém criada e a exchange criada no passo 3 é definido.

8. A implementação de MessageHandler informada é utilizada na associação do consumidor na fila criada no passo 6 .

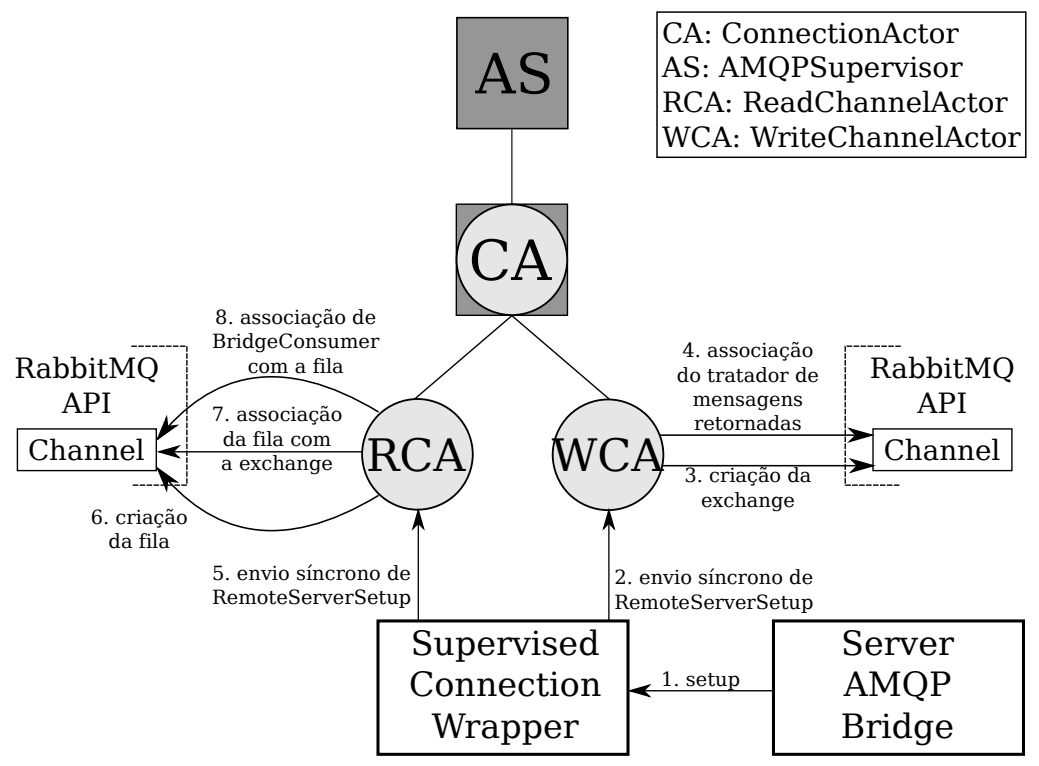

Figura 5.5: Passos de configuração da classe ServerAMQPBridge.

Vale lembrar que a criação de exchanges e filas pela biblioteca Java do RabbitMQ verifica a existência do objeto antes de sua criação. Caso já exista um objeto de mesmo nome e com as mesmas características, o objeto não é recriado e a execução prossegue normalmente. Podemos notar que os passos são divididos entre os canais. O canal de escrita tem a responsabilidade de criar a exchange e associar ao canal do RabbitMQ o tratador de mensagens rejeitadas. O canal de leitura tem a responsabilidade de criar a fila, associá-la à exchange e associá-la também ao consumidor padrão.

A execução do método setup da classe ClientAMQPBridge é ilustrada na Figura 5.6 e acontece em sete passos:

1. O método setup da classe SupervisedConnection é invocado.

2. A mensagem Remoteclient Setup é enviada para o canal de escrita com as configurações dos objetos a serem criados.

3. A implementação de MessageHandler informada é utilizada na associação do tratador de mensagens rejeitadas.

4. A mensagem RemoteClient Setup é enviada para o canal de leitura com as configurações dos objetos a serem criados.

5. O processamento da mensagem Remoteclient Setup leva à criação de uma fila que rotulamos como "fila de saída" que possui a configuração de durabilidade solicitada.

6. O binding entre a fila recém criada e a exchange definida pela ponte servidora correspondente é criado.

7. A implementação de MessageHandler informada é utilizada na associação do consumidor na fila criada no passo 5 . 


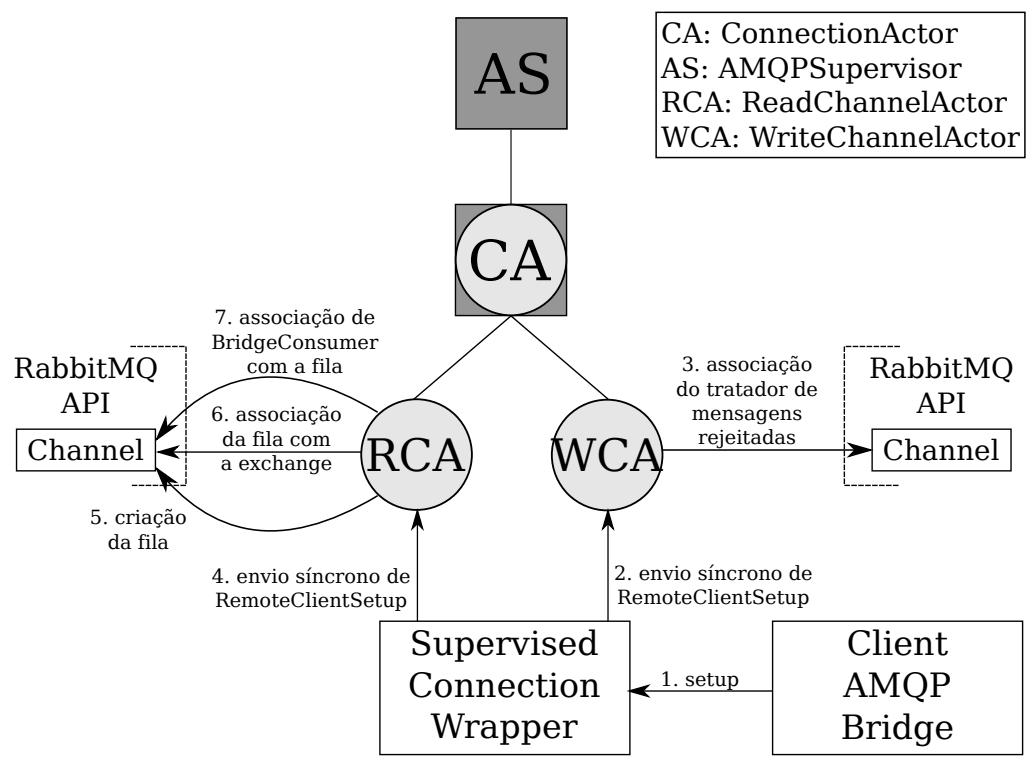

Figura 5.6: Passos de configuração da classe ClientAMQPBridge.

O Akka mantém um registro com todos os atores em execução. Esse registro permite localizar um ator por seu identificador e até mesmo interromper a execução de todos os atores registrados. Para evitar interações indesejadas entre as operações do registro de atores do Akka e a nossa implementação de pontes AMQP, optamos por remover do registro do Akka toda a hierarquia de atores que definimos. Essa remoção é feita por meio do método Actor.registry.unregister ( actor) e acontece após a criação de cada ator. Nossa hierarquia de atores, por sua vez, pode ter sua execução interrompida via método AMQPConnectionFactory . shut downAll.

\subsubsection{Envio e recebimento de mensagens via pontes AMQP}

O envio de mensagens de uma ponte cliente para uma ponte servidora acontece na invocação do método sendMessageToServer da classe ClientAMQPBridge. A execução do método é ilustrada na Figura 5.7 e acontece em quatro passos:

1. A método sendMessageToserver foi invocado por alguma classe que deseja enviar uma mensagem.

2. O método publishTo da classe supervisedConnectionWrapper é invocado. A invocação do método utiliza como argumentos a mensagem a ser enviada, o nome da exchange que foi criada com base no nome da ponte e o nome do binding entre a exchange e a fila de entrada da ponte servidora.

3. O método publishto faz um envio assíncrono da mensagem BasicPublish ao ator responsável pelo canal de escrita. A mensagem BasicPublish possui informações sobre detalhes do envio a ser executado, como por exemplo se o envio deve ser obrigatório e o consumo imediato.

4. O método basicPublish é invocado na classe Channel do RabbitMQ como resultado do processamento da mensagem BasicPublish. Os argumentos utilizados para execução do método são os que foram passados junto à mensagem BasicPublish.

Optamos por fazer envios obrigatórios (mandatory), porém sem consumo imediato. Isso significa que a fila de destino deve obrigatoriamente existir no momento do envio, mas a mensagem não precisa ser consumida no momento do depósito na fila. O trecho de código que executa o passo 4 é mostrado na Listagem 5.5. Os valores para as variáveis mandatory e immediate são respectivamente 


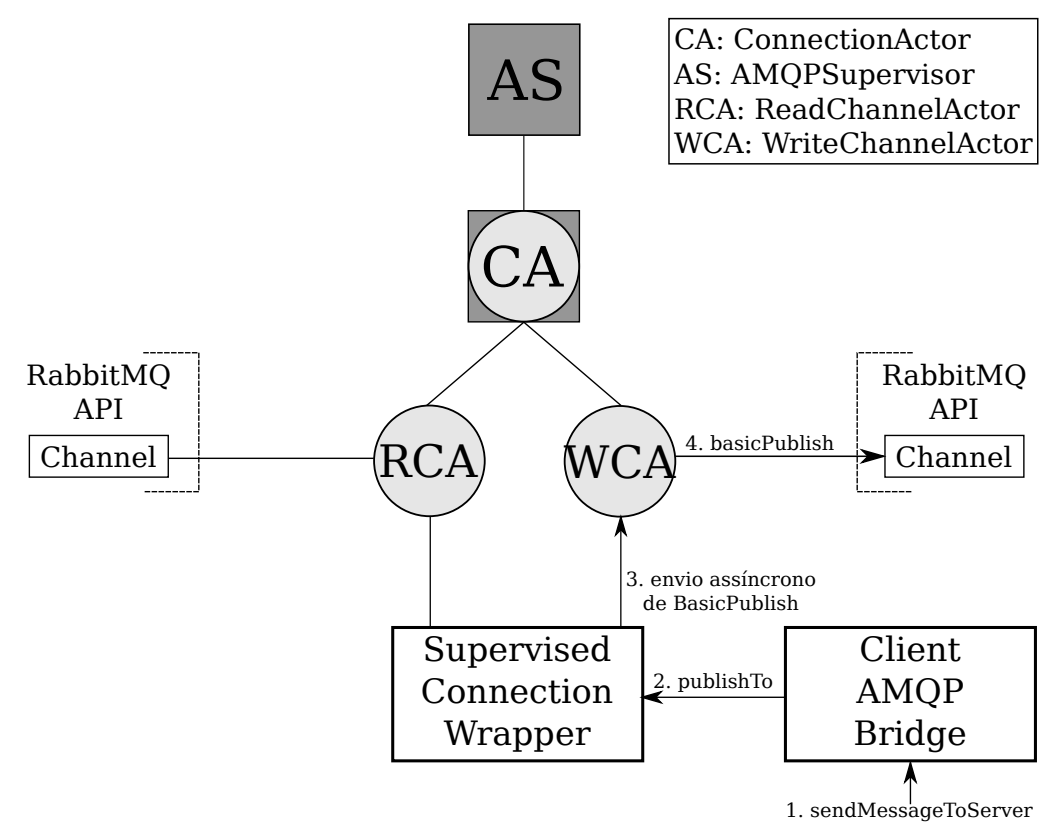

Figura 5.7: Passos do envio de mensagens de um cliente via pontes $A M Q P$.

true e false. Caso ocorra um envio massivo de mensagens, o consumo imediato das mensagens pode não ser possível, acarretando a devolução de mensagens para o remetente. Decidimos por não forçar um consumo imediato para não sobrecarregar as implementações dos consumidores, minimizando a possibilidade de rejeições de mensagens.

Ainda assim, caso uma mensagem seja rejeitada e devolvida, o método handleRejected do MessageHandler é invocado para que alguma ação seja tomada com a mensagem rejeitada. Mensagens podem ser rejeitadas por basicamente dois motivos: (i) uma mensagem não pôde ser roteada para uma fila pois a chave de roteamento utilizada no envio não está associada à exchange; (ii) uma mensagem foi depositada em alguma fila, porém a fila foi removida. Nesse caso, todas as mensagens são devolvidas aos seus respectivos remetentes.

O envio de mensagens de uma ponte servidora para uma ponte cliente é similar ao mostrado na Figura 5.7. A diferença está no nome do binding que é utilizado. O nome do binding utilizado é definido com base no identificador do cliente.

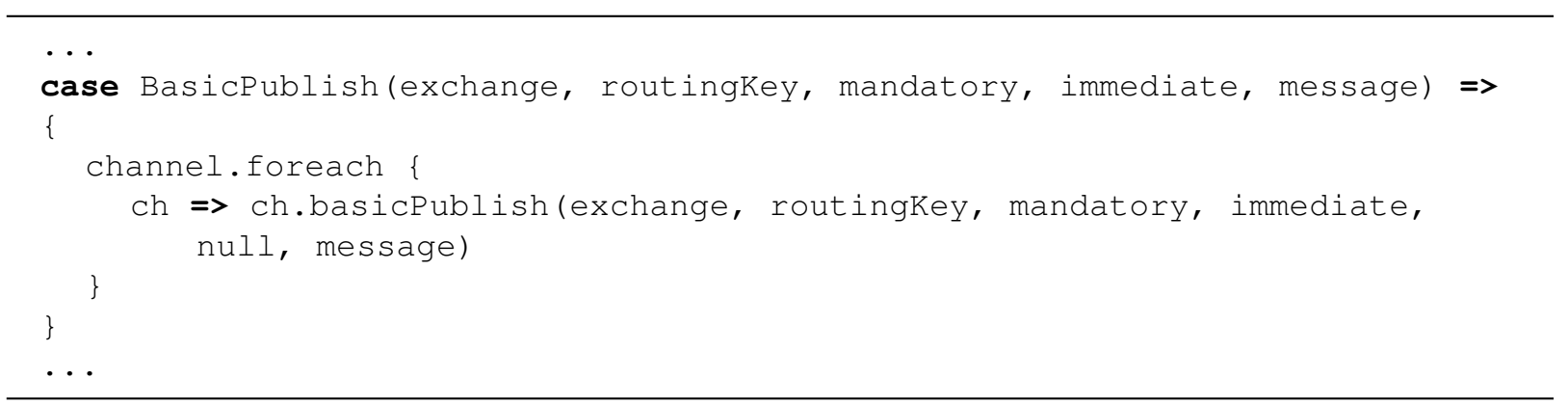

Listagem 5.5: Envio de mensagem obrigatória e não imediata.

O processo de roteamento da mensagem acontece como explicado na Sessão 4.1.1. A mensagem é enviada para a exchange relacionada a ClientAMQPBridge. O identificador do remetente (parâmetro id da Listagem 5.3) deve ser enviado como parte da mensagem e esse envio é de responsabilidade do criador da mensagem. Essa identificação será utilizada como argumento do método sendMessageTo no caso de haver uma mensagem de resposta. O recebimento de uma mensagem por uma ponte servidora é ilustrado na Figura 5.8 e acontece em três passos: 
1. O message broker repassa a mensagem ao canal de leitura.

2. O método handleDelivery da classe BridgeConsumer é invocado.

3. O método handleReceived da implementação de MessageHandler (definida durante a configuração da ponte servidora) é executado pelo BridgeConsumer para que a mensagem possa ser processada. Esse método devolve um valor booleano, que indica que a mensagem foi processada e deve ser removida da fila pelo message broker.

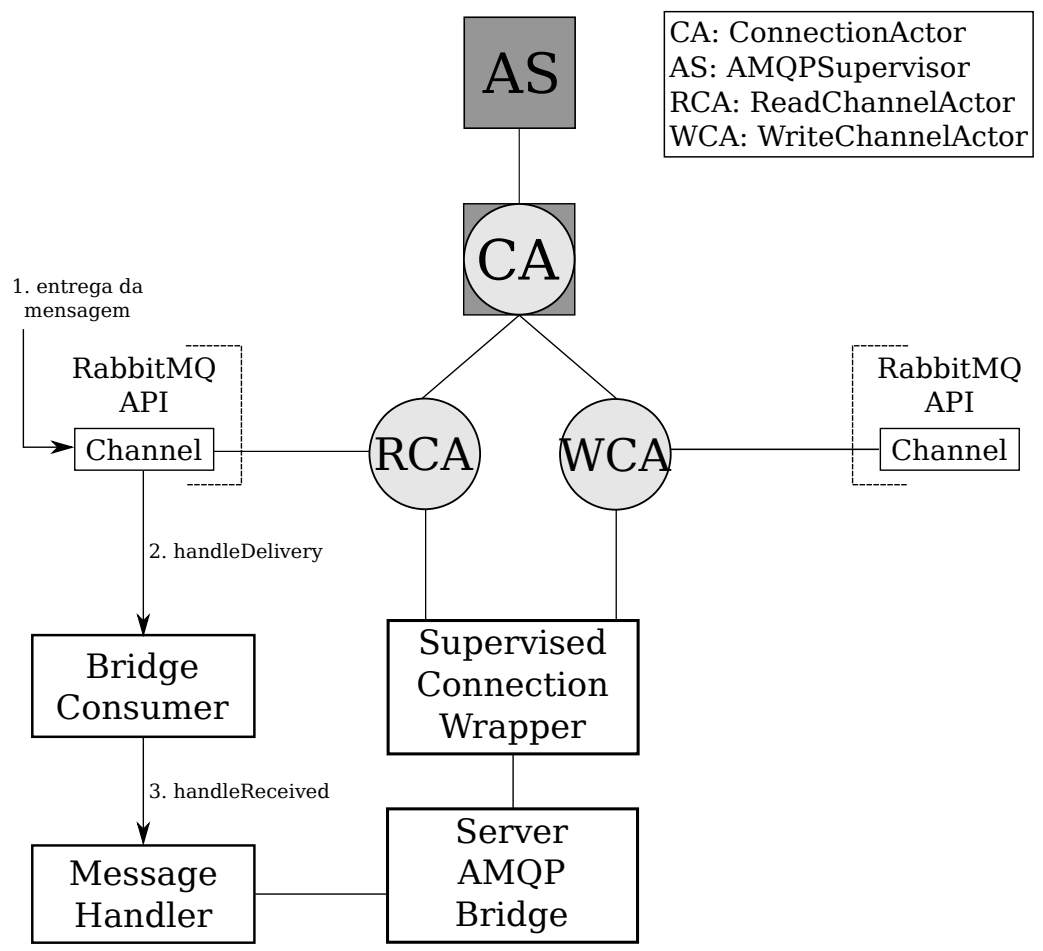

Figura 5.8: Passos para recebimento de mensagens via pontes AMQP.

Os passos utilizados para o recebimento de uma mensagem por uma ponte cliente são idênticos aos ilustrados na Figura 5.8. 


\section{Capítulo 6}

\section{Atores Remotos com o Padrão AMQP}

Apresentamos neste capítulo nossa implementação de atores remotos que utilizam o padrão AMQP como meio de transporte para troca de mensagens. Nossa implementação utiliza a implementação de atores remotos do projeto Akka apresentada no Capítulo 3. Na Seção 6.1 apresentamos os novos componentes que criamos dentro da estrutura do Akka e na Seção 6.2 como fizemos a integração dos novos componentes com a implementação existente.

\subsection{Novos componentes}

A implementação de atores remotos do projeto Akka define uma camada intermediária que desacopla a definição dos componentes para transporte das mensagens a atores remotos, como apresentado na Seção 3.3. Para viabilizar o envio de mensagens remotas via message broker AMQP, tivemos que criar novos componentes para a camada de implementação com base nas classes e feições que definem a interface remota (Figura 3.3). Utilizamos a estrutura apresentada no Capítulo 5 como suporte para a implementação dos novos componentes do Akka. Criamos os seguintes componentes:

- AMQPRemoteserver: É uma classe utilizada no lado do servidor onde estão os atores remotamente acessíveis. Essa classe implementa os métodos abstratos de um MessageHandler e é responsável pelo recebimento, desseriação e encaminhamento das mensagens para os atores que estão em seu registro. A classe também é responsável por enviar eventuais mensagens de resposta para os remetentes, seja como consequência de envios feitos via !! e !!!, ou ainda mensagens para atores supervisores. Tanto no recebimento como no envio de mensagens a classe utiliza um módulo separado para seriação e desseriação de mensagens. Existe um relacionamento bidirecional um para um entre um AMQPRemoteServer e uma ponte servidora. O nome da ponte servidora (parâmetro name do construtor da classe ServerAMQPBridge) é usado também como nome do servidor remoto.

- AMQPRemoteServerModule: É uma feição que estende a feição RemoteserverModule, possui um AMQPRemoteServer e mantém um registro de atores que ficam acessíveis remotamente. Há um relacionamento bidirecional um para um entre AMQPRemoteServerModule e AMQPRemoteServer. As mensagens recebidas pelo AMQPRemoteServer são encaminhadas para os atores registrados no AMQPRemoteServerModule.

- AMQPRemoteClient: É uma classe utilizada no lado do cliente onde ficam os proxies dos atores remotos. A classe mantém o registro de atores que são supervisores de atores remotos, além de também manter um registro para resultados futuros. Tal como a classe AMQPRemoteServer, essa classe também implementa os métodos abstratos de um MessageHandler e é também é responsável pelo recebimento, desseriação e encaminhamento das mensagens para os atores ou resultados futuros que estão em seu registro. O principal papel da classe é fazer o envio das mensagens para o seu servidor remoto. Existe uma relação bidirecional um para um entre um AMQPRemoteClient e uma ponte cliente. A classe ainda é responsável por manter um identificador que deve ser único entre todos os clientes do mesmo servidor remoto. Esse identificador é utilizado na criação da instância da ponte cliente. 
- AMQPRemoteclientModule: É uma feição que estende a feição RemoteclientModule. Essa feição que tem um papel complementar a AMQPRemoteServerModule. Seu papel principal é definir uma interface para envios de mensagens a atores remotos via AMQPRemoteclient. Ademais, esta feição mantém ainda um registro dos AMQPRemoteClients que são utilizados para enviar as mensagens para seus respectivos nós remotos, já que uma aplicação cliente pode interagir com diversos atores em diferentes nós.

- AMQPRemotesupport: É a implementação que tornamos acessível via Actor.remote. Essa classe é responsável por concentrar as responsabilidades definidas nas classes e feições acima listadas para prover o suporte remoto via message broker AMQP.

O modo como os novos componentes se relacionam com as pontes AMQP e com as classes do Akka é mostrado na Figura 6.1.

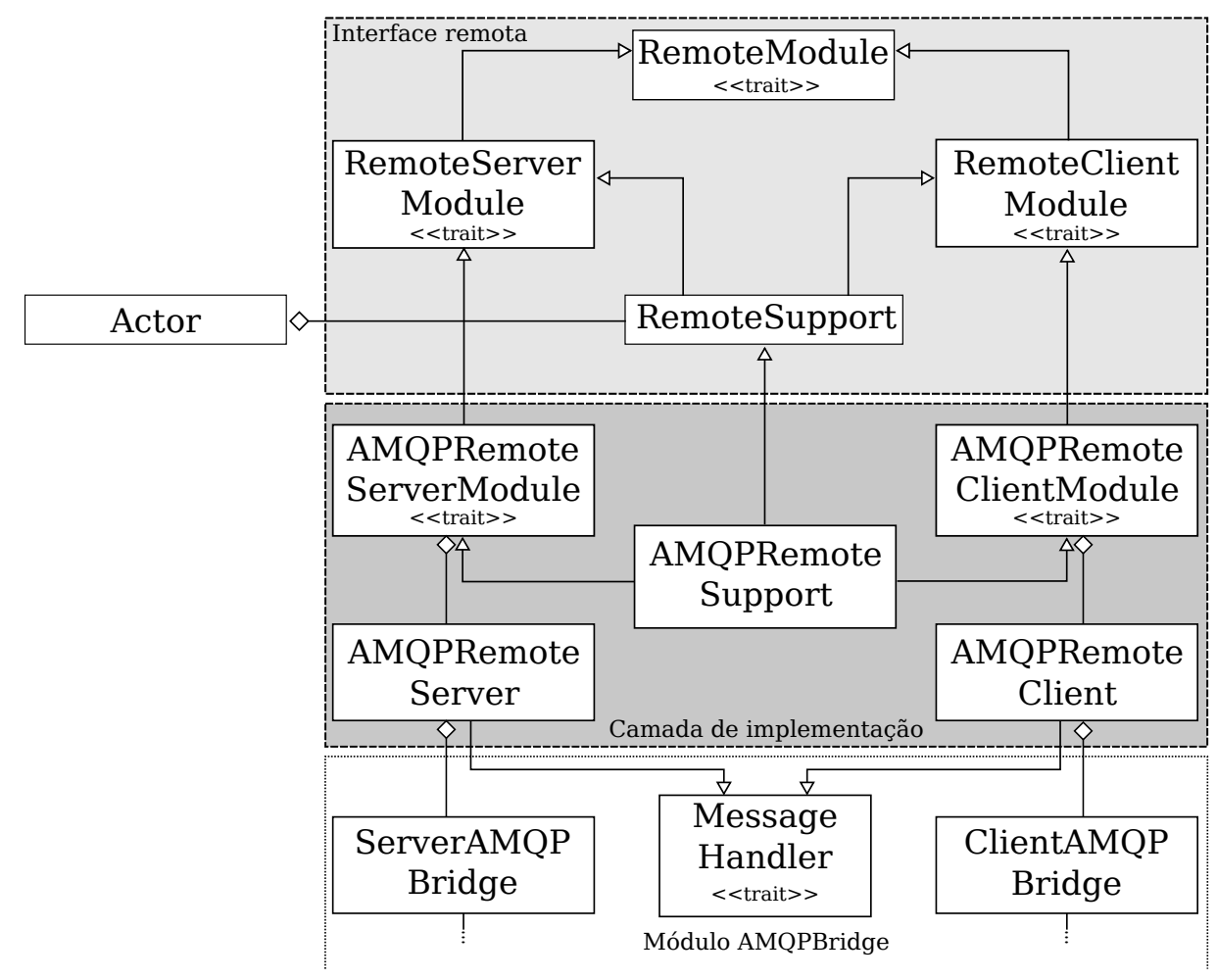

Figura 6.1: Relacionamento entre os componentes para atores remotos com AMQP.

A definição das feições para suporte a atores remotos do Akka utiliza assinaturas de métodos baseadas na identificação do hospedeiro e da porta. Para não quebrar a compatibilidade em nossa implementação e nem alterar a interface dos métodos do Akka, optamos por criar internamente uma ponte servidora e um servidor remoto identificados por um nome construído com base nos valores de host e port informados. Os nomes das pontes servidoras e dos servidores remotos seguem o padrão host:port. Além disso, o construtor da classe RemoteActorRef do Akka recebe como parâmetros o hospedeiro e a porta. Optamos por manter a compatibilidade e não mudar esse construtor. Como o projeto Akka possui desenvolvimento ativo, acreditamos que existe uma grande possibilidade de mudança na interface dos componentes do módulo de atores remotos, de modo a tornar essa interface independente da camada de transporte utilizada.

\subsection{Integração com o Akka}

Uma vez definidos os componentes dentro da estrutura do Akka, é necessário que a biblioteca do Akka faça uso deles, de modo que a instância referenciada por Actor. remote seja uma instância de AMQPRemotesupport. Ademais, devemos informar as configurações que nosso suporte espera, como 
por exemplo, as políticas de armazenamento e compartilhamento de canais. As alterações necessárias para a integração do nosso novo suporte com a biblioteca de atores do Akka são apresentadas nas seções a seguir.

\subsubsection{Alterações no arquivo akka.conf}

Além de alterar o valor da camada de suporte para atores remotos no arquivo akka.conf, optamos por adicionar novas propriedades para a configuração do suporte que implementamos, como os dados para conexão com o message broker, a política de armazenamento e de compartilhamento de conexões entre canais. Uma outra propriedade importante que adicionamos foi a definição do identificador a ser utilizado na criação de diferentes AMQPRemoteClients (e consequentemente de ClientAMQPBridges). O novo valor para a camada de suporte para atores remotos (propriedade layer) e as novas propriedades são exemplificados pelo seguinte fragmento de arquivo de configuração:

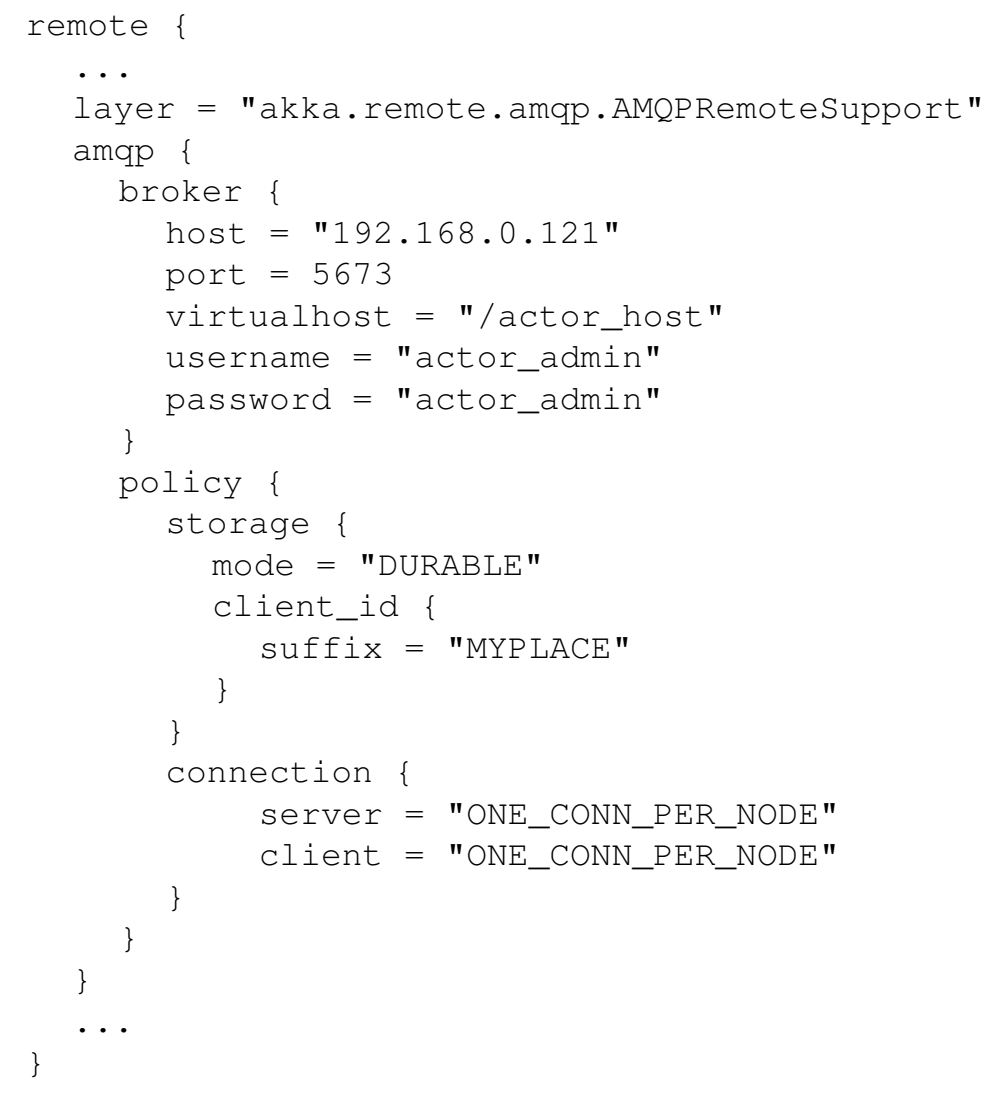

Listagem 6.1: Novas propriedades do arquivo akka.conf.

\section{Observações}

Pelo fato do arquivo akka.conf ser único por JVM, a maneira pela qual é feita a configuração das propriedades remotas impõe algumas restrições. Com o Akka em execução em uma JVM, podemos criar diversos servidores remotos nessa JVM, cada um com um nome diferente. A criação de um servidor remoto ocorre em consequência de chamadas Actor. remote. start (host, port), como a ilustrada na Listagem 3.9. Todos os clientes remotos criados numa mesma JVM utilizam o mesmo identificador de cliente, independentemente dos nomes dos servidores remotos aos quais os clientes estão conectados.

Contudo, essa restrição não impede a criação dos objetos no message broker. Para exemplificar, vamos considerar o caso em que, numa mesma JVM, são criados dois clientes remotos para servidores remotos cujos nomes são node1 e node2. Os objetos (fila e binding) criados por esses clientes remotos 
têm o sufixo node1. $<i d>$ e node $2 .<i d>$, respectivamente. Um outro detalhe importante é que, pelo fato da classe AMQPRemoteClientModule manter um registro com os clientes remotos, não há a possibilidade de, na mesma JVM, ser criada mais de uma instância de AMQPRemoteClient para um mesmo servidor remoto.

As propriedades para configuração da política de armazenamento são utilizadas tanto para os servidores quanto para os clientes remotos. Configurações divergentes entre JVMs podem levar aos seguintes cenários:

1. A JVM onde foi iniciado um servidor remoto utiliza uma configuração persistente e alguma das JVMs com um cliente remoto define uma configuração transiente. Esse não é um caso muito problemático, já que os objetos criados pelo servidor não dependem dos objetos criados pelos clientes. Como objetos definidos como transientes só são removidos quando o message broker é desligado, o problema se limita à devolução de eventuais mensagens que ainda estivessem na fila.

2. O servidor remoto possui uma configuração transiente e algum de seus clientes possui uma configuração persistente. Esse cenário é oposto ao anterior e é mais problemático, já que quando a exchange do servidor é removida todas as suas associações também são removidas, porém as filas persistentes não são. Devemos analisar esse cenário sob duas ópticas diferentes: (i) Óptica da criação dos objetos: como a biblioteca Java do RabbitMQ faz uma verificação da existência de um objeto antes de tentar fazer a sua criação (5.2.2), não há problemas. A associação da fila persistente com a exchange recém criada acontecerá durante a inicialização do módulo do cliente remoto; (ii) Óptica da aplicação: Eventuais mensagens não consumidas pelo servidor remoto são devolvidas.

As configurações referentes ao compartilhamento da conexão entre os canais de leitura e escrita são definidas separadamente para os clientes e servidores remotos. A divergência nas configurações entre um cliente remoto em um nó e um servidor remoto em outro nó pode acontecer sem problemas, já que o impacto será no volume de dados que trafega pela conexão.

\subsubsection{Segurança}

Com o intuito de prevenir conexões em servidores remotos de clientes em JVMs não autorizados, o Akka deixa como opção de configuração exigir que somente clientes autorizados possam interagir com os atores. A autorização é feita com um cookie de segurança, um segredo compartilhado por todas as JVMs cujos atores podem trocar mensagens entre si. O cookie de segurança é definido no arquivo akka.conf, na seção remote. O uso do cookie é opcional e deve ser exigido, quando necessário, pelo servidor remoto, por meio de uma propriedade em seu arquivo akka.conf.

O valor do cookie é parte do envelope para mensagens remotas definido no Akka (Listagem 3.15). Em nossa implementação mantivemos o suporte a cookies. Caso um servidor remoto exija cookies, as mensagens oriundas de clientes remotos não autorizados não serão processadas. Um cliente remoto não autorizado receberá uma mensagem de resposta indicando a necessidade de autorização.

Quando utilizamos um message broker AMQP, a segurança depende muito de quem possui as informações para acesso ao virtual host onde estão criadas as filas e exchanges. Com o uso das filas definidas no message broker como repositório intermediário das mensagens, qualquer entidade que possua os dados necessários para acessar o virtual host onde foram criadas as filas pode registrar outros consumidores (salvo no caso de filas com acesso exclusivo). Uma fila com mais de um consumidor pode ser interessante quando se deseja fazer um monitoramento do volume ou até do conteúdo das mensagens. No caso de haver mais de um consumidor em uma fila, uma cópia da mensagem é entregue a cada consumidor. Um consumidor mal intencionado não tem a possibilidade de "roubar" uma mensagem, fazendo com que ela não seja recebida por seu destinatário legítimo, nem mesmo alterar a integridade de uma mensagem. 


\subsubsection{Alteração no formato do envelope das mensagens remotas}

Para que o servidor remoto pudesse identificar qual o remetente de uma mensagem, foi necessária uma pequena alteração no envelope da mensagem. Esse envelope passa a incluir um campo não obrigatório para o identificador do cliente. O formato do envelope com a alteração é mostrado na Listagem 6.2. Cabe ressaltar que o novo campo não era necessário na implementação original de transporte com o Netty, que consegue obter do socket qual o endereço do cliente remoto.

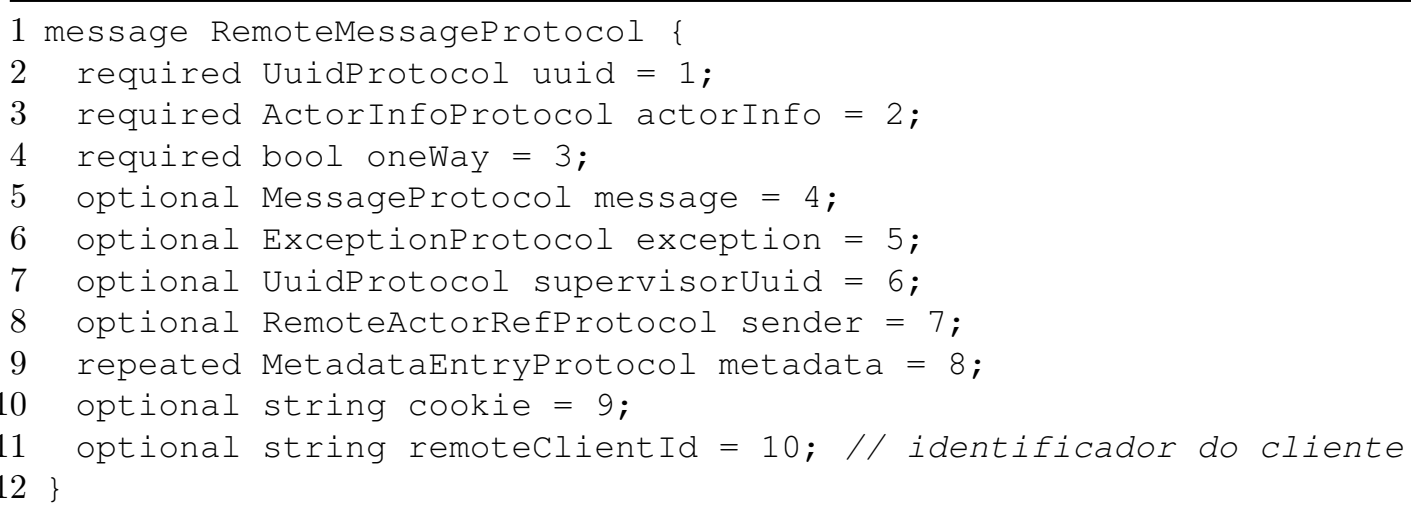

Listagem 6.2: Formato do envelope para mensagens remotas com identificador do cliente.

\subsection{Fluxo de envio das mensagens}

Parte do fluxo do envio de uma mensagem a um ator remoto com a nova camada de transporte continua acontecendo em sete passos, como descrito na Seção 3.3.1. O processo de envio começa com o proxy local embrulhando a mensagem e adicionando a ela informações de cabeçalho necessárias para o envio e posterior processamento. Antes da mensagem ser repassada para o seriador, o AMQPRemotesupport adiciona o identificador do cliente na mensagem (campo na linha 11 da Listagem 6.2).

O seriador continua sendo o responsável por converter a informação recebida em um vetor de bytes para que o transporte possa ocorrer. Uma vez que a informação esteja no formato a ser transportado, o proxy usa uma implementação de Remotesupport (que na Figura 6.2 é uma instância de AMQPRemoteSupport) para enviar a mensagem ao Remotesupport que está no lado do servidor.

Os passos 3 (transporte da mensagem do ClientBootstrap para o ServerBootstrap) e 4 (recebimento da mensagem pelo ServerBootstrap e repasse para o handler) acontecem de modo diferente em relação a implementação com Netty. Pelo fato de utilizarmos as pontes AMQP definidas no Capítulo 5, o passo 3 se resume em enviar uma mensagem à exchange associada a ponte utilizando o a chave de roteamento da ponte servidora. O message broker, então, roteia a mensagem para a fila criada pela ponte servidora. Ainda que o message broker tente entregar a mensagem para o consumidor da fila o quanto antes, a mensagem pode ficar armazenada caso o consumidor não esteja pronto para fazer o recebimento da mensagem. O passo 4 se resume ao consumo da mensagem enviada e no repasse para a implementação de MessageHandler utilizada na ponte servidora. Vale lembrar que, após o recebimento de um mensagem remota, ocorre um envio exatamente igual a um envio local. O envio local de uma mensagem leva tempo $O(1)$, que é o tempo gasto para colocar uma mensagem na fila de um ator.

Assim como na implementação com Netty, os envios feitos via métodos !! e ! ! , também possuem um passo a mais do que os mostrados na Figura 6.2. Entre os passos 2 e 3, é colocada no mapa de resultados futuros uma referência que instância de CompletableFuture criada pela chamada ao método !! ou !!!. A mensagem de resposta para um envio feito via !! ou !!! faz o caminho inverso. Essa mensagem é enviada para a mesma exchange empregada pela ponte cliente que fez o envio, 
JVM 1

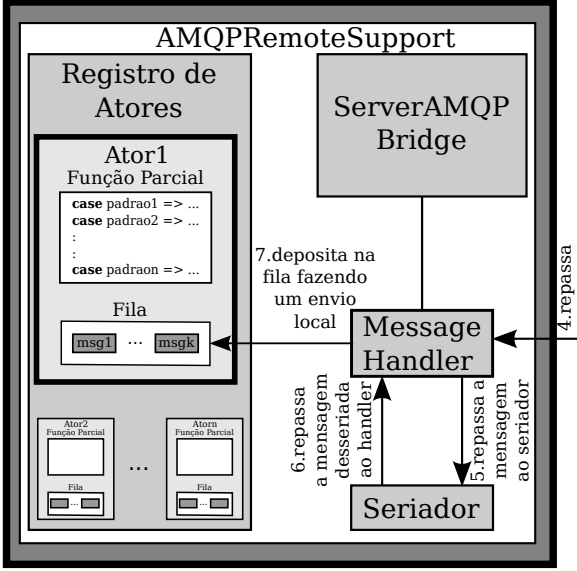

JVM 2

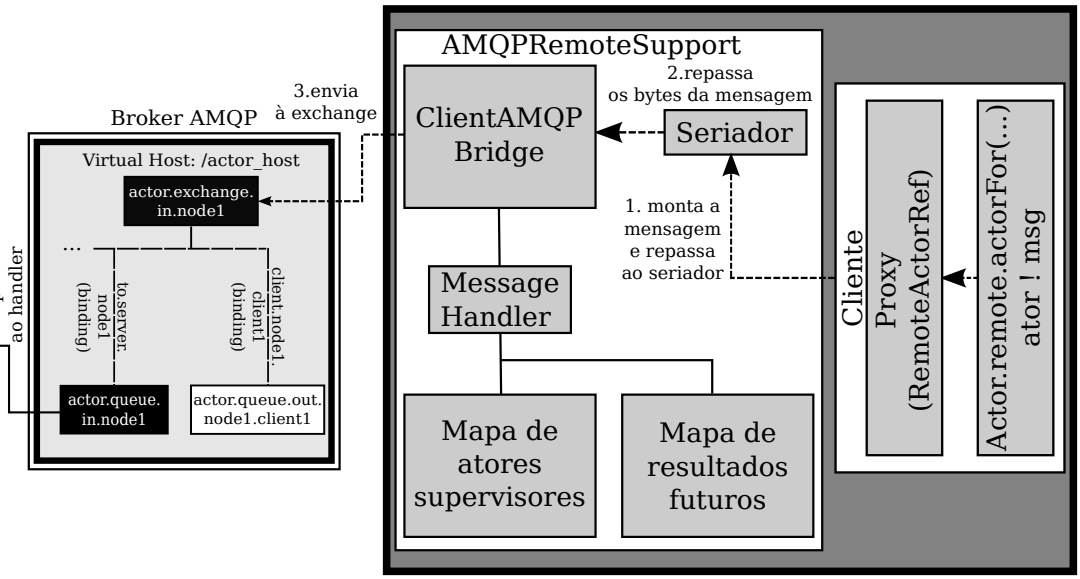

Figura 6.2: Fluxo de um envio assíncrono de mensagem entre atores com AMQP.

porém utilizando o identificador do cliente remoto como parte da chave de roteamento. Assim, o message broker pode fazer o roteamento da mensagem para a fila do cliente remoto. 


\section{Capítulo 7}

\section{Resultados Experimentais}

Apresentamos nesse capítulo uma aplicação de benchmark desenvolvida para medir o desempenho de nosso protótipo. Apresentamos também uma comparação de desempenho entre a implementação original de atores remotos do projeto Akka e o protótipo desenvolvido neste trabalho. Para finalizar, fazemos uma breve discussão dos resultados observados.

\subsection{Trading System}

Para medir como novas alterações na biblioteca de atores afetavam o desempenho da biblioteca, os desenvolvedores do projeto Akka criaram uma aplicação de benchmark que simula compra e venda de ações. Os desenvolvedores criaram também alguns módulos que auxiliam em tarefas como armazenamento dos dados coletados nos experimentos e geração de relatórios. A aplicação de benchmark tem um lado servidor, denominado Trading System, e um lado cliente. A disposição dos componentes do Trading System é mostrada na Figura 7.1. Os componentes são descritos a seguir:

- Order Book: É uma entidade que possui informações sobre as ordens de compra e de venda de uma determinada ação. Neste sistema, uma ação é rotulada por uma letra e por um número. Um order book tem como responsabilidade fazer o casamento de uma ordem de venda com uma ordem de compra. São utilizados como nomes de ações as letras A, B e C, combinadas com números de 1 a 5 , num total de quinze order books.

- Matching Engine: É um ator que age como intermediário no encaminhamento de mensagens aos order books. Existe um matching engine para cada letra de order book.

- Order Receiver: É um ator externo (visível para o lado cliente da aplicação) que tem o papel de receber mensagens de compra e venda de qualquer ação. Quando uma ordem é recebida por um order receiver, ele identifica o matching engine responsável pela ordem e encaminha a mensagem a esse matching engine. A quantidade de order receivers não possui relação com a quantidade de matching engines, já que um order receiver recebe ordens de qualquer tipo de ação. O sistema possui dez order receivers.

- Trading System: É um ator externo que tem o papel de recepcionista do sistema. Tem a responsabilidade de fazer a criação e a inicialização dos demais atores que fazem parte do lado servidor da aplicação. O lado cliente utiliza o ator recepcionista apenas uma vez, para obter uma lista com os order receivers criados na inicialização do lado servidor.

- Order: É um componente que não é mostrado na figura, mas que desempenha o papel de mensagem e representa uma ordem. É definida em uma classe abstrata e possui como atributos o código da ação, o volume e o valor da ordem. Suas implementações são Ask, para indicar uma ordem de venda, e Bid, para indicar uma ordem de compra.

O lado cliente da aplicação possui ainda atores rotulados como "clientes". Um ator cliente possui uma lista com ordens a serem enviadas a um order receiver. Um ator cliente possui também dois 


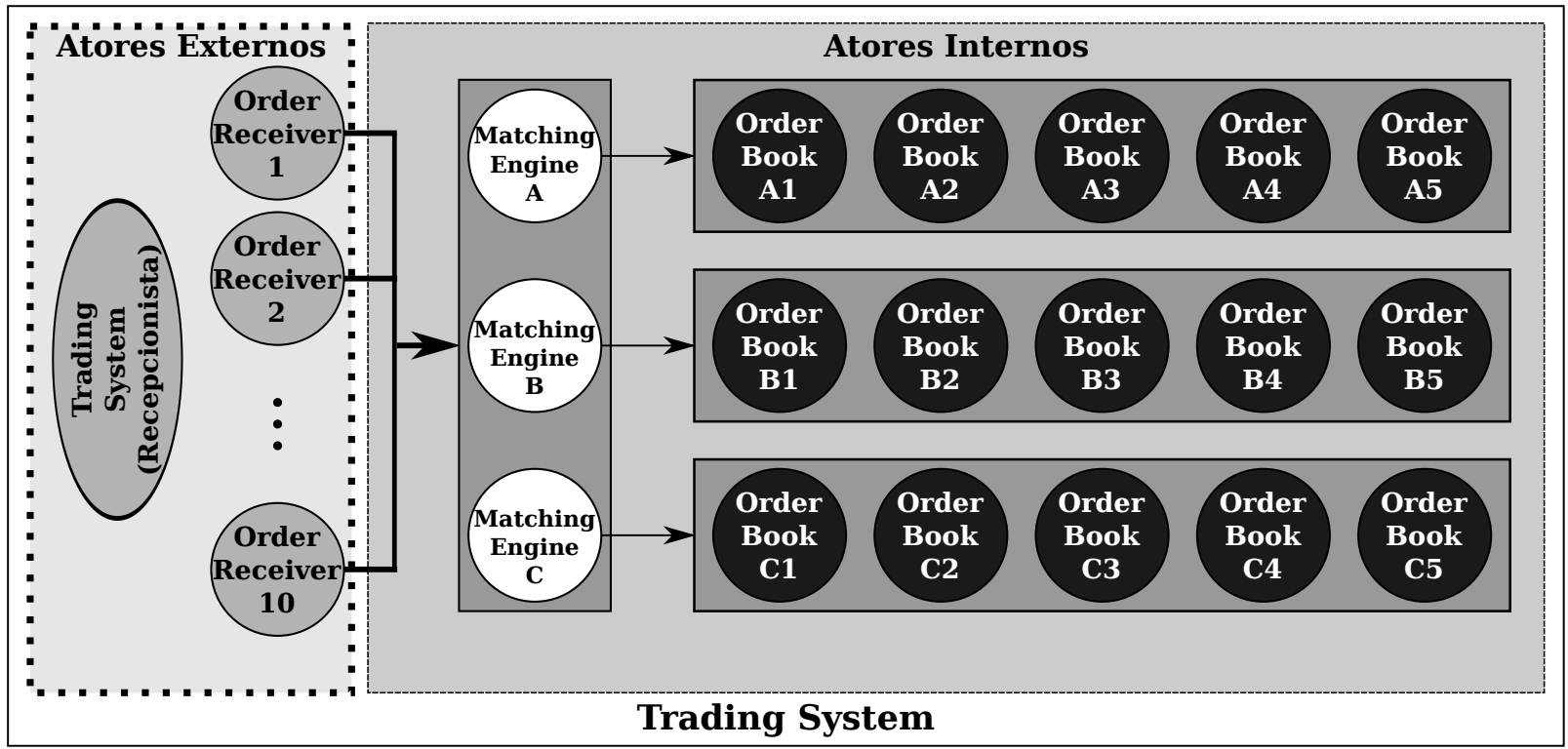

Figura 7.1: Trading System - Sistema de compra e vendas de ações.

atributos adicionais. O primeiro é o número de repetições, um valor inteiro que indica quantas vezes as ordens que estão na lista do ator serão enviadas. O segundo atributo é o order receiver para o qual as mensagens serão enviadas. A quantidade de atores clientes varia de acordo com a instância do experimento que se deseja fazer. Essa quantidade não precisa ser necessariamente igual à quantidade de order receivers. A associação entre atores clientes e order receivers é feita emparelhando-se os elementos da lista de atores clientes com os da lista de order receivers, sendo essa última considerada como uma lista circular (ou seja, uma vez que se tenha alcançado o último order receiver, o emparelhamento prossegue a partir do primeiro order receiver). Dependendo da quantidade de atores clientes, alguns order receivers podem recebem mais mensagens que outros.

Cada ator cliente possui uma lista com trinta ordens, das quais quinze são ordens de compra e quinze são ordens de venda. O número de ordens enviado por um ator cliente é o comprimento dessa lista (trinta) multiplicado pelo número de repetições. As mensagens são enviadas assincronamente. A medição do tempo de processamento de uma mensagem tem início imediatamente antes do envio da mensagem e término imediatamente após o processamento da mensagem por um order book.

\subsection{Trading System com atores remotos}

Ainda que o Trading System não tenha sido criado para experimentos com atores remotos, consideramos que ele é de grande utilidade para comparar o desempenho entre o suporte padrão a atores remotos do Akka e o desenvolvido neste trabalho. Para tal, foram necessárias as alterações listadas a seguir:

1. Registramos como atores remotos todos os atores que estão posicionados na área rotulada como "Atores Externos" na Figura 7.1. Como consequência dessa alteração, passamos a obter as referências para os atores externos via método actorFor (Seção 3.3).

2. Fizemos com que as classes Ask e Bid passassem a ser seriáveis. Optamos por utilizar como formato de seriação o formato definido na feição Scalauson (Seção 3.3.3).

3. Alteramos os envios das mensagens feitos pelos atores clientes. Os atores clientes passaram a fazer envios síncronos, com o uso do método ! !.

4. Modificamos a maneira de medir o tempo de processamento de uma mensagem. Na aplicação de benchmark original, a medição começa no lado cliente e termina no lado servidor da apli- 
cação. O fato de desses dois lados residirem na mesma JVM facilita essa medição. Em nossa aplicação de benchmark modificada, entretanto, os lados cliente e servidor residem em JVMs que rodam em nós diferentes. Por esse motivo, fazemos toda a medição no lado cliente. Para cada mensagem enviada por um ator cliente, a medição tem início imediatamente antes da execução do método !! (que é invocado sobre um order receiver remoto) e término logo após a execução desse método.

As configurações utilizadas no arquivo akka.conf para os experimentos com o suporte padrão a atores remotos do Akka são as recomendadas para uso geral (compressão média de mensagens e tamanho do janelamento das mensagens de 1KB). Nos experimentos executados com o suporte remoto via AMQP, utilizamos uma conexão por canal além da configuração DURABLE para as pontes AMQP (Seção 5.2.1).

\subsection{Comparação de desempenho}

Para que pudéssemos ter medidas mais reais, implantamos os atores clientes e os atores do Trading System em JVMs residentes em nós fisicamente separados. A máquina virtual Erlang com o RabbitMQ ficou separada em um terceiro nó. Essa máquina virtual foi executada em um laptop Dell Inspiron N4030 com processador Intel Core i3 de $2.4 \mathrm{GHz}, 4$ GB de RAM e Linux Ubuntu 10.10. A JVM na qual implantamos os atores clientes foi executada em um laptop Lenovo T410 com processador Intel Core i5 de $2.4 \mathrm{GHz}, 4 \mathrm{~GB}$ de RAM e Linux Ubuntu 10.10. Por fim, a JVM com o Trading System foi executada em um laptop MacBook Pro com processador Core 2 Duo de 2.4 $\mathrm{GHz}, 4 \mathrm{~GB}$ de RAM e Mac OS X 10.7. Os três laptops foram conectados por um roteador D-Link DI-524. Apesar deste ser um roteador para redes wireless, optamos por usar cabos de rede para conectá-lo a cada um dos laptops.

Com o intuito de avaliar a latência da rede utilizada nos nossos experimentos, utilizamos a ferramenta Netperf [Net] para medir quantas transações são completadas em um período de 10 segundos. Neste contexto, uma transação consiste em uma requisição TCP feita de um nó $A$ para um nó $B$, seguida de uma resposta do nó $B$ para o nó $A$. O tamanho utilizado para as mensagens enviadas em uma transação foi de 1 byte. A quantidade de transações por segundo variou entre 2163.99 e 2292.73 , com média de 2246.44. O desvio padrão ficou em 35.60 e coeficiente de variação em 1.5\%. Como o tempo de processamento das mensagens do Netperf é praticamente nulo, a latência de ida e volta (round-trip) é determinada pelo inverso da quantidade de transações por segundo.

A estrutura criada para medição e comparação de desempenho de atores locais do Akka utiliza algumas bibliotecas para o armazenamento e geração de relatórios. Os valores das medidas registradas em uma instância de experimento são organizados em percentis. A biblioteca utilizada para o cálculo de percentis é a Commons Math da fundação Apache [CML]. Os relatórios gerados apresentam também a quantidade de envios e respostas por segundo (ER/S), o tempo médio de cada envio e resposta e ainda o tempo total gasto para a execução de todos os envios e respostas.

Definimos o número de mensagens que cada cliente enviou da seguinte maneira: seja $n_{c}$ a quantidade de atores clientes utilizada em um experimento e seja $r$ o número de repetições; cada ator cliente enviou $(30 r) / n_{c}$ mensagens. O valor $r$ de repetições utilizado foi 1000 . Variamos os valores de $n_{c}$ de modo que o resultado da divisão fosse sempre inteiro. A quantidade total de mensagens enviadas por todos os atores clientes em uma instância de experimento foi sempre 30000 .

A Tabela 7.1 mostra os resultados de nossos experimento com atores via Netty e via AMQP. Cada linha dessa tabela representa um instância de experimento com o número de clientes indicado na coluna "Clientes". Os experimentos foram executados múltiplas vezes. Os valores apresentados na Tabela 7.1 são melhores medidas que obtivemos. O critério que utilizamos para comparar as medidas de um mesmo experimento foi o valor apresentado na coluna "Média". Em outras palavras, cada linha da Tabela 7.1 contém as informações do experimento que apresentou o menor valor do tempo médio para um envio síncrono. 


\begin{tabular}{|c|c|c|c|c|c|c|c|c|}
\hline Impl. & Clientes & ER/S & Média $(\mu s)$ & $25 \%(\mu s)$ & $50 \%(\mu s)$ & $75 \%(\mu s)$ & $95 \%(\mu s)$ & Dur. $(s)$ \\
\hline \hline Netty & 1 & 501 & 1995 & 1364 & 1433 & 1968 & 3266 & 59.85 \\
AMQP & 1 & 263 & 3797 & 3283 & 3361 & 3537 & 4550 & 113.91 \\
\hline & Variação & $-47.50 \%$ & $90.33 \%$ & $140.69 \%$ & $134.54 \%$ & $79.73 \%$ & $39.31 \%$ & $54.06(90.33 \%)$ \\
\hline Netty & 2 & 894 & 2238 & 1770 & 1796 & 1836 & 3290 & 33.57 \\
AMQP & 2 & 528 & 3789 & 3234 & 3359 & 3552 & 4208 & 56.83 \\
\hline & Variação & $-40.99 \%$ & $69.30 \%$ & $82.71 \%$ & $87.03 \%$ & $93.46 \%$ & $27.90 \%$ & $23.26(69.33 \%)$ \\
\hline Netty & 4 & 1245 & 3212 & 2070 & 2517 & 2726 & 4214 & 24.09 \\
AMQP & 4 & 906 & 4416 & 3248 & 3614 & 4134 & 5088 & 33.12 \\
\hline & Variação & $-27.31 \%$ & $37.48 \%$ & $56.91 \%$ & $43.58 \%$ & $51.65 \%$ & $20.74 \%$ & $9.03(37.48 \%)$ \\
\hline Netty & 8 & 1494 & 5353 & 3274 & 3771 & 4745 & 6168 & 20.07 \\
AMQP & 8 & 1389 & 5760 & 3567 & 4149 & 5168 & 6425 & 21.60 \\
\hline & Variação & $-7.10 \%$ & $7.60 \%$ & $8.95 \%$ & $10.02 \%$ & $8.91 \%$ & $4.17 \%$ & $1.52(7.60 \%)$ \\
\hline Netty & 10 & 1542 & 6484 & 4005 & 4330 & 5704 & 7041 & 19.45 \\
AMQP & 10 & 1424 & 7023 & 4396 & 5107 & 6136 & 7610 & 21.06 \\
\hline & Variação & $-7.72 \%$ & $8.31 \%$ & $9.76 \%$ & $17.94 \%$ & $7.57 \%$ & $8.08 \%$ & $1.61(8.31 \%)$ \\
\hline Netty & 20 & 1568 & 12757 & 8206 & 9646 & 10146 & 12015 & 19.13 \\
AMQP & 20 & 1503 & 13309 & 8728 & 9964 & 10888 & 13430 & 19.96 \\
\hline & Variação & $-4.15 \%$ & $4.33 \%$ & $6.36 \%$ & $3.30 \%$ & $7.31 \%$ & $11.78 \%$ & $0.82(4.33 \%)$ \\
\hline Netty & 40 & 1589 & 25176 & 17616 & 18183 & 19436 & 21350 & 18.82 \\
AMQP & 40 & 1518 & 26345 & 18496 & 19525 & 20842 & 23360 & 19.75 \\
\hline & Variação & $-4.41 \%$ & $4.64 \%$ & $5.00 \%$ & $7.38 \%$ & $7.23 \%$ & $9.41 \%$ & $0.87(4.64 \%)$ \\
\hline Netty & 80 & 1615 & 49525 & 35403 & 36541 & 37863 & 40041 & 18.57 \\
AMQP & 80 & 1535 & 52122 & 37915 & 39399 & 40943 & 43496 & 19.54 \\
\hline & Variação & $-5.02 \%$ & $5.24 \%$ & $7.10 \%$ & $7.82 \%$ & $8.13 \%$ & $8.63 \%$ & $0.97(5.24 \%)$ \\
\hline
\end{tabular}

Tabela 7.1: Medidas de tempo do Trading System com atores remotos.

O fato de introduzirmos um terceiro nó com o message broker usado na comunicação entre os atores remotos naturalmente adiciona mais passagens pela rede que conecta os nós. Um envio que utilize o Netty faz com que duas mensagens trafeguem pela rede: a ordem é enviada pelo Remoteclient diretamente ao RemoteServer. A mensagem de resposta, por sua vez, faz o caminho inverso, indo do Remoteclient para o RemoteServer. Já quando utilizamos nossa implementação com AMQP, quatro mensagens trafegam. A ordem é enviada pelo Remoteclient ao message broker e o message broker a envia para o Remoteserver. A mensagem de resposta, por sua vez, faz o caminho inverso, do RemoteServer para o message broker, e depois do message broker para o Remoteclient. Por esse motivo, esperávamos que o tempo gasto pela implementação com AMQP fosse por volta de duas vezes maior do que o tempo gasto pela implementação com Netty.

Observando a variação dos dados da Tabela 7.1 para a instância com apenas um ator cliente, podemos notar uma diferença bem próxima da esperada. O número de envios e respostas por segundo com nossa implementação é quase metade do valor obtido com o Netty (variação de $-47.50 \%$ ) e o valor médio para cada envio/resposta leva quase o dobro do tempo (variação de $90.33 \%$ ). Como consequência, a duração total também leva quase o dobro do tempo.

A análise por percentis nos ajuda a ter uma ideia muito interessante sobre o tempo de resposta de um sistema. Por exemplo, no Trading System, quando observamos o 95\% percentil, para apenas um ator cliente, sabemos que $95 \%$ dos envios e respostas são completados em no máximo $3266 \mu s$ com o Netty e $4550 \mu \mathrm{s}$ com AMQP, resultando em uma variação de $39.31 \%$. Contudo, se observarmos os demais percentis, podemos notar que, nos dois percentis mais baixos (25\% e $50 \%$ ), as execuções feitas com AMQP foram mais de duas vezes mais lentas que as execuções feitas com Netty (variações de $140.69 \%$ e $134.54 \%)$.

Com o aumento do número de atores clientes, a diferença de tempo apresenta uma boa diminuição. O gráfico da Figura 7.2 mostra a evolução da quantidade de envios e respostas com o aumento da quantidade de atores clientes. Podemos observar que, conforme a quantidade de atores clientes foi aumentando, os resultados obtidos com nossa implementação apresentaram uma boa melhora e se mantiveram muito próximos dos resultados obtidos com a implementação original do Akka. A diferença na quantidade de envios e respostas por segundo, que era de quase $-47.50 \%$, cai (em valor absoluto) até atingir o valor de apenas $-5.02 \%$, que no nosso experimento representa pouco menos de 1 segundo para completar todos os envios e respostas na instância com 80 atores clientes. De um modo geral, se observarmos os tempos de execução para os experimentos a partir de 8 atores 
clientes, quando o sistema começa a atingir seu ponto de saturação, temos uma diferença de tempo abaixo de 1.6 segundos.

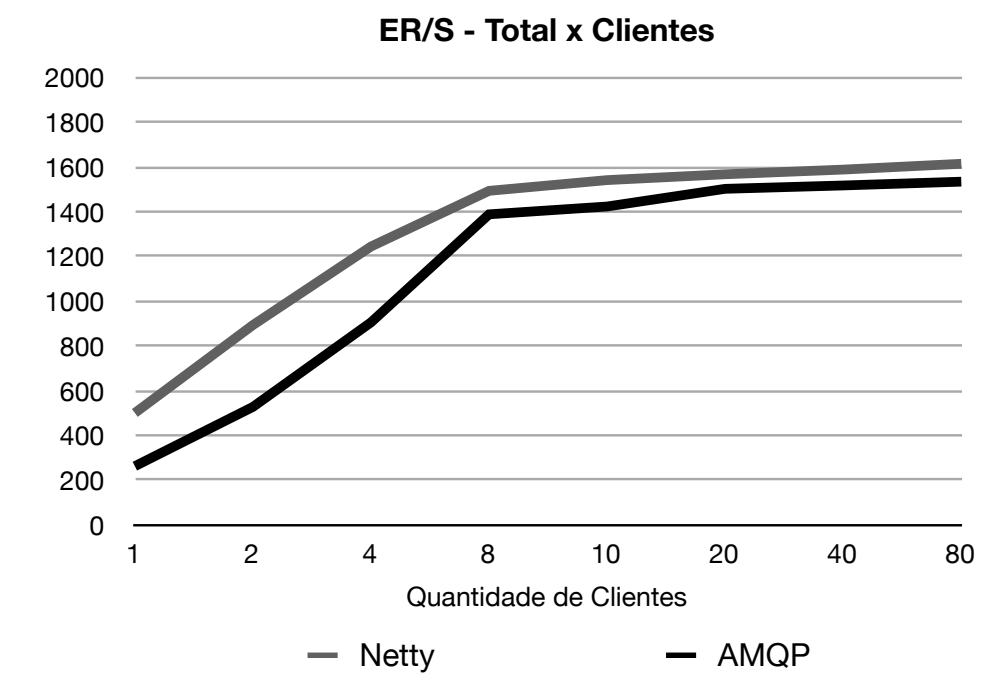

Figura 7.2: Comparação da quantidade de envios e respostas.

Vale relembrar que não adicionamos compressão nas mensagens em nossa implementação com AMQP e que os experimentos feitos com Netty utilizaram compressão média. Como as mensagens são menores que $1 \mathrm{~KB}$, entendemos que a implementação com AMQP possa ter sido ligeiramente beneficiada em relação a implementação com Netty. Ademais, o terceiro nó também colabora com a distribuição do processamento. Na implementação feita com Netty, tanto as classes responsáveis pelo envio e recebimento de mensagens quanto as classes do Netty compartilham a mesma JVM que executa os atores da aplicação de benchmark. Já na implementação com AMQP, apenas as classes responsáveis pelo envio e recebimento de mensagens compartilham a mesma JVM. Durante a execução dos experimentos, mesmo diante de um cenário com alta concorrência em que múltiplos atores clientes executaram envios em paralelo para um Remoteclient compartilhado, não tivemos problemas comuns de concorrência (como deadlocks e condições de corrida) em nossa implementação.

Pelo fato do tráfego de mensagens na rede ser duas vezes maior no caso AMQP, naturalmente a latência da rede é um dos principais fatores que podem afetar o desempenho de atores via AMQP. Refizemos os experimentos já descritos, agora empregando uma rede com maior latência que a utilizada anteriormente. Utilizamos a mesma configuração de hardware já descrita, porém retiramos os cabos que ligavam os laptops ao roteador. A conexão de cada laptop ao roteador passou a ser feita via rede wireless. Assim como para a rede anterior, executamos novamente o Netperf para avaliar a latência da nova configuração de rede. A quantidade de transações por segundo variou entre 462.88 e 671.88, com média de 597.31. O desvio padrão ficou em 77.99 e coeficiente de variação em $13.05 \%$. Note que a rede wireless apresentou uma latência quase quatro vezes maior do que a rede anterior.

A Tabela 7.2 apresenta os resultados dos novos experimentos. Os dados dessa tabela mostram que, no pior caso, o tempo gasto com a implementação com AMQP é pouco mais de duas vezes e meia maior que o gasto pela implementação com Netty. Esse pior caso ocorre quando o número de atores clientes é igual a 4. Quando observamos os percentis, podemos notar que, nos dois percentis mais baixos, as execuções feitas com AMQP foram aproximadamente três vezes mais lentas que as execuções feitas com Netty (variações de $209.28 \%$ e 197.17\%). Nos dois percentis mais altos, há uma redução razoável nessa diferença (variações de $179.11 \%$ e $145.07 \%$ ). Assim como na Tabela 7.1, conforme aumentamos a quantidade de atores clientes, a diferença de tempo cai (em valores absolutos) até atingir $26.74 \%$, que corresponde a pouco menos que 9 segundos para todos os envios e respostas. 


\begin{tabular}{|c|c|c|c|c|c|c|c|c|}
\hline Impl. & Clientes & ER/S & Média $(\mu s)$ & $25 \%(\mu s)$ & $50 \%(\mu s)$ & $75 \%(\mu s)$ & $95 \%(\mu s)$ & Dur. $(s)$ \\
\hline \hline Netty & 1 & 163 & 6129 & 3387 & 4279 & 6265 & 13403 & 183.87 \\
AMQP & 1 & 106 & 9464 & 5998 & 7223 & 9624 & 17360 & 283.92 \\
\hline & Variação & $-34.97 \%$ & $54.41 \%$ & $77.09 \%$ & $68.80 \%$ & $53.62 \%$ & $29.52 \%$ & $100.05(54.41 \%)$ \\
\hline Netty & 2 & 341 & 5857 & 3418 & 4113 & 5635 & 11481 & 87.855 \\
AMQP & 2 & 152 & 13121 & 8963 & 10784 & 14077 & 22309 & 196.815 \\
\hline & Variação & $-55.43 \%$ & $124.02 \%$ & $162.23 \%$ & $162.19 \%$ & $149.81 \%$ & $94.31 \%$ & $108.96(124.02 \%)$ \\
\hline Netty & 4 & 479 & 8337 & 5248 & 6334 & 8219 & 13892 & 62.5275 \\
AMQP & 4 & 183 & 21872 & 16231 & 18823 & 22940 & 34045 & 164.04 \\
\hline & Variação & $-61.80 \%$ & $162.35 \%$ & $209.28 \%$ & $197.17 \%$ & $179.11 \%$ & $145.07 \%$ & $101.51(162.35 \%)$ \\
\hline Netty & 8 & 491 & 16292 & 10528 & 12692 & 15780 & 23123 & 61.095 \\
AMQP & 8 & 198 & 40463 & 26918 & 33224 & 41392 & 58513 & 151.73625 \\
\hline & Variação & $-59.67 \%$ & $148.36 \%$ & $155.68 \%$ & $161.77 \%$ & $162.31 \%$ & $153.05 \%$ & $90.64(148.36 \%)$ \\
\hline Netty & 10 & 559 & 17883 & 12737 & 14918 & 18099 & 25705 & 53.649 \\
AMQP & 10 & 243 & 40891 & 29653 & 34970 & 41936 & 56755 & 122.673 \\
\hline & Variação & $-56.27 \%$ & $128.66 \%$ & $132.81 \%$ & $134.41 \%$ & $131.70 \%$ & $120.79 \%$ & $69.02(128.66 \%)$ \\
\hline Netty & 20 & 563 & 35486 & 22392 & 26879 & 32957 & 47837 & 53.23 \\
AMQP & 20 & 323 & 61951 & 47710 & 55291 & 64509 & 84108 & 92.92 \\
\hline & Variação & $-42.63 \%$ & $74.58 \%$ & $113.07 \%$ & $105.70 \%$ & $95.74 \%$ & $75.82 \%$ & $39.69(74.58 \%)$ \\
\hline Netty & 40 & 607 & 65782 & 41155 & 49748 & 60805 & 83042 & \\
AMQP & 40 & 390 & 98951 & 62679 & 77785 & 98463 & 150803 & 79.33 \\
\hline & Variação & $-35.75 \%$ & $50.42 \%$ & $52.30 \%$ & $56.36 \%$ & $61.93 \%$ & $81.60 \%$ & $24.87(50.42 \%)$ \\
\hline Netty & 80 & 889 & 89089 & 36654 & 39031 & 50225 & 103695 & 139215 \\
AMQP & 80 & 628 & 112913 & 66128 & 77563 & 94990 & 139.21 \\
\hline & Variação & $-29.36 \%$ & $26.74 \%$ & $80.41 \%$ & $98.72 \%$ & $89.13 \%$ & $34.25 \%$ & $8.93(26.74 \%)$ \\
\hline
\end{tabular}

Tabela 7.2: Medidas de tempo do Trading System com atores remotos (wireless).

O gráfico da Figura 7.3 mostra que, com o aumento de atores clientes, a quantidade de envios e respostas obtida com nossa implementação não teve a mesma melhora que a obtida com o Netty. Uma melhora mais significativa acontece somente quando a quantidade de clientes passa de 10 . Se observamos novamente o gráfico da Figura 7.2, notamos que o aumento no número de envios e respostas foi mais acentuado no início (de 1 a 8 atores clientes) quando o sistema ainda não tinha atingido a saturação.

ER/S - Total x Clientes

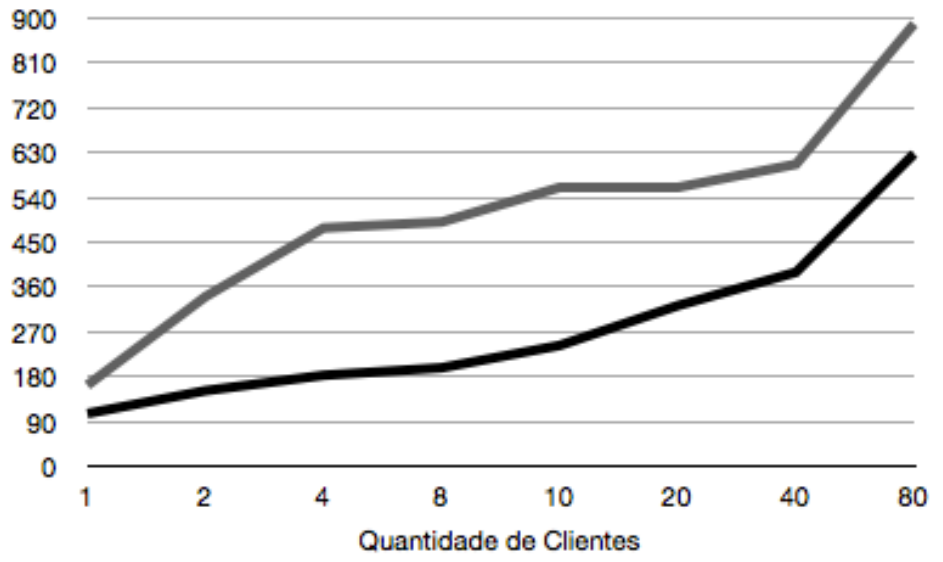

- Netty $\quad-$ AMQP

Figura 7.3: Comparação da quantidade de envios e respostas na rede wireless.

Argumentamos que, na rede com maior latência, o sistema não conseguiu chegar próximo a seu ponto de saturação. Nosso argumento é baseado na comparação dos valores de envios e respostas por segundo entre os experimentos com 1 e 2 atores clientes da Tabela 7.1 e os experimentos com 10 e 80 clientes mostrados na Tabela 7.2.

Se verificarmos o valor da Tabela 7.1 para experimentos com Netty e 1 ator cliente, temos 501 envios e respostas por segundo. Na rede com maior latência, só obtemos esse fluxo de mensagens com o Netty quando passamos de 8 para 10 atores clientes e o fluxo aumenta de 491 para 559 envios e respostas por segundo, como mostra a Tabela 7.2. Quando passamos para 2 atores clientes, temos 894 envios e respostas na Tabela 7.1. Esse fluxo com o Netty só é aproximado na rede com maior 
latência quando utilizamos 80 clientes. Nesse caso temos 889 envios e respostas por segundo.

Analogamente, se verificarmos o valor da Tabela 7.1 para experimentos com AMQP e 1 ator cliente, temos 263 envios e respostas por segundo. Na rede com maior latência, esse fluxo de mensagens via AMQP só é aproximado quando utilizamos 10 atores clientes, caso em que temos 243 envios e respostas por segundo na Tabela 7.2. Quando passamos para 2 atores clientes, o fluxo com AMQP aumenta para 528 (Tabela 7.1). Na rede com maior latência, esse fluxo com AMQP só é obtido quando utilizamos 80 clientes. Nesse caso temos 628 envios e respostas por segundo.

Com base na variação da quantidade de envios e respostas por segundo, nossa conclusão é de que o número de atores clientes utilizados na rede com maior latência não foi suficiente para fazer com que o sistema chegasse próximo a seu ponto de saturação. Ao contrário, na rede com maior latência, o sistema teve um fluxo próximo ao obtido nos experimentos com 1 e 2 clientes na rede com menor latência. Em outras palavras, nosso entendimento é que, sob o ponto de vista do fluxo de envios e respostas, o trecho de 10 a 80 clientes do gráfico da Figura 7.3 corresponde ao trecho de 1 a 2 clientes do gráfico da Figura 7.2. A figura 7.4 ilustra esse fato.

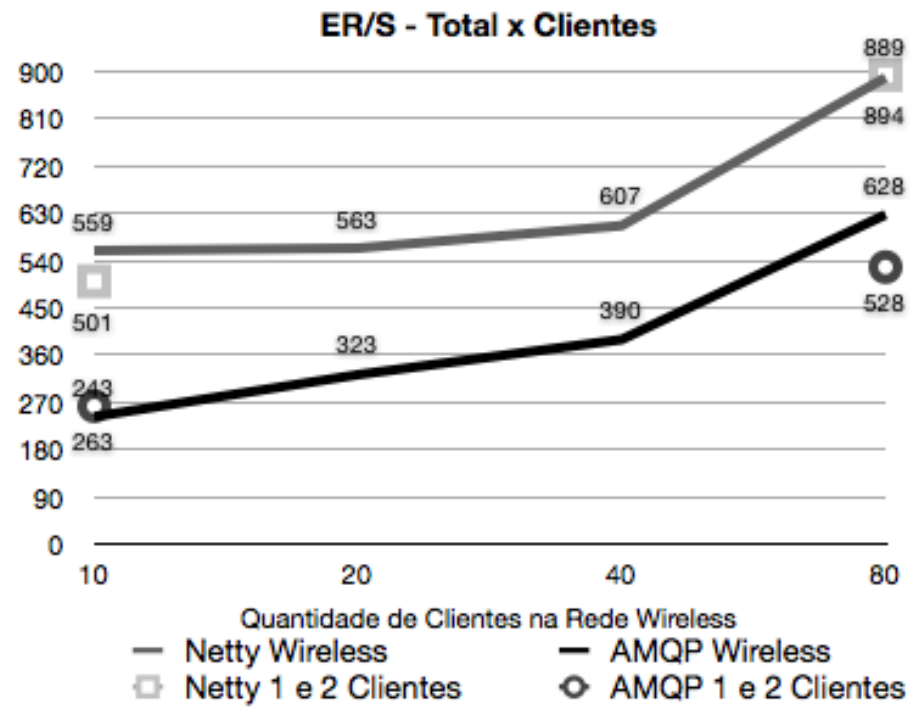

Figura 7.4: Fluxos nas redes de alta e de baixa latência.

Concluímos que existe uma vantagem relativa da nossa implementação para transporte de mensagens entre atores remotos com padrão AMQP em relação a implementação original do Akka feita com o Netty. Ainda que exista um processamento extra a cargo do message broker para receber, rotear e entregar as mensagens, tal vantagem deve-se ao fato do Netty também possuir tarefas semelhantes, e desse processamento acontecer nos mesmos nós onde estão em execução as classes que fazem o processamento das mensagens, como os atores. Vimos na Figura 7.2 que, conforme o fluxo das mensagens foi aumentando e o sistema foi chegando ao seu ponto de saturação, houve uma redução considerável na diferença de tempo entre as execuções com Netty e AMQP. Assim, entendemos que a carga extra de processamento adicionada pelo message broker não invalida o seu uso como suporte para a troca de mensagens entre atores remotos. Enfatizamos que em muitos cenários realistas espera-se que um sistema de atores tenha um alto número de atores clientes. 


\section{Capítulo 8}

\section{Trabalhos relacionados}

Apresentamos neste capítulo alguns trabalhos que possuem relação com o nosso. Apresentamos também uma breve comparação das características desses trabalhos relacionados, no que diz respeito ao uso de um message broker AMQP, com as características do nosso trabalho.

\subsection{Replicação de transações no Drizzle com RabbitMQ}

Drizzle [Dri] é um sistema gerenciador de bancos de dados voltado para computação em nuvem (cloud computing). Sua implementação é de código aberto e foi desenvolvida tomando como base o código do sistema MySQL [MSQ].

Uma das características do Drizzle é a replicação de transações. Transações (como inserções ou atualizações) executadas na instância principal (master) de um banco de dados são replicadas para uma ou mais instâncias secundárias (slaves) do banco de dados. O módulo [DRS] responsável por dar suporte a replicação de transações utiliza uma combinação de tabelas transacionais (tabelas sobre as quais pode-se executar operações no escopo de uma transação ${ }^{1}$ ) e mensagens no formato Protobuf. O uso das tabelas transacionais tem como característica a criação de um arquivo para registro das transações executadas. Cada transação executada em uma tabela transacional gera uma entrada no arquivo de registro.

O Drizzle oferece a possibilidade de replicação de transações via message broker AMQP. Tal suporte a replicação de transações é oferecido pelo módulo RabbitMQ Integration [DMQ]. Quando esse módulo está ativado, uma aplicação Java associada à instância principal coleta as informações do arquivo onde as transações foram registradas e envia ao message broker mensagens com as transações. As aplicações Java associadas às instâncias secundárias são responsáveis por consumir as mensagens vindas do RabbitMQ e tomar as ações que se fizerem necessárias, como, por exemplo, executar as operações de cada transação na instância secundária do Drizzle ao qual está associada.

Quando esse módulo é utilizado, deve-se configurá-lo com as informações necessárias para conexão ao RabbitMQ, tais como endereço, porta, virtual host, usuário e senha. Deve-se informar também o nome da exchange para onde as mensagens devem ser enviadas e a chave de roteamento. Vale destacar que a aplicação Java associadas à uma instância secundária do Drizzle é responsável por fazer a criação da fila e definir seu binding com a exchange configurada na ativação do módulo de integração com o RabbitMQ.

\section{Comparação com nosso trabalho}

Tanto o módulo RabbitMQ Integration quanto o nosso trabalho fazem uso do RabbitMQ para interligar instâncias distribuídas de um mesmo sistema (Drizzle ou Akka). Ainda que o propósito do módulo RabbitMQ Integration seja bem mais específico que o do nosso trabalho, esse módulo define uma estrutura de filas e exchanges que é similar à de nossas pontes AMQP. Contudo, ele se limita a fazer difusão (broadcast) de mensagens oriundas da instância principal do banco de dados. Não

\footnotetext{
${ }^{1}$ No caso do MySQL e do Drizzle, o suporte a essas tabelas é provido pelo componente InnoDB.
} 
há envios específicos de mensagens, nem envios de respostas e nem tampouco mensagens originadas nas instâncias secundárias.

\subsection{Camada de comunicação entre agentes remotos com RabbitMQ}

Arlekar e outros [ $\left.\mathrm{ACH}^{+} 11\right]$ apresentam uma proposta de um arcabouço voltado para simulações baseadas no modelo de agentes. Esse arcabouço prove a infraestrutura necessária para a criação de agentes, a troca de mensagens entre agentes e o armazenamento e a exibição das informações geradas no sistema. O arcabouço possui diversos componentes, contudo destacamos aqui apenas os três nos quais identificamos semelhanças com nosso trabalho:

- Care Take Agent (CTA): Um CTA possui como algumas de suas responsabilidades criar agentes e controlar a troca de mensagens entre agentes residentes em diferentes CTAs.

- Agente: Um agente representa uma entidade que faz parte da simulação como, por exemplo, uma pessoa.

- Camada de comunicação: A camada de comunicação é um componente fundamental no arcabouço que permite que agentes residentes em diferentes CTAs possam trocar mensagens entre si.

A implementação da camada de comunicação é feita com filas criadas no RabbitMQ. Cada CTA possui uma fila associada para recebimento de mensagens. As filas criadas no message broker são identificadas pelo endereço IP do CTA proprietário da fila e por um nome. Cada CTA é executado em sua própria JVM. As mensagens recebidas em um CTA são repassadas a um ou vários dos seus agentes. O CTA age também como proxy no envio de uma mensagem. Para enviar mensagens a outros agentes, uma agente utilizando como proxy o CTA no qual ele reside.

\section{Comparação com nosso trabalho}

Ainda que este arcabouço seja baseado em agentes e o nosso trabalho seja voltado ao modelo de atores, ambos apresentam semelhanças. Um agente é análogo a um ator. Um CTA é um componente análogo ao Remotesupport existente na implementação de atores remotos do Akka. A camada de comunicação deste arcabouço é análoga à implementação da camada de transporte do Akka. Entretanto, o escopo deste arcabouço é bem mais específico que o do Akka. Ademais, a estrutura de filas e exchanges definida pela camada de comunicação deste arcabouço é bem menos flexível que a nossa. Entre outras limitações, ela associa o endereço IP de um CTA ao nome da fila.

\subsection{Akka AMQP Integration}

O projeto Akka possui um módulo adicional cujo nome é AMQP Integration [AKK]. O módulo AMQP Integration permite que objetos como conexões e canais RabbitMQ sejam abstraídos e implementados como atores. Esse módulo permite ainda que os produtores e os consumidores das mensagens enviadas via message broker sejam definidos como atores. O módulo AMQP Integration adiciona benefícios como a criação de uma hierarquia de supervisão para conexões e canais. No caso de uma falha que leve ao fechamento de uma conexão ou de um canal, a hierarquia de supervisão tentará restabelecer a conexão ou recriar o canal.

\section{Comparação com nosso trabalho}

O módulo AMQP Integration oferece uma API que é baseada em atores e que dá acesso às funcionalidades da biblioteca do RabbitMQ para clientes Java. Uma aplicação pode usar esse módulo para fazer entidades remotas trocarem mensagens via AMQP. Entretanto, a aplicação precisará lidar explicitamente com as abstrações do módulo AMQP Integration que representam objetos do 
message broker. Além disso, a troca de mensagens será sempre mediada pelos atores do módulo AMQP Integration.

Já em nosso trabalho um ator pode enviar mensagens diretamente a atores destinatários remotos. As mensagens são enviadas via message broker, sem que a aplicação precise tomar quaisquer providências. O uso de AMQP como camada de transporte de mensagens é completamente transparente para as aplicações. Embora o módulo AMQP Integration tenha objetivos bem diferentes dos nossos, foi o código desse módulo que nos inspirou a criar as pontes AMQP apresentadas no Capítulo 5. 


\section{Capítulo 9}

\section{Considerações finais}

A principal motivação para o uso de AMQP como mecanismo de transporte de mensagens para atores remotos é fazer a integração entre o modelo de atores e os sistemas de middleware orientado a mensagens. Embora venha ganhando muita atenção como um modelo não convencional de programação concorrente, o modelo de atores ainda não tem emprego difundido em ambientes corporativos. Nossa expectativa é que a integração com os sistemas orientados a mensagens amplamente usados em tais ambientes contribua para a adoção do modelo de atores em cenários de processamento de dados empresarial.

Em nossos experimentos, o uso do RabbitMQ, em conjunto com a estrutura descrita no Capítulo 5 , se mostrou eficaz em nossos experimentos para transportar mensagens entre atores remotos. $\mathrm{O}$ tempo extra de processamento adicionado com o uso do message broker se mostrou baixo no cenário mais realista, em que há baixa latência de rede e uma quantidade razoável de atores sendo executados concorrentemente. Nossa conclusão é de que as duas classes de sistemas estudadas neste trabalho possuem boa sinergia.

O uso do message broker AMQP como ponto central de comunicação de todos os atores remotos cria um ponto crítico em caso de falhas. Caso o nó onde o message broker está em execução sofra alguma avaria, a comunicação de todos os atores remotos é afetada. Entretanto, o RabbitMQ pode ser configurado em cluster [RCL], com múltiplos nós compartilhando as informações dos virtual hosts. O uso do RabbitMQ em cluster minimiza o problema do message broker ser um ponto central de falhas. Além das configurações de cluster, o RabbitMQ dá suporte à criação de filas de alta disponibilidade [RHA]. O uso de filas de alta disponibilidade é uma solução complementar, baseada no espelhamento das filas, para o RabbitMQ prover alta disponibilidade dos seus serviços.

O emprego de um message broker ainda traz outros benefícios, como por exemplo:

- Mensagens duráveis: O fato de utilizarmos filas para fazer o armazenamento intermediário das mensagens (ainda que, na maior parte das vezes, por um período breve), permite que tanto um RemoteServer quanto um Remoteclient possa receber mensagens mesmo após sua execução ter sido interrompida. Para tal, basta que o Remoteserver ou Remoteclient tenha sido executado com uma configuração durável ${ }^{1}$. As mensagens ficam armazenadas até que um novo consumidor seja registrado.

- Ferramentas administrativas: A maioria dos message brokers possui ferramentas para administração e monitoramento. O uso deste tipo de ferramenta ajuda na administração de uma parte importante da infraestrutura de um sistema distribuído. O RabbitMQ, por exemplo, possui um módulo de gerenciamento que é acessível por meio de um navegador web [RMG]. Com este módulo é possível criar, alterar e remover objetos como filas e exchanges, além de observar informações como, por exemplo, o volume de mensagens em determinado objeto, a quantidade de clientes conectados ao message broker e a quantidade de mensagens que está

\footnotetext{
${ }^{1} \mathrm{O}$ mesmo vale para configurações transientes, desde que o message broker não seja reiniciado. No RabbitMQ, filas e exchanges criadas como transientes só são removidas na reinicialização do RabbitMQ.
} 
em uma fila aguardando confirmação de recebimento.

- Simplificação de acesso: Para identificar os nós onde residem os atores remotos, nossa implementação usa nomes ao invés de endereços IP e números de portas. Graças a esse uso de nomes, conseguimos certa independência dos endereços IP. O único endereço que deve ser conhecido é o do nó onde o message broker está em execução. Ainda que tenhamos mantido as assinaturas dos métodos definidos pelo projeto Akka, nossa implementação não se atrela aos detalhes de hospedeiro e porta expostos pela API do Akka. Existe ainda uma outra vantagem que é a redução do número de portas que devem ser desbloqueadas em um firewall. A única porta que deve necessariamente aceitar conexões é a porta que o message broker disponibilizou para os clientes, a qual precisa estar desbloqueada somente no nó onde o message broker está em execução.

\subsection{Trabalhos futuros}

Concluímos esta dissertação deixando algumas sugestões para trabalhos futuros. Os trabalhos listados a seguir podem ser desenvolvidos tomando como ponto de partida o estado atual da nossa implementação de atores remotos.

\subsubsection{Melhoria no tratamento de erros nas pontes AMQP}

O fato de utilizarmos atores para encapsular as principais classes da biblioteca para clientes Java do RabbitMQ permite que nossa hierarquia de atores venha ser utilizada para tratamento de erros. Ainda que nossa implementação seja de uma hierarquia de supervisão, os atores supervisores não possuem comportamento para tratamento de erros nos atores supervisionados.

A implementação pode ser ampliada para que, no caso de erros em atores supervisionados, como os responsáveis pelos canais ou conexões, os atores supervisores possam criar novos atores supervisionados. A restauração do estado nos atores filhos deverá obedecer as configurações originais dos objetos que foram criados no message broker. Quando não for possível restabelecer o sistema, seja por não se conseguir reconectar ao message broker ou por algum outro motivo, é necessário ainda notificar a ponte AMQP para que ela possa propagar o erro para o nível da aplicação.

\subsubsection{Experimentos em um ambiente de computação em nuvem}

Nos últimos anos o conceito de computação em nuvem vem ganhando bastante espaço, não só na comunidade acadêmica, mas também na indústria de tecnologia. Computação em nuvem é um conceito que se refere tanto a aplicações disponibilizadas como serviços via internet quanto pelo hardware e pelos sistemas de software que estão nos centros de processamento de dados para prover aqueles serviços $\left[\mathrm{AFG}^{+} 10\right]$. O termo "nuvem" é utilizado para denotar o hardware e o software que ficam no centro de processamento de dados. Um dos principais atrativos da computação em nuvem é a capacidade de elasticidade da nuvem. Caso a demanda por um serviço aumente, recursos que estão disponíveis, como computadores e máquinas virtuais, podem ser alocados para aumentar a capacidade de processamento. Quando a demanda pelo serviço diminui e a capacidade de processamento necessária passa a ser menor, esses recursos podem ser liberados e utilizados para atender outros serviços.

Diversas plataformas de computação em nuvem existentes no mercado, como EC2 (Amazon) [AEC], Nebula (NASA) [NEB], Heroku [HER] e Cloud Foundry (VMWare) [CFY], possuem o RabbitMQ como message broker ou permitem que o RabbitMQ seja instalado. Acreditamos que nossa implementação de atores remotos esteja muito próxima de ser implantável em uma infraestrutura de computação em nuvem e necessite de poucas adaptações para ser executada na nuvem. Acreditamos que a elasticidade da nuvem, alinhada com a capacidade do RabbitMQ de trabalhar com um número alto de requisições, proporcione alta escalabilidade. Um trabalho futuro interessante seria usar o Trading System para fazer uma avaliação experimental de nossa implementação em 
um ambiente de nuvem, com uma quantidade de clientes bem maior que a utilizada em nossos experimentos. 
CONSIDERAÇÕES FINAIS 


\section{Referências Bibliográficas}

$\left[\mathrm{ACH}^{+} 11\right]$ Sagar Arlekar, Amar Chadgar, Onkar Hoysala, Harsha Krishna, Niket Narang, Bharath Palavalli e Jayanth Raghothama. Platform for large scale agent based simulations. Relatório técnico, Center for Study of Science, Technology and Policy (CSTEP), Maio 2011. 62

[ACKM04] Gustavo Alonso, Fabio Casati, Harumi Kuno e Vijay Machiraju. Web Services: Concepts, Architecture and Applications. Springer Verlag, 2004. 1, 2

[Act] Apache ActiveMQ. http://activemq.apache.org/. Último acesso em 30/10/2010. 2

[AEC] Amazon Elastic Compute Cloud (Amazon EC2). http://aws.amazon.com/ec2. Último acesso em $6 / 12 / 2011.66$

$\left[\mathrm{AFG}^{+} 10\right]$ Michael Armbrust, Armando Fox, Rean Griffith, Anthony D. Joseph, Randy Katz, Andy Konwinski, Gunho Lee, David Patterson, Ariel Rabkin, Ion Stoica e Matei Zaharia. A view of cloud computing. Commun. ACM, 53:50-58, Abril 2010. 66

[AFY] The Actor Foundry: A Java-Based Actor Programming Environment - Open Systems Laboratory, University of Illinois at Urbana-Champaign. http://osl.cs.uiuc.edu/af. Último acesso em $27 / 5 / 2011.11$

[Agh86] Gul Agha. Actors: a model of concurrent computation in distributed systems. MIT Press, 1986. $2,5,6,7$

[AKK] Akka, Simpler Scalability, Fault-Tolerance, Concurreny \& Remoting through Actors. http://www.akka.io. Último acesso em 15/2/2011. 11, 62

[AMQ08] AMQP Working Group. AMQP Specification v0.10, 2008. 27

[AMST98] Gul Agha, Ian A. Mason, Scott F. Smith e Carolyn L. Talcott. A foundation for actor computation. Journal of Functional Programming, 7:1-72, 1998. 6, 7

[API] RabbitMQ Java API 2.4.1 Javadoc. http://www.rabbitmq.com/releases/ rabbitmq-java-client/v2.4.1/rabbitmq-java-client-javadoc-2.4.1. Último acesso em 12/5/2011. 31

[APL04] Apache License 2.0. http://www.apache.org/licenses/, 2004. Último acesso em 11/5/2011. 31

[App09] Apple Inc. Technology Brief - Grand Central Dispatch, 2009. 15

[Arm97] Joe Armstrong. The development of erlang. Em ICFP '97: Proceedings of the second ACM SIGPLAN international conference on Functional programming, páginas 196-203. ACM, Agosto 1997. 10, 31

[Arm07] Joe Armstrong. Programming Erlang: Software for a Concurrent World. Pragmatic Bookshelf, Julho 2007. 8, 10, 17 
[Bos] Sérgio Bossa. Actorom - actors concurrency in java, made simple. http://code.google. $\mathrm{com} / \mathrm{p}$ /actorom. Último acesso em 22/7/2011. 16

[Bri89] Jean Pierre Briot. Actalk: a testbed for classifying and designing actor languages in the smalltalk-80 environment. Em European Conference on Object-Oriented Programming (ECOOP'89), páginas 109-129. Cambridge University Press, Julho 1989. 10

[Bur] Johann Burkard. Generate uuids (or guids) in java. http://johannburkard.de/software/ uuid/. Último acesso em 24/7/2011. 24

[CFY] VMWare - Cloud Foundry. http://www.cloudfoundry.com. Último acesso em 6/12/2011. 66

[CML] Math - Commons Math: The Apache Commons Mathematics Library. http://commons. apache.org/math/. Último acesso em 9/9/2011. 55

[Cora] Microsoft Corporation. Asynchronous agents library. http://msdn.microsoft.com/en-us/ library/dd492627.aspx. Último acesso em 27/5/2011. 11

[Corb] Microsoft Corporation. Axum programming language. http://msdn.microsoft.com/ en-us/devlabs/dd795202. Último acesso em 24/5/2011. 8

[Cor09] Microsoft Corporation. Axum - Language Overview, Junho 2009. 8

[Cro06] Douglas Crockford. The application/json media type for javascript object notation (json). Relatório Técnico RFC 4627, The Internet Engineering Task Force (IETF), Julho 2006. 12

[DMQ] Drizzle - RabbitMQ Integration. http://docs.drizzle.org/plugins/rabbitmq/index.html. Último acesso em 10/01/2012. 61

[Dri] Drizzle - a database for the cloud. http://www.drizzle.org/. Último acesso em 10/01/2012. 61

[DRS] Drizzle - Replication Slave. http://docs.drizzle.org/plugins/slave/index.html. Último acesso em 10/01/2012. 61

[FPV98] Alfonso Fuggetta, Gian Pietro Picco e Giovanni Vigna. Understanding code mobility. IEEE Trans. Softw. Eng., 24:342-361, 1998. 7

[Goo] Protocol Buffers - Google's data interchange format. http://code.google.com/p/ protobuf. Último acesso em 27/5/2011. 12, 23

[Gri75] Irene Grief. Semantics of communicating parallel process. Tese de Doutorado, Department of Electrical Engineering and Computer Science, MIT, EUA, Agosto 1975. 7

[Gro] AMQP Working Group. Advanced message queuing protocol. http://www.amqp.org. Último acesso em 5/5/2011. 2, 27, 37

[HA79] Carl Hewitt e Russell R. Atkinson. Specification and proof techniques for serializers. IEEE Trans. Software Eng., 5(1):10-23, 1979. 7

[HAL79] Carl Hewitt, Giuseppe Attardi e Henry Lieberman. Specifying and proving properties of guardians for distributed systems. Em Proceedings of the International Sympoisum on Semantics of Concurrent Computation, páginas 316-336, London, UK, 1979. SpringerVerlag. 7

[Har] Mark Harrah. Library for describing binary formats for Scala types. https://github.com/ harrah/sbinary. Último acesso em 27/5/2011. 12 
[HB77] Carl Hewitt e Henry G. Baker. Laws for communicating parallel processes. Em IFIP Congress, páginas 987-992, 1977. 7

[HBS73] Carl Hewitt, Peter Bishop e Richard Steiger. A universal modular actor formalism for artificial intelligence. Em Proceedings of the 3rd international joint conference on Artificial intelligence, páginas 235-245, San Francisco, CA, USA, 1973. Morgan Kaufmann Publishers Inc. 7

[HER] Heroku Cloud Application Platform. http://www.heroku.com. Último acesso em 6/12/2011. 66

[Hew71] Carl Hewitt. Description and Theoretical Analysis (Using Schemata) of PLANNER: A language for Manipulating models and proving theorems in a robot. Tese de Doutorado, MIT, 1971. 7

[HO09] Philipp Haller e Martin Odersky. Scala actors: Unifying thread-based and event-based programming. Theoretical Computer Science, 410(2-3):202 - 220, 2009. Distributed Computing Techniques. 11

[IAN] Service Name and Transport Protocol Port Number Registry. https://www.iana. org/assignments/service-names-port-numbers/service-names-port-numbers.txt. Último acesso em 18/5/2012. 35

[IBM] IBM Websphere MQ - Software. http://www-01.ibm.com/software/integration/wmq/. Último acesso em 30/08/2011. 2

[Ins81] Information Sciences Institute. Transmisson control protocol - protocol specification. Relatório Técnico RFC 793, University of Southern California, Setembro 1981. 35

[JBM] JBoss Messaging. http://www.jboss.org/jbossmessaging. Último acesso em 30/08/2011. 2

[JNY] Netty - the Java NIO Client Server Socket Framework. http://www.jboss.org/netty. Último acesso em $27 / 5 / 2011.12,20$

[JOW07] Simon Jones, Andy Oram e Greg Wilson. Beautiful Code: Leading Programmers Explain How They Think (Theory in Practice (O'Reilly)). O'Reilly Media, Inc., 2007. 2

[KA95] WooYoung Kim e Gul Agha. Efficient support of location transparency in concurrent object-oriented programming languages. Em Proceedings of the 1995 ACM/IEEE conference on Supercomputing (CDROM), Supercomputing '95, página 39, New York, NY, USA, 1995. ACM. 7

[Kim97] Wooyoung Kim. THAL: An Actor System For Efficient and Scalable Concurrent Computing. Tese de Doutorado, University of Illinois at Urbana-Champaign, 1997. 10

[KML93] Dennis Kafura, Manibrata Mukherji e Greg Lavender. Act ++2.0 : A class library for concurrent programming in $\mathrm{c}++$ using actors. Journal of Object-Oriented Programing, 6:47-55, 1993. 10

[KSA09] Rajesh K. Karmani, Amin Shali e Gul Agha. Actor frameworks for the JVM platform: a comparative analysis. Em Proceedings of the 7th International Conference on Principles and Practice of Programming in Java, PPPJ '09, páginas 11-20, New York, NY, USA, 2009. ACM. 11

[Lee] Jacob Lee. Parley. http://osl.cs.uiuc.edu/parley/. Último acesso em 26/5/2011. 10

[LGP07] GNU lesser general public license. http://www.gnu.org/licenses/lgpl.html, 2007. Último acesso em 11/5/2011. 31 
[Lie87] Henry Lieberman. Concurrent object-oriented programming in Act 1, páginas 9-36. MIT Press, Cambridge, MA, USA, 1987. 7

[Man87] Carl Roger Manning. Acore - the design of a core actor language and its compiler. Dissertação de Mestrado, Dept. of Electrical Engineering and Computer Science, MIT, EUA, Maio 1987. 8

[Mas] Ashton Mason. Theron multiprocessing library. http://theron.ashtonmason.net/. Último acesso em 26/5/2011. 10

[MPL] Mozilla Public License. http://www.mozilla.org/MPL/MPL-1.1.html. Último acesso em 11/5/2011. 31

[MSQ] MySQL - the world's most popular open source database. http://www.mysql.com/. Último acesso em 10/01/2012. 61

[NEB] NASA - Nebula Cloud Computing Platform. http://nebula.nasa.gov. Último acesso em 6/12/2011. 66

[Net] The Netperf Home Page. http://www.netperf.org/netperf/. Último acesso em $24 / 05 / 2012.55$

$\left[\mathrm{OAC}^{+} 06\right]$ Martin Odersky, Philippe Altherr, Vincent Cremet, Iulian Dragos, Gilles Dubochet, Burak Emir, Sean McDirmid, Stephane Micheloud, Nikolay Mihaylov, Michel Schinz, Lex Spoonn, Erik Stenman e Matthias Zenger. An Overview of the Scala Programming Language (2. edition). Relatório Técnico LAMP 2006-001, EPFL, 2006. 3

[PA94] Rajendra Panwar e Gul Agha. A methodology for programming scalable architectures. J. Parallel Distrib. Comput., 22:479-487, 1994. 7

[Pro03] Java Community Process. JSR-000914 JavaTM Message Service (JMS) API, Dezembro 2003. 31

[Qpi] Apache Qpid: Open Source AMQP Messaging. http://qpid.apache.org/. Último acesso em 11/5/2011. 31

[RAG] RabbitMQ - API Guide. http://www.rabbitmq.com/api-guide.html. Último acesso em 12/5/2011. 33

[RCL] RabbitMQ - Clustering Guide. http://www.rabbitmq.com/clustering.html. Último acesso em 28/11/2011. 65

[Reta] Mike Rettig. Jetlang - Message based concurrency for Java. http://code.google.com/p/ jetlang. Último acesso em 27/5/2011. 11

[Retb] Mike Rettig. Retlang - Message based concurrency in .Net. http://code.google.com/p/ retlang. Último acesso em 27/5/2011. 11

[RHA] RabbitMQ - High Available Queues. http://www.rabbitmq.com/ha.html. Último acesso em 30/11/2011. 65

[RMG] RabbitMQ - Management Plugin. http://www.rabbitmq.com/management.html. Último acesso em 30/11/2011. 65

[RMQ] RabbitMQ - Messaging that just works. http://www.rabbitmq.com/. Último acesso em 11/5/2011. 31

[RUB] Rubinius. http://rubini.us/. Último acesso em 26/5/2011. 10 
[Sca] Scalaz: Type Classes and Pure Functional Data Structures for Scala. http://code.google. $\mathrm{com} / \mathrm{p} /$ scalaz. Último acesso em 27/5/2011. 11

[Sil08] Jonathan Sillito. Stage: exploring erlang style concurrency in ruby. Em Proceedings of the 1st international workshop on Multicore software engineering, IWMSE '08, páginas 33-40. ACM, 2008. 10

[SL05] Herb Sutter e James Larus. Software and the concurrency revolution. Queue, 3(7):54 $62,2005.2$

[SM08] Sriram Srinivasan e Alan Mycroft. Kilim: Isolation-typed actors for java. Em Proceedings of the 22nd European conference on Object-Oriented Programming, ECOOP '08, páginas 104-128. Springer-Verlag, 2008. 11

[ST95] Nir Shavit e Dan Touitou. Software transactional memory, 1995. 2

[Sut05] Herb Sutter. The free lunch is over: A fundamental turn toward concurrency in software. Dr. Dobb's Journal, 30:202 - 210, 2005. 2

[Tis] Christian Tismer. Stackless python. http://www.stackless.com/. Último acesso em 26/5/2011. 10

[TKS $\left.{ }^{+} 88\right]$ C. Tomlinson, W. Kim, M. Scheevel, V. Singh, B. Will e G. Agha. Rosette: An objectoriented concurrent systems architecture. SIGPLAN Not., 24:91-93, 1988. 8

[VA01] Carlos A. Varela e Gul Agha. Programming dynamically reconfigurable open systems with salsa. ACM SIGPLAN Notices. OOPSLA'2001 Intriguing Technology Track Proceedings, $36: 20-34,2001.8$

[ZMQ] Less is More - zeromq. http://www.zeromq.org/. Último acesso em 11/5/2011. 31 


\section{Índice Remissivo}

Akka, 13

atores locais, 13

despachadores, 14

envios de respostas, 15

atores remotos, 19

fluxo de envio, 20

formato das mensagens, 23

seriação, 25

hierarquias de supervisão, 17

AMQP, 27

exemplo, 31

padrão

implementações, 31

modelo, 27

sessão, 30

transporte, 30

Atores, 5

histórico, 7

implementações, 8

bibliotecas, 10

linguagens, 8

modelo, 5

Atores Remotos com AMQP, 47

componentes, 47

integração Akka, 49

Considerações finais, 65

trabalhos futuros, 66

Estrutura, 35

message broker amqp, 36

criação dos objetos, 40

envios e recebimentos via pontes, 44

gerenciamento de conexões, 39

pontes, 37

ponto-a-ponto, 35

Resultados

comparação de desempenho, 55

Trading System, 53

Trading System com atores remotos, 54

Trabalhos relacionados, 61 